$\underset{D E F / P C 2-949494152-10}{D}-18$

\title{
Appalachian Clean Coal Technology Consortium
}

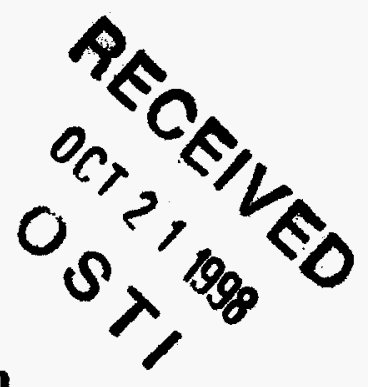

\author{
Final Report \\ October 10, 1994 - March 31, 1997 \\ By: \\ R. -H. Yoon; B. K. Parekh \\ T. Meloy
}

Work Performed Under Contract No.: DE-FC22-94PC94152

For

U.S. Department of Energy

Office of Fossil Energy

Federal Energy Technology Center

P.O. Box 880

Morgantown, West Virginia 26507-0880

By

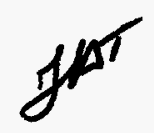

Virginia Polytechnic Institute \& State University

146 Holden Hall

648 Whittemore Hall

Blacksburg, Virginia 24061-0258 


\section{Disclaimer}

This report was prepared as an account of work sponsored by an agency of the United States Government. Neither the United States Government nor any agency thereof, nor any of their employees, makes any warranty, express or implied, or assumes any legal liability or responsibility for the accuracy, completeness, or usefulness of any information, apparatus, product, or process disclosed, or represents that its use would not infringe privately owed rights. Reference herein to any specific commercial product, process, or service by trade name, trademark, manufacturer, or otherwise does not necessarily constitute or imply its endorsement, recommendation, or favoring by the United States Government or any agency thereof. The views and opinions of authors expressed herein do not necessarily state or reflect those of the United States Government or any agency thereof. 


\section{DISCLAIMER}

Portions of this document may be illegible in electronic image products. Images are produced from the best available original document. 


\section{PROJECT ABSTRACT}

The Applachian Clean Coal Technology Consortium is a group comprised of representatives from the Virginia Polytechnic Institute and State University, West Virginia University, and The University of Kentucky Center for Applied Energy Research, that was formed to pursue research in areas related to the treatment and processing of fine coal.

Each member performed research in their respective areas of expertise and the report contained herein encompasses the results that were obtained for the three major tasks that the Consortium undertook from October, 1994 through March, 1997.

In the first task, conducted by Virginia Polytechnic Institute, novel methods (both mechanical and chemical) for dewatering fine coal were examined. In the second task, the Center for Applied Energy Research examined novel approaches for destabilization of [highly stable] flotation froths. And in the third task, West Virginia University developed physical and mathematical models for fine coal spirals.

The Final Report is written in three distintive chapters, each reflecting the individual member's task report. Recommendations for further research in those areas investigated, as well as new lines of pursuit, are suggested. 


\section{DISCLAIMER}

This report was prepared as an account of work sponsored by an agency of the United States Government. Neither the United States Government nor any agency thereof, nor any of their employees, makes any warranty, express or implied, or assumes any legal liability or responsibility for the accuracy, completeness, or usefulness of any information, apparatus, product, or process disclosed, or represents that its use would not infringe privately owned rights. Reference herein to any specific commercial product, process, or service by trade name, trademark, manufacturer, or otherwise does not necessarily constitute or imply its endorsement, recommendation, or favoring by the United States Government or any agency thereof. The views and opinions of authors expressed herein do not necessarily state or reflect those of the United States Government or any agency thereof. 


\section{EXECUTIVE SUMMARY}

Fine coal constitutes a relatively small portion of a product stream in a coal cleaning plant. However, its processing cost is approximately three times higher than the cost of processing coarse coals. Therefore, many coal companies chose to discard the fines to refuse ponds, causing a loss of profit and creating environmental concerns. This problem can be resolved by developing more efficient fine coal dewatering processes, since bulk of the cost associated with processing fine coal is due to dewatering. For this reason, Virginia Tech has developed new chemicals that can increase the efficiency of mechanically dewatering coal fines.

A series of laboratory scale vacuum filtration tests were conducted using a dewatering aid, which is referred to as Reagent $\mathrm{A}$ in this report for proprietary reasons. The tests were conducted on five different coal samples, which included clean coal samples from Lower Kittanning, Pittsburgh No. 8, Pocahontas No. 3 seams plus flotation products from Middle Fork plant, Elkview Mining Company, and CONSOL, Inc.

The tests conducted with the Lower Kittanning (100 mesh $\times 0)$ and Pocahontas coal samples showed that the cake moisture can be reduced to below $10 \%$ by weight. Reducing the moisture to below $10 \%$ was also possible with the Microcel flotation products. It was necessary to use relatively long drying cycle times and high vacuum pressures to achieve such high levels of moisture reduction.

The results obtained with the Middle Fork coal sample (100 mesh $x$ ) showed that cake moisture can be reduced by more than $10 \%$ beyond what can be achieved without using dewatering aid. This improvement was achieved at $1 \mathrm{lb} /$ ton of Reagent $\mathrm{A}$ and 0.1 inch cake thickness. At 0.5 inches of cake thickness, the improvement was 
limited to $8 \%$ at the same reagent dosage.

The results obtained with the Elkview coal $(28$ mesh $\times 0$ ) showed similar advantages in using the novel dewatering aid. Depending on the reagent dosage, cake thickness, drying cycle time and temperature, it was possible to reduce the cake moisture to 12 to $14 \%$ rage. In addition to achieving lower cake moisture, the use of Reagent $\mathrm{A}$ substantially decreased the cake formation time, indicating that the reagent improves the kinetics of dewatering. The test results obtained with CONSOL coal were not as good as with the other coals tested in the present work, which may be attributed to possible oxidation and/or contamination. 


\section{TABLE OF CONTENTS}

DISCLAIMER

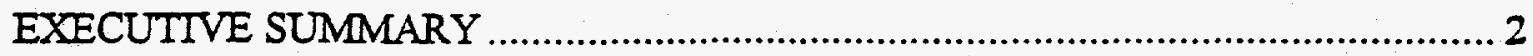

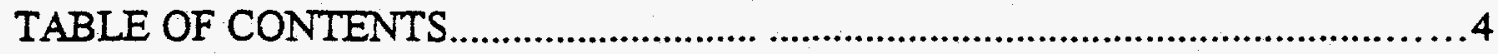

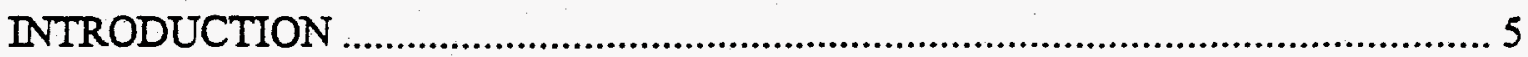

EXPERMMENTAL

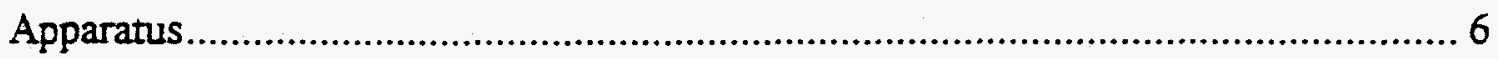

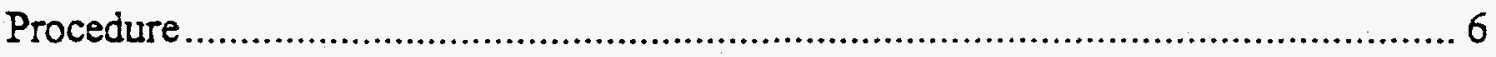

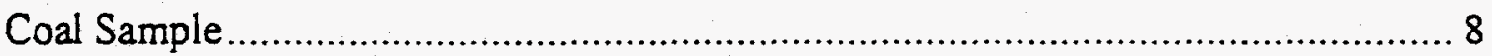

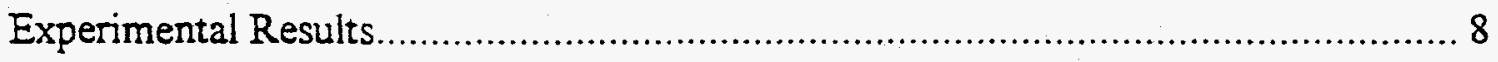

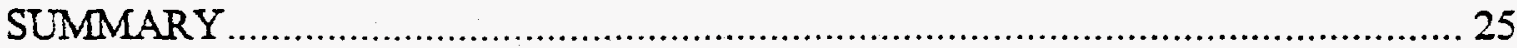




\section{INTRODUCTION}

At present, the cost of cleaning and dewatering fine coal (finer than $0.5 \mathrm{~mm}$ ) is approximately 3 times of those for cleaning coarser coals. For this reason, it is often more economical to discard the fines, if the fine coal constitutes only a small fraction of the product stream. This is typically the case with many coal producers around the worid. In the U.S. alone, it is estimated that approximately 2 billion tons of fine coal has been discarded in abandoned ponds, and approximately 500 to 800 million tons of fine coal in active ponds. On a yearly basis, the U.S. coal producers discard approximately 30 to 50 million tons of fine coals to ponds. These problems cause not only losses of profit to coal companies but also environmental concerns.

The main component for the high cost of processing fine coal is the cost of dewatering the clean coal products rather than the costs of cleaning itself. The only process that can satisfactorily remove the surface moisture from fine coal is thermal drying, which is costly. Furthermore, thermal drying is difficult to get permits for new installations as it is perceived to emit pollutants. Mechanical dewatering processes, on the other hand, cannot remove the moisture below $20-35 \%$ by weight depending on the coal type and particle size. One way of increasing the extent of moisture reduction is to use surfactants, which will aid mechanical dewatering processes by lowering the surface tension of the water. However, most of the dewatering aids available today can remove the moisture by 1 to $2 \%$ beyond what can be achieved without them.

In an effort to solve this long-standing problem, Virginia Tech has recently developed novel dewatering processes. One of the processes entails use of chemicals that can be added to coal slurry before mechanical dewatering. It is the purpose of this 
project to test the dewatering chemicals in laboratory filtration tests. The new dewatering chemicals are proprietary in nature at this point; therefore, the authors of this report are not at liberty to disclose their identities.

\section{EXPERIMENTAL}

\section{Apparatus}

Figure 1 shows the apparatus used for laboratory vacuum filtration tests. A 94mm diameter Buchner funnel with a medium porosity glass frit was used as the filter. Use of a Buchner funnel for filtration test is advantageous over the standard vacuum leaf filter test in that the cake thickness can be controlled. The Buchner funnel was mounted on a vacuum flask, which in turn was connected to a larger vacuum flask. The larger flask heiped stabilize the vacuum pressure during filtration. A coal slurry placed in the Buchner funnel was subjected to a vacuum pressure when the valve between the two vacuum flasks was opened. Most of the filtration tests were conducted at 25 inches $\mathrm{Hg}$ of initial vacuum pressure (the pressure measured before the valve was open), which decreased to $22-23$ inches $\mathrm{Hg}$ at the end of a test.

\section{Procedure}

In most cases, coal samples were received in 5-gallon buckets as slurry. A coal sample contained in a bucket was agitated by means of a dynamic mixer to homogenize the slurry. A known volume of the slurry was removed from the bucket while the slurry was being agitated. The slurry was poured into a $250-\mathrm{ml}$ flask, to which a known volume 


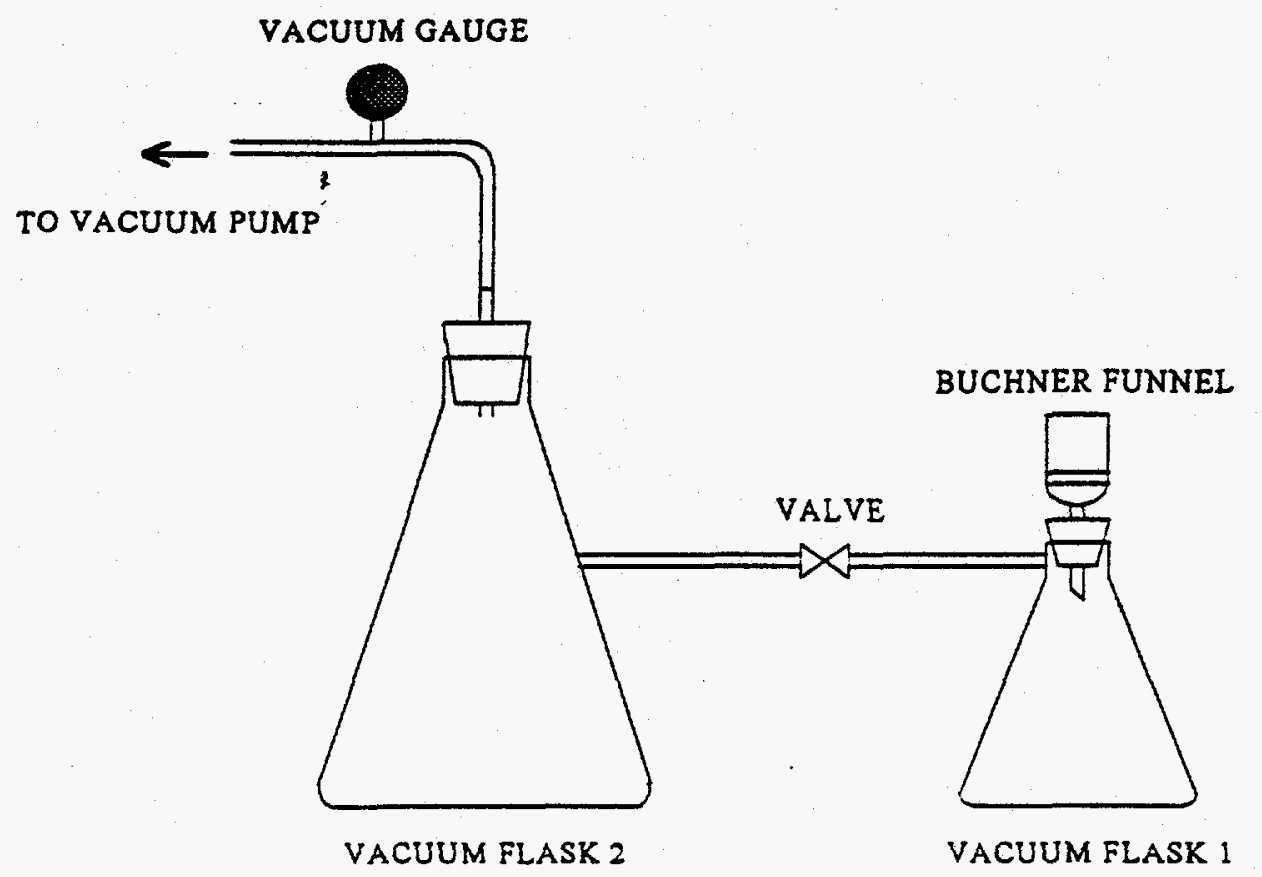

Figure 1. Experimental setup for laboratory vacuum filtration tests

of solution containing dewatering aid was added by means of a Microliter syringe. The flask was subjected to hand shaking for 1 minute to allow for the reagent to adsorb on the surface of coal particles. The coal slurry conditioned in this manner was then transferred to the Buchner funnel. Filtration test was commenced when the slurty was subjected to a vacuum pressure by opening the valve between the two flasks. Bulk of the water was quickly removed, and a cake was formed on the glass frit of the Buchner funnel. After the cake was formed, the vacuum pressure was kept on for a desired period of time to further drain the water from the cake. After the drying cycle time, approximately 10 grams of the filter cake was removed from the funnel, weighed, and dried for 12 hours at $115^{\circ} \mathrm{F}$. The coal sample was weighed again after the drying, and the moisture content was calculated from the difference between the dry and wet weights. 


\section{Coal Sample}

Five different coal samples were used for laboratory filtration tests. All of the samples were flotation products mostly from operating coal preparation plants. The coal samples used in the present work are listed below:

1. 100 mesh $\times 0$ Lower Kittaning coal, Pennsylvania, U.S.A.

2. 28 mesh $\times 0$ Pittsburgh No. 8 coal, Feed to Disc Filters, from CONSOL Inc., U.S.A.

3. 100 mesh $\times 0$ Pittsburgh No. 8 coal, Flotation Product, from CONSOL Inc., U.S.A.

4. 100 mesh $\times 0$ Pond Fines cleaned by flotation, Middle Fork Preparation Plant, Pittston Coal Management Company, Virginia U.S.A.

5. 28 mesh $\times 0$ Feed to Disc Filters from Elkview Mining Co., British Columbia, Canada

The lower Kittanning coal is a flotation product, which had been in dry storage in a freezer. All others were fresh coal samples that had never been dried.

\section{Experimental Results}

\section{A. Lower Kitanning Coal Sample Tested Using a Buchner Funnel}

Table I shows the test results obtained with the 100 mesh $\times 0$ Lower Kittaning coal samples. This sample had been in storage in a freezer for more than a year before it was mixed with tap water to prepare a feed to the filtration tests. Each test was conducted with $3 \mathrm{lb} /$ ton of Reagent $\mathrm{A}$. (The identity of the reagents are not disclosed here due to proprietary reason.) The slurry, which was at $14 \%$ solids, was agitated for one minute after the addition of the reagent to allow for the reagent to react with the 
Table 1. Dewatering test results obtained for Lower Kittaning coal.

\begin{tabular}{cccc}
\hline & \multicolumn{3}{c}{ Cake Moisture (\% weight) } \\
\cline { 2 - 4 } Drying Cycle Time & $1 \mathrm{~min}$ & $5 \mathrm{~min}$ & $10 \mathrm{~min}$ \\
\hline Without Dewatering Aid & 29.0 & 28.0 & 27.1 \\
With Dewatering Aid & 13.1 & 8.8 & 3.9 \\
\hline
\end{tabular}

coal sample. The filtration tests were conducted using a Buchner funnel with a coarse glass frit (40-60um pore size).

In the absence of the dewatering aid, the moisture content of the filter cake did not change significantly with increasing filtration time. Even after a 10 minutes of dewatering time, the cake moisture remained as high as $27 \%$. In the presence of the Reagent A, however, the moisture content was reduced substantially with increasing drying cycle time. After a 10 minutes of drying cycle time, the cake moisture was reduced to as low as $3.9 \%$. It should also be noted here that the use of the novel dewatering aids increased the filtration rates by $4-5$ times.

\section{B. Tests on Actual Coal Samples from Coal Preparation Plants}

\section{a) Coal Samples}

There were some questions raised in using samples that had been in dry storage. The concern was that once a coal sample has been dried, it may be difficult to get the sample completely wetted again. For this reason, the next series of tests were conducted on the actual flotation products sent to CCMP from coal preparation plants. The samples tested included: i) 28 mesh $\times 0$ feed (Pittsburgh No. 8) to a disc filter at a plant operated 
by CONSOL Inc., ii) 100 mesh $\times 0$ flotation product (Pittsburgh No. 8) from CONSOL Inc., and iii) 100 mesh $\times 0$ flotation product from the Middle Fork plant, Pittston Coal Management Company, Virginia.

b) Filter Leaf Tests Using $3 \mathrm{lb} /$ ton of Reagent $\mathrm{A}$

Initially, these samples were subjected to the standard filter leaf tests using the equipment obtained from EIMCO. The filter leaf was made of polypropylene media. In each experiment, the leaf was dipped into the slurry face down for 15 seconds to form a cake (cake-formation time). The leaf was then taken out of the water while the vacuum pressure was on and held in air at an upright position for 60 seconds to dry the cake (drying cycle time). After the drying cycle time, the vacuum was cut off and the cake was discharged by means of a spatula.

Table 2 shows the results of the filter leaf tests conducted with the actual coal samples. In the absence of dewatering aid, the cake moisture of the Middle Fork coal sample was $41.9 \%$. The moisture content was reduced to $23.7 \%$ in the presence of 3 $\mathrm{lb} /$ ton of Reagent $\mathrm{A}$. In addition to reducing the cake moisture, the use of dewatering aid

Table 2. Dewatering Test Results Obtained with the Actual Coal Samples from Coal Preparation Plants Using $3 \mathrm{lb} /$ ton of Reagent $\mathrm{A}$

\begin{tabular}{|c|c|c|}
\hline \multirow[b]{2}{*}{ Coal Sample } & \multicolumn{2}{|c|}{ Cake Moisture (\% weight) } \\
\hline & $\begin{array}{c}\text { Without } \\
\text { Dewatering Aid }\end{array}$ & $\begin{array}{c}\text { With } \\
\text { Dewatering Aid }\end{array}$ \\
\hline Middle Fork Column Concentrate ${ }^{1}$ & 41.9 & 23.7 \\
\hline Pittsburgh No. 8 Filter Feed ${ }^{2}$ & 41.8 & 23.0 \\
\hline Pittsburgh No. 8 Flotation Product ${ }^{3}$ & 42.0 & 24.4 \\
\hline
\end{tabular}

${ }^{1}$ Flotation column concentrate ( $15 \%$ solids, 100 mesh $\times 0$ ) from refuse pond;

${ }^{2}$ Filter feed ( $30 \%$ solids, 28 mesh $\times 0$ ); ${ }^{3}$ flotation concentrate ( $20 \%$ solids, 100 mesh $\times 0$ ). 
resulted in improved filtration rate, which is manifested by the cake thickness and the volume of filtrate collected. For the Pittsburgh No. 8 filter feed sample, the moisture content was reduced from $41.8 \%$ to $23 \%$ in the presence of $3 \mathrm{lb} /$ ton of Reagent $\mathrm{A}$ Similar results were obtained with the Pittsburgh No. 8 flotation product.

\section{c) Buchner Funnel Tests}

Although the filter leaf tests are commonly used in industry, it has one draw back; that is, an effective dewatering aid causes an increase in cake thickness, which in tum causes an increase cake moisture. Thus, it is difficult to see the beneficial effects of using dewatering aids using the filter leaf test procedure, which is described in the foregoing paragraph. For this reason, all of the ensuing filtration tests were conducted using Buchner funnels, as described in the Apparatus Section. With this technique, the cake thicknesses can be controlled by controlling the volume of a coal slurry added to a Buchner funnel. Also, the drying cycle time can be controlled at will, which is a very important advantage of using Buchner funnels. As shown in Table 1, the longer the drying cycle time, the lower the moisture when novel dewatering aids are used. When no dewatering aids were used, the cake moisture does not decrease significantly with increasing drying cycle time as shown in the table. Furthermore, the use of Buchner funnel allows the filtration rate to be measured readily by collecting the volume of the filtrate at the bottom. 
Table 3. Dewatering of Lower Kittanning Coal" Using Different Amounts of Reagent A

\begin{tabular}{cc}
\hline $\begin{array}{c}\text { Reagent A Dosage } \\
(\mathrm{lbs} / \mathrm{ton})\end{array}$ & $\begin{array}{c}\text { Cake Moisture } \\
\text { (\% weight) }\end{array}$ \\
\hline 0 & 27.1 \\
1.52 & 11.5 \\
$\frac{3.04}{-100 \text { mesh; } 14 \% \text { solids; } 100 \mathrm{ml} \text { of slurry was used in each test }}$
\end{tabular}

Using Various Dosages of Reagent A Table 3 shows the results obtained with the Lower Kittanning coal sample (-100 mesh), which had been in dry storage for more than a year before filtration tests. The dry coal sample was dispersed in water at $14 \%$ solids. While the slurry was being agitated, a known volume $(100 \mathrm{ml})$ of the slurry was removed and poured into an Erlenmeyer flask. A volume of reagent was added to the flask, which was then hand-shaken for a few minutes to provide the time needed for the reagent to react with the coal. After the conditioning the slurry was poured into a Buchner funnel to commence filtration tests as described under Apparatus section. As shown in Table 3, the cake moisture was $27.1 \%$ in the absence of dewatering aid. At $1.52 \mathrm{lb} /$ ton of Reagent A, the cake moisture was reduced to $11.5 \%$. At $3.04 \mathrm{lb} /$ ton, the cake moisture was further reduced to $3.9 \%$. All of the tests were conducted using 10 minutes of drying cycle time. This may seem excessive. It should be pointed out, however, that the 10 minute of drying cycle time did not reduce the cake moisture when no dewatering aids were used. 
Table 4. Dewatering of Pocahontas No. 3 Concentrate ( -28 mesh filter feed)

\begin{tabular}{cc}
\hline $\begin{array}{c}\text { Reagent A Dosage } \\
\text { (bs/ton) }\end{array}$ & $\begin{array}{c}\text { Cake Moisture } \\
\text { (\% weight) }\end{array}$ \\
\hline 0 & 28.7 \\
2 & 14.3 \\
4 & 11.1 \\
\hline
\end{tabular}

The next series of experiments were conducted on a clean Pocahontas No. 3 seam coal (-28 mesh). The feed coal had a pulp density of $30 \%$ solids. The tests were conducted using 0 to $4 \mathrm{lb} /$ ton Reagent $A$, and the results are given in Table 4 . In the absence of dewatering aids, the cake moisture was $28.7 \%$. At $2 \mathrm{lb} / \mathrm{ton}$, the moisture was reduced to $14.3 \%$, which was further reduced to $11.1 \%$ at $4 \mathrm{lb} /$ ton. All of the tests were conducted using 3 minutes of drying cycle time and 0.65 inches of cake thickness.

The next set of experiments was conducted on a Pittsburgh No. 8 coal sample using 0 to $2 \mathrm{lb} /$ ton of Reagent $A$. As seen on Table 5 , at $2 \mathrm{lb} /$ ton, the cake moisture was $16.7 \%$, which is higher than the case with the Pocahontas and Lower Kittanning coals. However, this moisture is only $46 \%$ of the case without the dewatering aid.

Table 5 Dewatering of Pittsburgh No. 8 Concentrate ( -100 mesh flotation concentrate, 20 $\%$ solids feed)

\begin{tabular}{cc}
\hline $\begin{array}{c}\text { Reagent A Dosage } \\
\text { (lbs/ton) }\end{array}$ & $\begin{array}{c}\text { Cake Moisture } \\
\text { (\% weight) }\end{array}$ \\
0 & 36.2 \\
1 & 18.6 \\
2 & 16.7 \\
\hline
\end{tabular}


Table 6. Dewatering of Middle Fork Column Concentrate

\begin{tabular}{cc}
\hline $\begin{array}{c}\text { Reagent A Dosage } \\
\text { (lbs/ton) }\end{array}$ & $\begin{array}{c}\text { Cake Moisture } \\
\text { (\% weight) }\end{array}$ \\
0 & 26.0 \\
0.32 & 15.2 \\
0.96 & 15.2 \\
1.60 & 14.2 \\
\hline 100 mesh $\times 0$ flotation concentrate; $15 \%$ solids feed
\end{tabular}

Table 6 shows the results of the tests conducted on the Middle Fork column concentrate. Although the coal sample was nominally 100 mesh $\times 0$, it was a very fine coal with the median size being $20 \mu \mathrm{m}$. At $1.6 \mathrm{lb} /$ ton of Reagent A, the cake moisture was reduced to $14.2 \%$, which was only $52 \%$ of what was obtained without dewatering aid.

Effect of Cake Thickness In order to more closely represent actual plant conditions, the filtration tests were conducted at higher cake thicknesses using Buchner funnel. The tests were conducted on the Pittsburgh No. 8 filter feed $(28$ mesh $\times 0)$ using $2 \mathrm{lb} /$ ton of Reagent A. The results are shown in Table 7. The cake moisture decreased with decreasing cake thickness. It was observed that at higher cake thicknesses, the cake was cracking, which in tum may be attributed to the high dewatering rate. Once a crack was formed, the vacuum was lost and the drainage process stopped. 
Table 7. Results of the Dewatering Tests Conducted on the Pittsburgh No. 8 Flotation Product

\begin{tabular}{|c|c|}
\hline $\begin{array}{l}\text { Cake Thickness } \\
\text { (inches) }\end{array}$ & $\begin{array}{l}\text { Cake Moisture } \\
\text { (\% weight) }\end{array}$ \\
\hline 0.5 (w/o Reagent A) & 32.3 \\
\hline 0.7 & 23.1 \\
\hline 0.5 & 18.1 \\
\hline 0.4 & 15.6 \\
\hline 0.2 & 11.7 \\
\hline
\end{tabular}

Effect of Vacuum Pressure One parameter of interest is the effect of vacuum pressure on product moistures. As seen in Figure 2, the higher the vacuum pressure, the lower the product moisture becomes, regardless of whether the dewatering aids were used or not. At all levels of vacuum pressure, the moisture was 10 to $12 \%$ lower with the use of the dewatering aid than without.

Table 8 shows the resuits obtained with the Microcel ${ }^{T M}$ flotation product from the Middle Fork plant. In each test, a $100 \mathrm{ml}$ of coal slurry was poured into the funnel before a vacuum pressure was applied. After most of the water was removed, the vacuum pressure was kept on for five minutes to remove the residual moisture. The cake thickness was approximately 0.5 inches. 


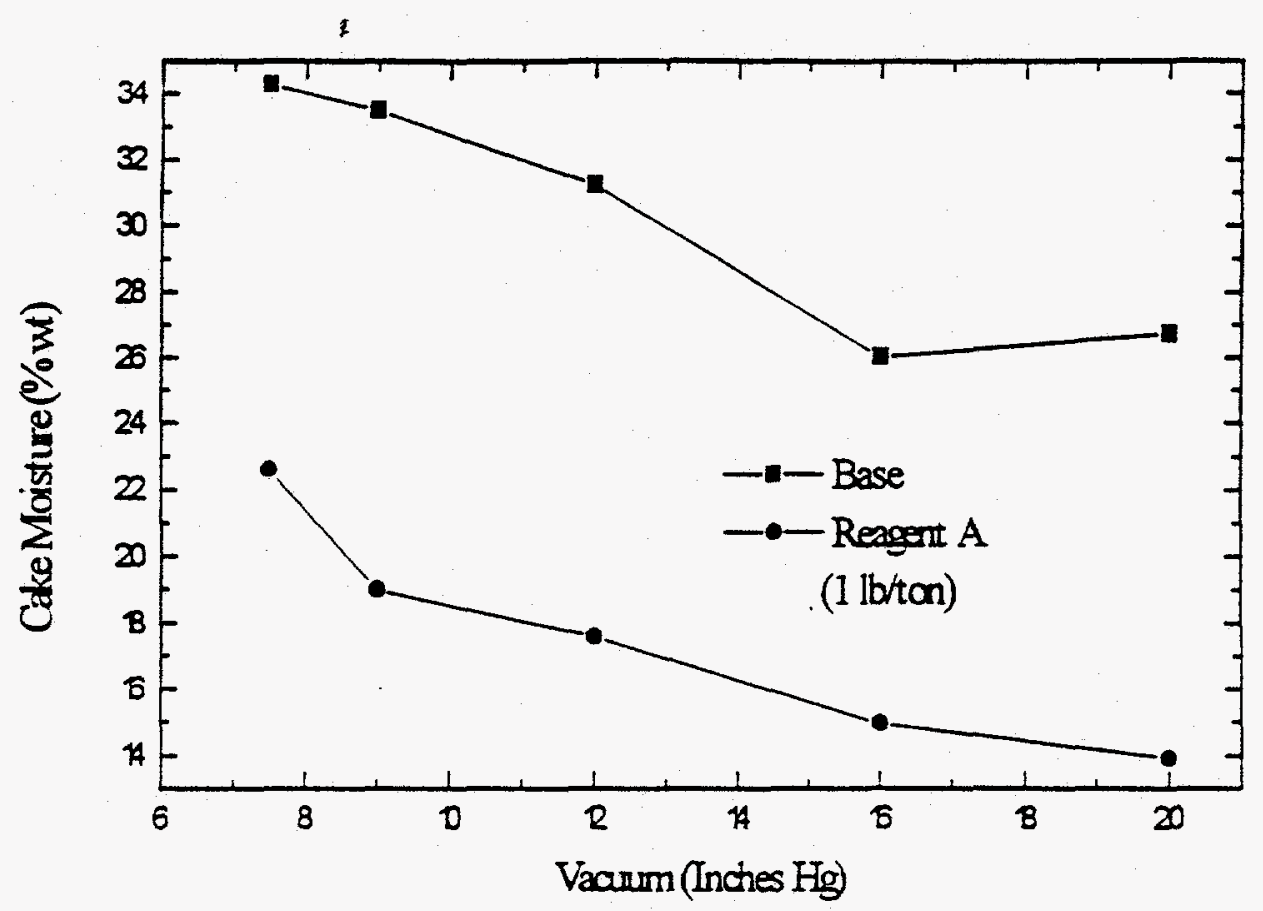

Figure 2. Results of the filtration tests conducted on the flotation products (100 mesh $\times$ 0) from the Middle Fork coal preparation plant as a function of applied vacuum with and without dewatering aid ( $1 \mathrm{lb} /$ ton of Reagent $\mathrm{A}$ ). All tests were conducted at 3 minutes of drying cycle time.

Table 8. Results of the Filtration Tests Conducted on a -100 Mesh Microce ${ }^{T M}$ Flotation Product

\begin{tabular}{|c|c|c|c|}
\hline \multirow[b]{2}{*}{$\begin{array}{c}\text { Vacuum Pressure } \\
\text { (inches } \mathrm{Hg} \text { ) } \\
\end{array}$} & \multirow[b]{2}{*}{$\begin{array}{c}\text { Reagent Dosage } \\
\text { (lb/ton) }\end{array}$} & \multicolumn{2}{|c|}{ Product Moisture (\% wt.) } \\
\hline & & W/O & With \\
\hline 24.5 & 2.5 & 22.9 & 11.9 \\
\hline 28.5 & 2.0 & 17.8 & 5.4 \\
\hline
\end{tabular}

"20 um median size 
Similar tests were conducted with a Pittsburgh No. 8 coal sample (-28 mesh). At a pressure of 24.5 inches $\mathrm{Hg}$, the moisture content was reduced to $14.1 \%$ with $2 \mathrm{lb} /$ ton of reagent $\mathrm{A}$ at 0.5 inches of cake thickness and 5 minutes of drying cycle time. This result is far superior to that (20.7\%) obtained without a dewatering aid. At a pressure of 28.5 inches of $\mathrm{Hg}$, the moisture content was reduced to $11.9 \%$. The results obtained with the Middle Fork and Pittsburgh coal samples suggest that the dewatering aids used in the present work are useful for increasing the efficiency of vacuum filtration. Although the 5 minutes of drying cycle time may be excessive, the beneficial effect of using the reagent can also be seen at shorter cycle times.

Dewatering tests were also conducted on a 28 mesh $\times 0$ mesh Elkview coal sample from British Columbia. Two sets of tests were conducted using different amounts

Table 9. Results Obtained Using Reagent $A$ on the Elkview Coal Sample $(-28$ mesh $\times 0)$

\begin{tabular}{|c|c|c|c|c|}
\hline \multirow[b]{2}{*}{$\begin{array}{l}\text { Temperature } \\
{ }^{\circ} \mathrm{C}\end{array}$} & \multicolumn{2}{|c|}{$100 \mathrm{ml}^{\text {siurry }}{ }^{1}$} & \multicolumn{2}{|c|}{$200 \mathrm{ml}$ slurry ${ }^{2}$} \\
\hline & $\begin{array}{l}\text { Reagent Dosage } \\
\text { (lbs/ton) }\end{array}$ & $\begin{array}{c}\text { Moisture } \\
(\% W t)\end{array}$ & $\begin{array}{l}\text { Reagent Dosage } \\
\text { (lbs/ton) }\end{array}$ & $\begin{array}{c}\text { Moisture } \\
(\% \mathrm{Wt})\end{array}$ \\
\hline \multirow{5}{*}{$\begin{array}{c}-23 \\
\text { (ambient) }\end{array}$} & 0 & 22.5 & 0 & 27.8 \\
\hline & 0.5 & 16.5 & 0.5 & 21.3 \\
\hline & 1.0 & 13.8 & 1.0 & 16.8 \\
\hline & 2.0 & 10.3 & 2.0 & 13.6 \\
\hline & 5.0 & 9.4 & 5.0 & 11.1 \\
\hline \multirow{3}{*}{60} & 0 & 19.4 & 0 & 22.1 \\
\hline & 0.5 & 15.7 & 0.5 & 18.4 \\
\hline & 5.0 & 8.0 & 5.0 & 10.4 \\
\hline
\end{tabular}

${ }^{1} 0.20$ inches cake thickness: 0.40 inches cake thickness 
of coal slurry. The tests conducted with $100 \mathrm{ml}$ of slurry gave approximately 0.2 -inches of cake thickness, while the tests conducted with $200 \mathrm{ml}$ slurry gave 0.4 -inches of cake thickness. A 5-minute drying cycle time was employed in each test. The results are shown in Table 9. It shows that moisture content decreases with increasing reagent dosage, decreasing cake thickness, and with increasing temperature.

Figure 3 shows the results of the filtration tests conducted on the Middle Fork coal sample (100 mesh $\times 0$ ) as a function of drying cycle time. The tests were conducted with and without dewatering aid (Reagent A) for comparison. The cake thickness was approximately 0.1 inches in all tests. The tests conducted using $1 \mathrm{lb} /$ ton of Reagent $\mathrm{A}$

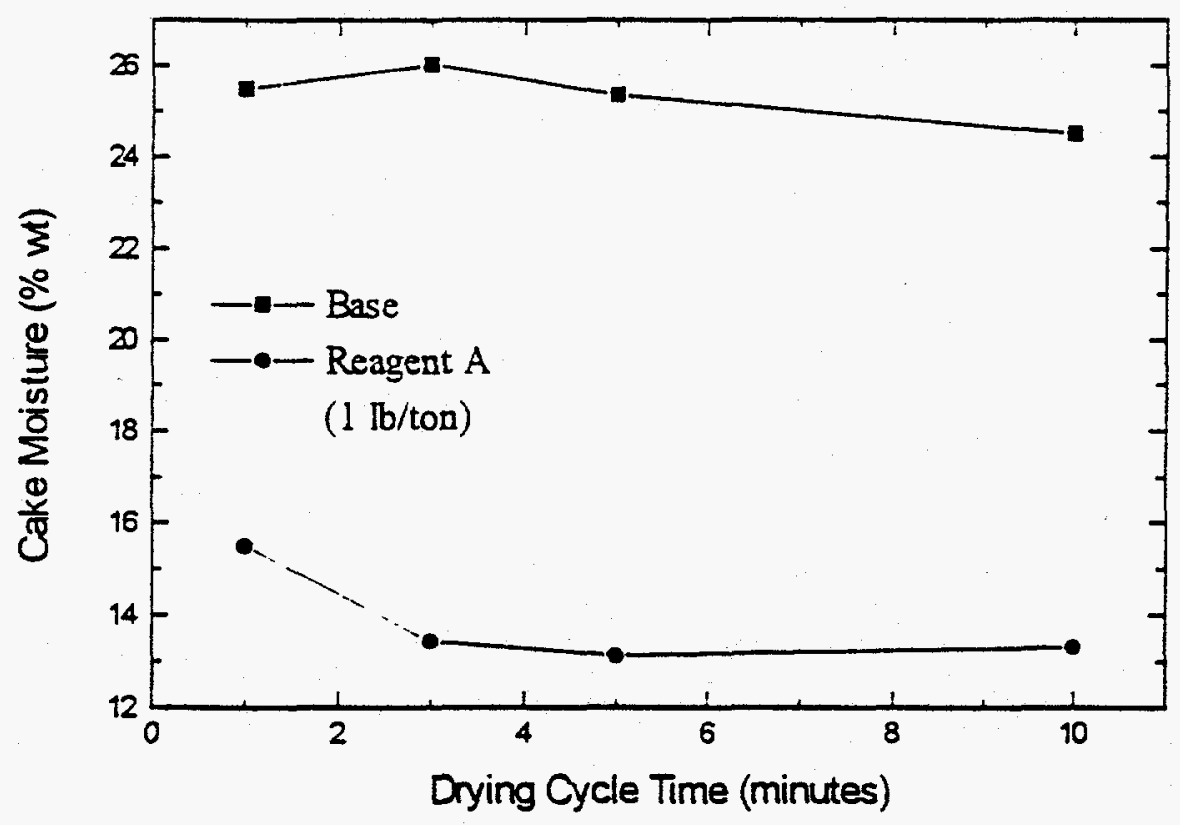

Figure 3. Effects of drying cycle time on the cake moisture. Filtration tests were conducted on a Microcel flotation product from the Middle Fork coal preparation plant with and without dewatering aid (1 $\mathrm{lb} /$ ton of Reagent $\mathrm{A}$ ). The cake thickness was approximately 0.1 inches. 
produced filter cake with approximately $10 \%$ lower moisture than without dewatering aid. After 1 minute drying cycle time, the cake moisture was 25.4 and $15.5 \%$ in the absence and the presence of the reagent. Increase in drying cycle time beyond 5 minutes did not make a significant difference in cake moisture. In the absence of dewatering aid, however, drying cycle time did not show a significant difference.

Next series of filtration tests were conducted by changing the cake thickness. The tests were conducted on the flotation product $(100$ mesh $\times 0)$ from the Middle Fork coal preparation plant using $1 \mathrm{lb} /$ ton of Reagent $\mathrm{A}$. For the purpose of comparison, control tests were conducted without using dewatering aid. The drying cycle time was fixed at 5 minutes in all tests. The cake thickness was varied by changing the volume of the slurry to be filtered in the range of 100 to $500 \mathrm{ml}$. The results are shown in Figure 4. As expected, the cake moisture increased with increasing cake thickness. As the cake thickness increased from 0.1 to 0.5 inches, the cake moisture increased from 13.1 to $20.5 \%$, respectively. Thus, the advantage of using the dewatering aid diminished considerably at higher cake thicknesses. However, the cake moisture of the control tests also increased with increasing cake thickness. Therefore, the advantage of using Reagent A was evident even at higher cake thicknesses. At 0.5 inches of cake thickness, for example, the cake moisture obtained at $1 \mathrm{lb} /$ ton of Reagent $\mathrm{A}$ was approximately $8 \%$ lower than the control tests. This difference may increase at higher dosages of Reagent A. 


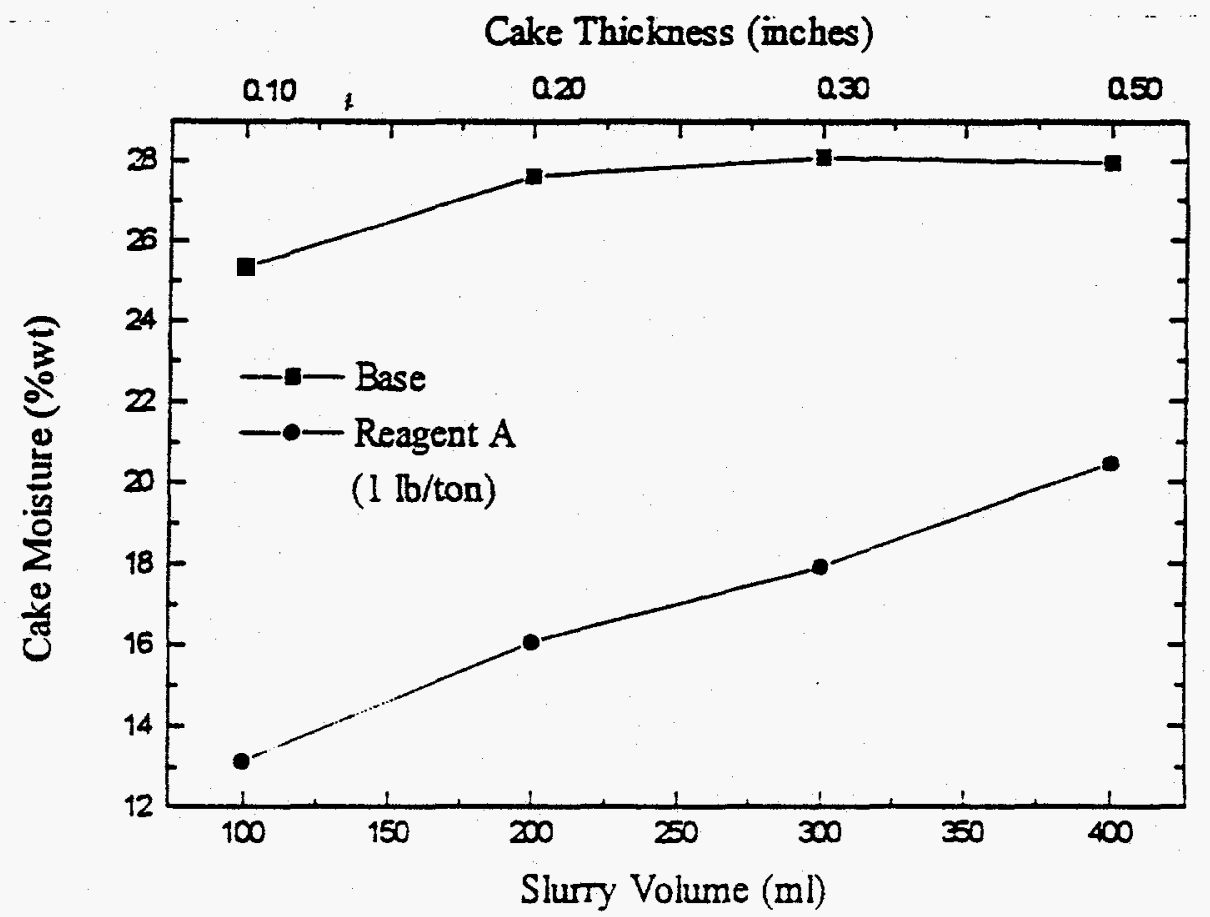

Figure 4. Effects of cake thickness on the cake moisture. Filtration tests were conducted on the flotation products ( 100 mesh $\times 0$ ) obtained at the Middle Fork preparation plant with and without dewatering aid ( $1 \mathrm{lb} /$ ton of Reagent A). All tests were conducted at 5 minutes of drying cycle time.

Figure 5 shows the results of the filtration tests conducted on the flotation products from Middle Fork using varying amounts of Reagent A. All of the tests were conducted with $200 \mathrm{ml}$ of slurry, which gave approximately 0.2 inches of cake thickness. At ambient temperature, the cake moisture obtained without using dewatering aid was $22.9 \%$. The cake moisture decreased when the reagent dosage increased. At $5 \mathrm{lb} / \mathrm{ton}$, the cake moisture became as low as $11.9 \%$. Note, however, that there were no significant benefits for increasing reagent additions beyond $2.5 \mathrm{lb} /$ ton when the coal slurry was filtered at ambient temperature.

Also shown in Figure 5 are the results obtained at $60^{\circ} \mathrm{C}$. In general, the cake 


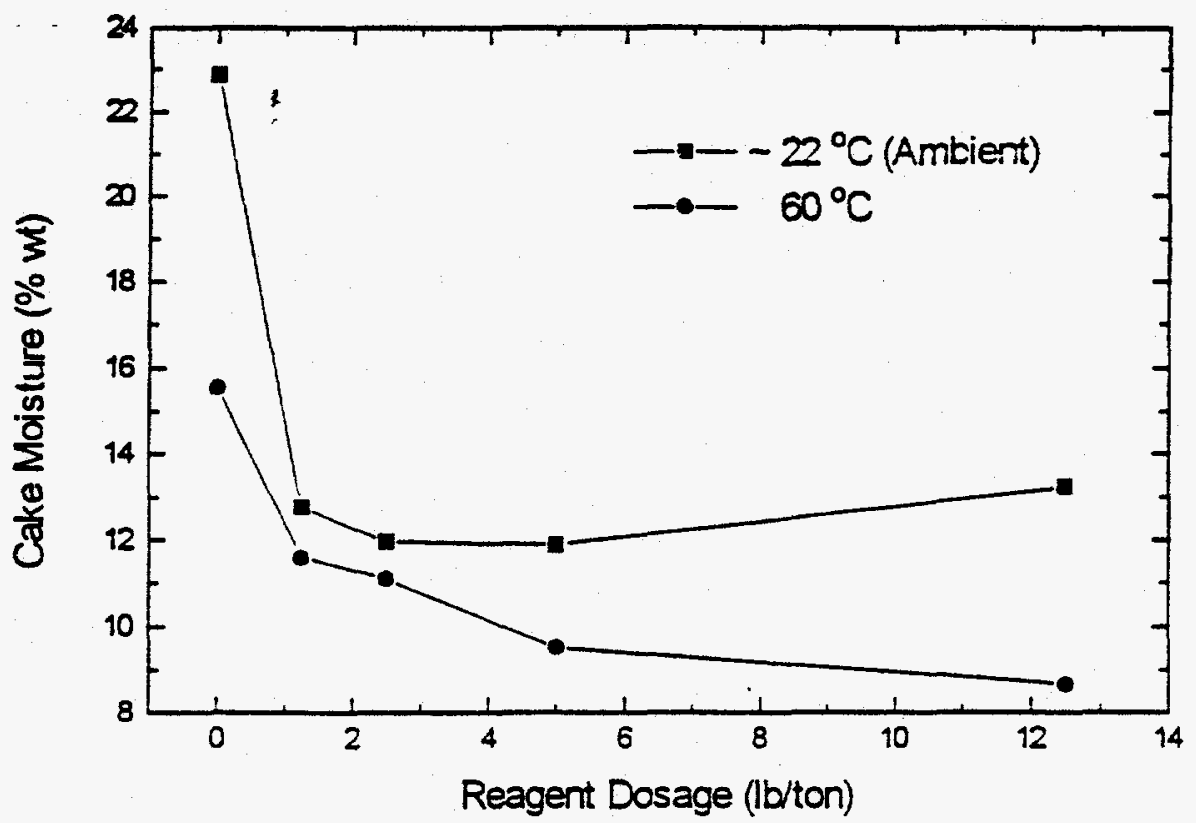

Figure 5. Results of the filtration tests conducted on the flotation products from the Middle Fork coal preparation plant as a function of reagent dosage (Reagent $\mathrm{A}$ ). The tests were conducted at 0.2 inches of cake thickness and at two different temperatures.

moistures obtained at this elevated temperature were substantially lower than at the ambient condition. When no dewatering aids were used, the cake moisture was only $15.6 \%$, which was substantially lower than obtained $(22.9 \%)$ at the ambient temperature. The cake moisture decreased further as Reagent $\mathrm{A}$ was added to aid the filtration. It is interesting that the cake moisture continued to decrease with increasing reagent dosage without reaching a plateau, which is different from what was observed at the ambient temperature. The beneficial effects of filtering fine coal slurry at an elevated temperature may be attributed to the reduction in the viscosity of the water trapped in the capillary formed between the particles. Apparently, there is a synergy between using Reagent A and doing filtration at an elevated temperature. 


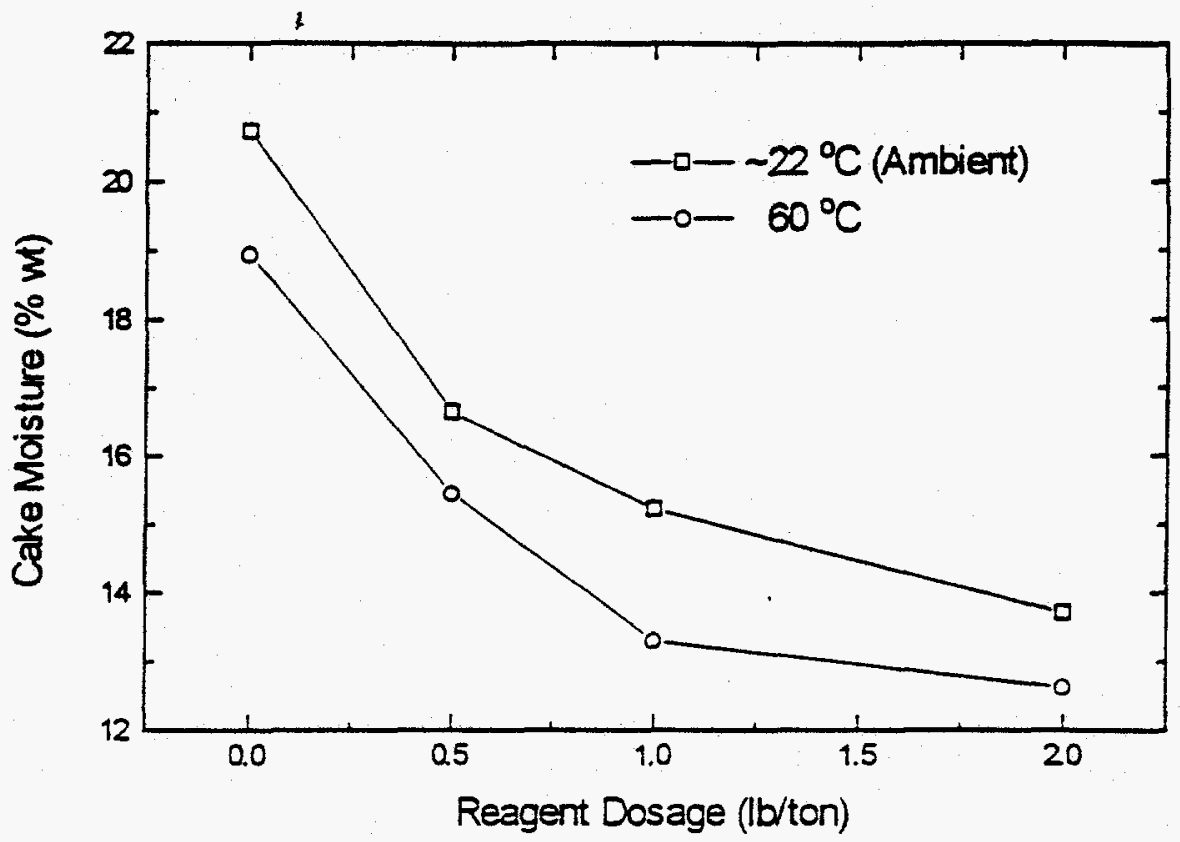

Figure 6. Results of the filtration tests conducted on the flotation products (28 mesh x 0) from Elkview Mining Company as a function of reagent dosage (Reagent A). The tests were conducted at 0.2 inches of cake thickness and at two different temperatures.

Figure 6 shows a similar set of test results obtained with the flotation product (28 mesh $\times 0$ ) from the Elkview Mining Company using Reagent $A$. The tests were conducted both at the ambient temperature $\left(-22^{\circ} \mathrm{C}\right)$ and at $60^{\circ} \mathrm{C}$ using $200 \mathrm{ml}$ of coal slurry in each test. The cake thicknesses measured after the drying cycle time were in the neighborhood of 0.2 inches. When the tests were conducted without using dewatering aid, the cake moistures were 20.8 and $18.9 \%$ at 22 and $60^{\circ} \mathrm{C}$, respectively. With the addition of Reagent $A$, the cake moisture decreased substantially. The moisture reduction increased with increasing reagent dosage. At $2 \mathrm{lb} / \mathrm{ton}$, the cake moisture decreased to $13.7 \%$ at $22{ }^{\circ} \mathrm{C}$. At the elevated temperature, it was further reduced to $12.6 \%$ at the same 
reagent dosage. It is interesting that, unlike the case with the Middle Fork coal, the cake moisture continued to decrease beyond $2 \mathrm{lb} /$ ton, which was the maximum dosage used for the Elkview coal. It is possible that the moisture reduction reaches a plateau at higher reagent dosages, which should be determined in the future.

In addition to helping to reduce the cake moisture, Reagent $\mathrm{A}$ is capable of improving the kinetics of dewatering. When no reagent was used, the cake formation time was 20 seconds. At $2 \mathrm{lb} /$ ton of Reagent $\mathrm{A}$, the cake formation time decreased to 7 seconds. At $60^{\circ} \mathrm{C}$, the cake formation time was further reduced to 5 .

The dewatering aid used in the present work is sensitive to the oxidation of a coal sample. Table 10 shows the results obtained after aging the Elview coal sample for four weeks at the ambient temperature before filtration tests. Although Reagent $\mathrm{A}$ was able to reduce the cake moisture substantially below the level that can be achieved without dewatering aid, the final moisture was not as low as obtained when the tests were conducted soon after the sample had been received. It is likely that coal particles are

Table 10. Results Obtained Using Reagent A on the Elkview Coal Sample (28 mesh x 0)

\begin{tabular}{ccc}
\hline $\begin{array}{c}\text { Reagent Dosage } \\
(\mathrm{lb} / \text { ton })\end{array}$ & $\begin{array}{c}\text { Cake Formation Time } \\
(\mathrm{sec})\end{array}$ & $\begin{array}{c}\text { Product Moisture } \\
(\% \text { weight })\end{array}$ \\
\hline 0 & 25 & 24.37 \\
0.5 & 20 & 21.24 \\
1 & 18 & 19.48 \\
2 & 15 & 16.64 \\
\hline
\end{tabular}


superficially oxidized during the process of aging, which may be detrimental to the adsorption of the dewatering aid used in the present work.

Table 11 shows the results of the filtration tests conducted on the flotation product from CONSOL, Inc., which was a 28 mesh $x 0$ Pittsburgh seam coal. Each test was conducted using $200 \mathrm{ml}$ of coal slurry, which gave approximately 0.2 inches of cake thickness. As shown, the cake moisture was lower than that obtained without dewatering aid by $4 \%$ only at $2 \mathrm{lb} /$ ton of Reagent $\mathrm{A}$. This result was very poor as compared to the result obtained with another Pittsburgh coal sample received from the same company. As shown in our previous quarterly report, Reagent $A$ was able to reduce the cake moisture of a Pittsburgh coal to less than $10 \%$. The poor results obtained with the sample tested during the current reporting period may be attributed to the possible contamination of the coal sample by the flocculants during plant operation.

Table 11. Results Obtained Using Reagent A on the Pittsburgh Coal Sample (28 mesh $\times 0)$

\begin{tabular}{|c|c|c|}
\hline $\begin{array}{l}\text { Reagent Dosage } \\
\text { (lb/ton) }\end{array}$ & $\begin{array}{l}\text { Cake Formation Time } \\
\qquad(\mathrm{sec})\end{array}$ & $\begin{array}{l}\text { Product Moisture } \\
\text { (\% weight) }\end{array}$ \\
\hline 0 & 61 & 25.57 \\
\hline 0.5 & 48 & 23.96 \\
\hline 1 & 36 & 22.42 \\
\hline 2 & 36 & 21.92 \\
\hline
\end{tabular}




\section{SUMMARY}

Five different coal' samples were subjected to laboratory vacuum filtration tests using one of the more promising novel dewatering aids (Reagent $\mathrm{A}$ ) developed at Virginia Tech. The results may be summarized as follows:

- The tests results obtained on the Lower Kittanning coal sample (100 mesh $\times 0$ ) showed that use of Reagent $A$ as a dewatering aid reduced the cake moisture to as low as $3.9 \%$ at 10 minutes of drying cycle time. At 1 minute of drying cycle time, the moisture was $11.9 \%$. These results were substantially lower than those ( 27 to $29 \%$ ) obtained without using dewatering aids.

- The tests conducted on the Middle Fork coal sample (100 mesh x 0 ) showed that use of Reagent $\mathrm{A}$ in the amount of $\mathrm{l} \mathrm{lb} / \mathrm{ton}$ reduced the cake moisture by more than $10 \%$, which accounted for a $50 \%$ moisture reduction. The tests were conducted using a relatively thin cake ( 0.1 inches) and long drying cycle times. However, extending the drying cycle time beyond 3 to 5 minutes did not make a significant difference.

- The test results obtained with the Middle Fork coal sample using $1 \mathrm{lb} /$ ton of Reagent A showed that cake moisture increases with cake thickness. However, the same trend was observed when no dewatering aid was used. Thus, the use of Reagent $\mathrm{A}$ showed an advantage in moisture reduction by approximately $12 \%$ at 0.1 inches cake, which diminished to $8 \%$ at 0.5 inches cake thickness.

- Tests were conducted on the Middle Fork coal sample by using different amounts of Reagent $\mathrm{A}$ at 0.2 inches of cake thickness and at two different 
temperatures. At the ambient temperature, the cake moisture was reduced sharply at $1 \mathrm{lb} /$ ton and reached a plateau at $2.5 \mathrm{lb} /$ ton. At $60^{\circ} \mathrm{C}$, however, the ?

cake moisture continued to decrease with increasing reagent addition. In general, significantly lower cake moistures could be obtained at the elevated temperature. The improved moisture reduction at the higher temperature may be attributed to a decreased in the viscosity of the capillary water.

- Effects of reagent dosage on the cake moisture were also studied on the Elkview coal $(28$ mesh $\times 0$ coal). The tests were conducted at 0.2 inches of cake thickness and at two different temperatures. The cake moistures obtained at $60^{\circ} \mathrm{C}$ were considerably lower than those obtained at the ambient temperatures. The results showed that judicious use of Reagent $A$ can reduce the cake moisture to 12 to $14 \%$ range.

- A series of tests were conducted on the Elkview coal sample after aging the coal sample for a period of four weeks at ambient temperature. Although the results showed substantially improved moisture reductions, the improvement was less than obtained with fresh sample. The detrimental effect of aging may be attributed to the superficial oxidation of the coal sample.

- Tests conducted on the Pittsburgh coal from CONSOL, Inc. showed that use of Reagent $A$ reduced the cake moisture by approximately $4 \%$, which was poor as compared to those obtained with another Pittsburgh coal sample. The poor performance of the novel dewatering aid may be attributed to the possible contamination of the coal sample by a flocculant during plant operation. 
- The novel dewatering aid developed at Virginia Tech is capable of reducing moisture to the, level that would not require thermal drying. In general, the dewatering efficiency increases with increasing vacuum pressure, increasing drying cycle time, increasing reagent dosage, decreasing cake thickness, and increasing temperature. Judicious control of these parameters will enable commercialization of the dewatering aid. 


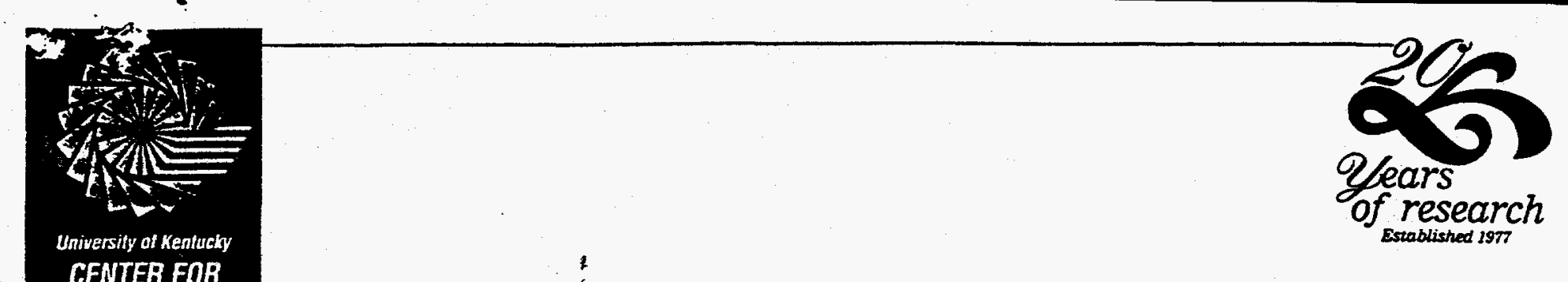

CENTER FOR

SARPUEMEHERTY

RESEARCH

3572 l:on Works Pike Lexington, KY 40511-8433

FAX: 606-257-0302

T.N. 606-257-0239

March 27, 1997

Mr. Lee Rasnik

Project Manager

Center for Mineral \& Coal Processing

146 Holden Hall

Virginia Polytechnic \& State University

Blacksburg, VA 24061

\section{Dear Lee:}

Enclosed are two copies of our final report of our project funded by the Appalachian Clean Coal Consortium. It was a pleasure working on this project. We will have one M.S. thesis completed using the results obtained in this project. We appreciate USDOE and ACCTC support of the project. Also, enclosed is a floppy containing the final report. If you need any additional information, please contact me.

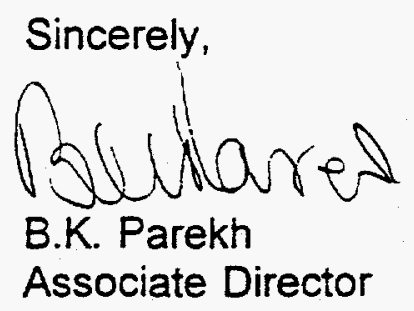

Enclosures

ij 


\title{
STUDY OF NOVEL APPROACHES FOR \\ DESTABILIZATION OF FLOTATION FROTH
}

FINAL REPORT

Prepared for

The Appalachian Clean Coal Technology Consortium

By

\author{
X. Jiang, D. Tao, and B.K.Parekh \\ Center for Applied Energy Research \\ University of Kentucky \\ Lexington, KY 40511
}

March 27,1997 
"THIS REPORT WAS 'PREPARED AS AN ACCOUNT OF WORK SPONSORED BY AN AGENCY OF THE UNITED STATES GOVERNMENT. NEITHER THE UNITED STATES GOVERNMENT NOR ANY AGENCY THEREOF, NOR ANY OF THEIR EMPLOYEES, MAKES ANY WARRANTY, EXPRESS OR IMPLIED, OR ASSUMES ANY LEGAL LIABILITY OR RESPONSIBILITY FOR THE ACCURACY, COMPLETENESS, OR USEFULNESS OF ANY INFORMATION, APPARATUS, PRODUCT, OR PROCESS DISCLCSED, OR REPRESENTS THAT ITS USE WOULD NOT INFRINGE PRIVATELY OWNED RIGHTS. REFERENCE HEREIN TO ANY SPECIFIC COMMERCIAL PRODUCT, PROCESS, OR SERVICE BY TRADE NAME, TRADEMARK, MANUFACTURER, OR OTHERWISE DOES NOT NECESSARILY CONSTITUTE OR IMPLY ITS ENDORSEMENT, RECOMMENDATION, OR FAVORING BY THE UNITED STATES GOVERNMENT OR ANY AGENCY THEREOF. THE VIEWS AND OPINIONS OF AUTHORS EXPRESSED HEREIN DO NOT NECESSARILY STATE OR REFLECT THOSE OF THE UNITED STATES GOVERNMENT OR ANY AGENCY THEREOF." 
THIS REPORT WAS PREPARED BY THE UNIVERSITY OF KENTUCKY CENTER FOR APPLIED ENERGY RESEARCH AS AN ACCOUNT OF WORK SPONSORED BY THE PITTSBURGH ENERGY TECHNOLOGY CENTER. NEITHER THE UNIVERSITY OF KENTUCKY NOR ANY PERSON ACTING ON ITS BEHALF:

(A) MAKES ANY WARRANTY, EXPRESSED OR IMPLIED, WITH RESPECT TO THE USE OF ANY INFORMATION, APPARATUS, METHOD, OR PROCESS DISCLOSED IN THIS REPORT OR THAT SUCH USE MAY NOT INFRINGE PRIVATELY OWNED RIGHTS; OR

(B) ASSUMES ANY LIABILITIES WITH RESPECT TO THE USE OF, OR FOR THE DAMAGES RESULTING FROM THE USE OF, ANY INFORMATION, APPARATUS, METHOD, OR PROCESS DISCLOSED IN THIS REPORT. 


\section{TABLE OF CONTENTS}

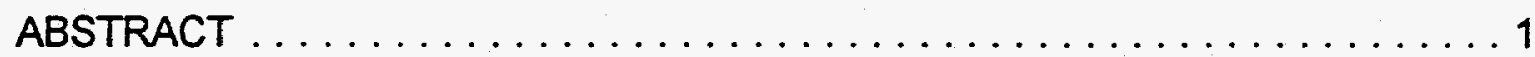

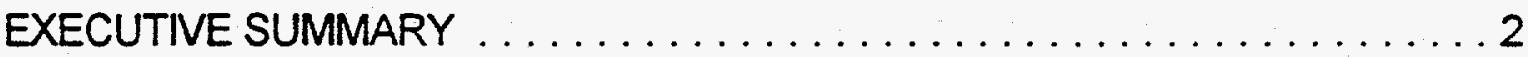

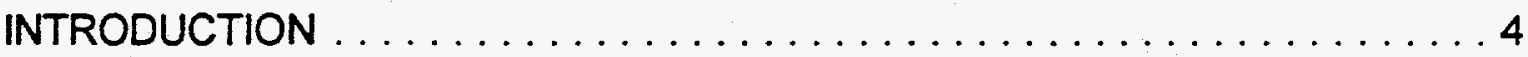

OBJECTIVES AND SCOPE $\ldots \ldots \ldots \ldots \ldots \ldots \ldots \ldots \ldots \ldots \ldots$

BACKGROUND $\ldots \ldots \ldots \ldots \ldots \ldots \ldots \ldots \ldots \ldots \ldots \ldots \ldots \ldots \ldots \ldots \ldots$

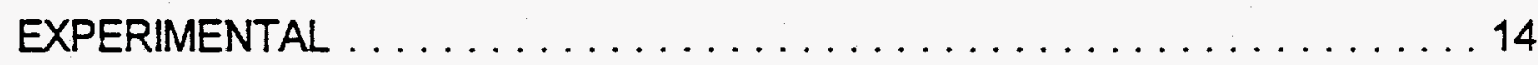

COAL SLURRY SAMPLES AND REAGENTS $\ldots \ldots \ldots \ldots \ldots \ldots 14$

EXPERIMENTAL APPARATUS $\ldots \ldots \ldots \ldots \ldots \ldots \ldots \ldots \ldots$

RESULTS AND DISCUSSION $\ldots \ldots \ldots \ldots \ldots \ldots \ldots \ldots \ldots \ldots$

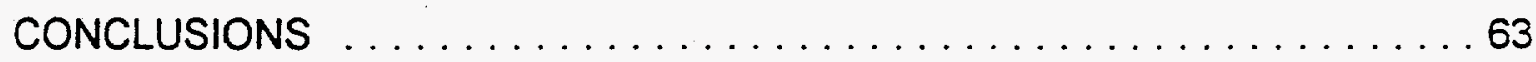

RECOMMENDATIONS $\ldots \ldots \ldots \ldots \ldots \ldots \ldots \ldots \ldots \ldots \ldots \ldots \ldots \ldots \ldots$

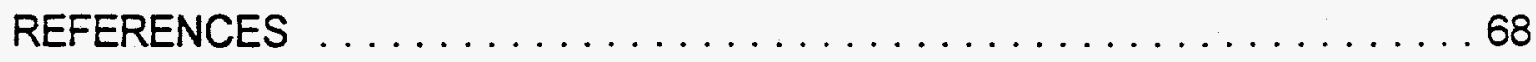




\section{LIST OF FIGURES}

3

Page

Fig. 1. Schematics of the "Foam Stabo System" ... . . . . . . . . . 15

Fig. 2. Calibration curve of the pressure transducer voltage

output and pressure in $\mathrm{mm}_{2} \mathrm{O} \ldots \ldots \ldots \ldots \ldots \ldots \ldots \ldots$

Fig. 3. Particle size distribution of flotation feed . . . . . . . . . . . 20

Fig. 4. Particle size distribution of flotation product $\ldots \ldots \ldots \ldots \ldots \ldots 21$

Fig. 5. Surface tension versus concentration of emulsified and non-emulsified Allied Colloid 944 B frother concentration. . . . . . 23

Fig. 6. Change of surface tension with the concentration of emulsified frother.

Fig. 7. Differential pressure and surface area obtained with dynamic froth as a function of drainage time using 250 ppm frother concentration

Fig. 8. Differential pressure and surface area obtained with steady state froth as a function of drainage time using $250 \mathrm{ppm}$ frother concentration

Fig. 9. Differential pressure and surface area obtained with dynamic froth as a function of drainage time using 375 ppm frother concentration

Fig. 10. Differential pressure and surface area obtained with steady state froth as a function of drainage time using $375 \mathrm{ppm}$ frother concentration

Fig. 11. Differential pressure and surface area obtained with dynamic froth as a function of drainage time using $500 \mathrm{ppm}$ frother concentration

Fig. 12. Differential pressure and surface area obtained with steady state froth as a function of drainage time using $500 \mathrm{ppm}$ frother concentration

Fig. 13. Half-drainage time vs. air flow rate for dynamic and steady state froth using $250 \mathrm{ppm}$ frother concentration

Fig. 14. Change of differential pressure and surface area of froth with drainage time at different frother concentrations

Fig. 15. Effects of reagent concentration on surface area of froth remaining after 10 minutes. 
Fig. 16. Effects of solids concentration in slumy on surface area of froth remaining after 10 minutes $\ldots \ldots \ldots \ldots \ldots \ldots \ldots 40$

Fig. 17. Changes in surface area of coal froth with drainage time in the presence of frother $944 \mathrm{~B}$

Fig. 18. Changes in surface area of coal froth with drainage

Fig. 19. Changes in surface area of coal froth with dosage of defoamer 347 added to the top of froth

Fig. 20. Changes in surface area of coal froth with dosage of defoamer 0149 added to the top of froth . . . . . . . . . . . . . . 45

Fig. 21. Changes in surface area of coal froth with dosage of defoamer 347 added to the slurry prior to flotation

Fig. 22. Effects of limestone concentration on surface area of froth remaining after 10 minutes. $(\odot$ Coated with cetylpyridium chloride)

Fig. 23. Effects of uncoated limestone particle size on surface area of froth remaining after 10 minutes

Fig. 24. Effects of coated limestone concentration on surface area of froth remaining after 5 minutes

Fig. 25. Effects of concentration of limestone coated/uncoated with surfactant on surface area of froth remaining after 5 minutes

Fig. 26. Froth destabilizing effects of magnetite particles coated with defoamer 0149 in water and added to the top of froth

Fig. 27. Froth destabilizing effects of magnetite particles coated with defoamer 347 in water and added to the top of froth 55

Fig. 28. Froth destabilizing effects of magnetite particles coated with defoamer 0149 in water and added to the top of froth together with $5 \mathrm{ml}$ water

Fig. 29. Froth destabilizing effects of magnetite particles coated with CPCL in water and added to the top of froth . . . . . . . . 57

Fig. 30. Froth destabilizing effects of magnetite particles coated with $\mathrm{CPCL}$ in water and added to slumy prior to flotation

Fig. 31. Froth destabilizing effects of magnetite particles coated with $\mathrm{CPCL}$ in fuel oil and added to slumy prior to flotation

Fig. 32. Froth destabilizing effects of limestone particles coated with $C P C L$ in fuel oil and added to slumy prior to flotation 
Fig. 33. Froth destabilizing effects of coal particles coated with CPCL in fuel oil and added to slurry prior to flotation

Fig. 34. Effect of dosagé of frother on surface tension of coal slumy filtrate

Fig. 35. Effect of dosage of frother and fuel oil at a constant ratio of $2: 1$ on surface tension of coal slumy filtrate 65 


\title{
STUDY, OF NOVEL APPROACHES FOR DESTABILIZATION OF FLOTATION FROTH
}

\begin{abstract}
Fine coal recovery from fine waste stream using froth flotation technique is becoming an important and integral part of coal preparation plants. Column flotation technique has proven to be the most effective and costefficient in recovery of fine coal. However, in some columns use of glycol-based frother produces a stāble froth, which is not destroyed easily creating problem in dewatering of the slumy. The main objective of this program was to develop novel technique for characterization of froth and develop economical approaches for destabilization of stable froth. The approaches involved addition of chemically treated coarse coal, magnetite, limestone particles suspended in an oil medium to break the stable froth. The results of the studies identified that either magnetite, or limestone, or coal particles coated with a cationic surfactant and suspended in fuel oil was effective in destabilizing a stable clean coal froth. Recommendations are offered for pilot scale evaluation of this novel froth destabilization approach.
\end{abstract}




\section{EXECUTIVE SUMMARY}

Frothers play an important role in froth flotation of mineral and coal. Frothers are heteropolar organic compounds which reduce surface tension of water, which, in tum, provide stability to bubbles to carry hydrophobic particles to the top of slurry and remove it. Recently, column flotation technique is gaining acceptance in mineral and coal industries. However, some of the glycol based frother used in columns provide a froth product, which stays as such for a significant amount of time. This problem has been specifically encountered in a few coal preparation plants in the United States.

The main objective of the present study was to develop a technique to characterize coal froth and to develop a novel efficient and economical technique to stabilize the froth.

For the project, flotation feed and froth product were acquired from the Pittston Coal Company's Holston plant located in Hatfield, Kentucky. The froth characterization studies were conducted using the "Foam Stabo System" developed at the University of Kentucky Center for Applied Energy Research (CAER). The system was found to provide reproducible data on froth surface area derived based on first principle of froth stability.

Results obtained with two-phase (water-air) froth confirmed that higher gas flow rate and higher frother dosage increased froth stability. Allied Colloid 944 B frother, which is glycol based, produced much more stable froth than commonly used methylisobutylcarbinol (MIBC). It was found that a linear relationship existed between 
froth surface area and frother concentration. However, an excessive dosage of frother was found to destabilize froth.

The studies showed that three phase (coal-water-air) froth exhibited much stronger stability than two phase (water-air) froth for a given amount of frother and fuel oil combination. Increasing coal concentration in slurry substantially increased froth stability. Coal froth obtained using Allied Colloid 944B frother was highly stable and could only be destabilized using more than $7 \mathrm{Kg} / \mathrm{t}$ of the commercial defoamer.

Most effective approach to coal froth destabilization was found to be the use of limestone or coal particles coated with a cationic surfactant such as cetylpyridinium chloride (CPCL) suspended in fuel oil. It was shown that a dosage of $2-3 \mathrm{~kg} / \mathrm{t}$ of coal particles coated with CPCL in fuel oil was effective in destroying coal froth when properly added to the froth. It was also found that the stabilization and destabilization mechanisms of three-phase froth may well be different from two-phase froth. Important factors determining defrothing effectiveness of solid particles are: type of solid, coating reagent, coating medium, dosage of particles, addition method, etc. Particle size showed relatively small effect over the range studied. Based on the results of the present study, recommendations are offered that the new approach developed in this project be evaluated on a pilot scale to obtain techno-economic data for a commercial operation. 


\section{INTRODUCTION}

*

In froth flotation process, frothers are utilized to produce stable small bubbles which carry the floatable particle. In case of an ideal froth flotation, the froth should have good fluidity and optimal rigidity. The froth should be just stable enough to carry the floated particles out of the flotation cell. Once the froth is scraped out the cell, it should collapse to free floated particles. Such a froth will also minimize the entrainment of undesired mineral particles into the concentrate and can provide additional selectivity for the flotation process. Too stable or unstable froths penalize the separation efficiency and operation smoothness. If the froths are too stable, they will not break up after being removed from the flotation cell. Usually, such overly stable froths have low fluidity. The unwanted excessive stability of froth causes serious problems for downstream processes, such as dewatering, tailings handling, and re-use of the process water.

Generally, alcohol-based frothers provide froth which collapses as soon as froth is removed from the flotation cell and sprayed with water. Glycol-based frothers on the other hand produce a much stronger froth which is difficult to break by simple physical techniques and requires a large amount of chemicals to break the froth, which adds to the processing cost.

Recently, the use of column flotation technique at a few coal preparation plants froth destabilization prior to dewatering is becoming a serious problem. Until an economic and effective defrothing reagent or process is developed, the coal 
companies will be reluctant to use the advanced froth flotation technique. This project was initiated based on the recommendation of the Appalachian Clean Coal Consortium board members. The results of the study has identified an economic froth destabilizer which consist of addition of coal, or limestone, or magnetite, coated with a cationic surfactant to the froth. This report summarizes the experimental data, results, and conclusions of the study. Recommendations are being offered to evaluate the novel approach on a pilot scale to obtain detailed techno-economic data for a commercial application.

\section{OBJECTIVES AND SCOPE}

The main objective of the proposed project was to develop new defoaming techniques for destruction of overly stable froths produced in fine coal froth flotation. It was also the objective of the project to study chemical dynamics of the three phrase froth.

The scope of this project was to investigate new defoaming techniques. The existing commercial defoamers, such as surfactants, copolymers and hydrophobic silica, are expensive and thus economically unfavorable for breaking up fine coal froths. In this project, new techniques for defoaming coal froth with less expensive chemical were investigated. Two approaches studied involved use of coarse coal particles coated with a cationic surfactant and use of the surfactant coated magnetite and limestone particles dispersed In fuel oil. The scope of the study also involved

understanding characteristics of froth interns of bubble half life, drainage time, etc., 
using a novel 'Foam Stato System' developed at the University of Kentucky Center for Applied Energy Research"

\section{BACKGROUND}

Frothers, as generally defined, are compounds that are used for the purpose of creating a froth in a flotation separation. Frothers play an important role in froth flotation of mineral or coal by influencing particle-bubble contact and by affecting the degree of separation obtained in the froth column. Frothers are heteropolar organic compounds and as such when added to water it reduces its surface tension. The stability of froths or foams is in part a function of the rapidity with which the surface tension can vary when a bubble is subjected to mechanical stress. Generally, it is found that foam stability is maximum where the surface tension can vary rapidly with concentration (Booth and Freyberger, 1962). Brown et al. (1953) have reported that froth stability increases with increasing viscosity and with decreasing permeability.

A froth phase in flotation cells that possesses appropriate stability is essential to achieve satisfactory separation performance. Too stable a froth is difficult to handle and results in unwanted hydraulic entrainment of particles while an unstable froth can not successfully carry attached hydrophobic particles to the froth product. It is well known that alcohol-based frothers provide less stable froth than glycol-based frothers.

Results obtained with different columns (Groppo and Parekh, 1993) have shown that use of glycol-based frothers in fine coal column flotation is essential for 
achieving high flotation recovery. This is especially true for the flotation column that requires strong turbulence in the bubble generator to generate small bubbles. The use of microbubble flotation column (Microcel ${ }^{\text {TM }}$ ) at the Pittston Coal Company's Holston Coal Preparation Plant located at Hatfield, Kentucky effectively recovered fine coal using an Allied Colloid $944 \mathrm{~B}$ as frother which contains glycol. However, the column froth is too stable to break, which creates serious operational problems dealing with dewatering. A study of coal froth stability and development of an effective froth destabilization technique is important for smooth operation of the preparation plant.

\section{Froth/Foam Stability}

Froth in flotation cells is thermodynamically unstable and bubbles tend to contract and combine with each other to reduce the total interfacial area in the system. This process proceeds through liquid drainage from lamellar regions into Plateau borders. When the lamellar layer reaches a critical thickness of 5 to $15 \mathrm{~nm}$, bubble coalescence occurs since the liquid film can no longer support the pressure of the gas in the bubble. The processes occurring in the froth give rise to the "secondary cleaning" of flotation. Froth drainage removes particles not strongly attached to the bubble surface; froth coalescence introduces shocks and reduces bubble surface area, both of which cause weakly attached particles to detach from the bubble films. Froth can be made to last minutes, days, or even months by manipulating viscosity of the liquid phase and surface viscosity of bubbles that retard 
liquid drainage from between bubble interfaces and electrostatic and stearic repulsions between adjacent interfaces that prevent bubbles from approaching each other.

The froth phase was described mathematically by Arbiter and Harris [1962] who assumed it to be a perfectly mixed phase. This perfectly mixed concept is generally recognized to be applicable to mechanically agitated flotation cells. Cooper [1966] first used the plug flow concept to describe the variation of froth grade with height. The plug flow concept has proven most useful in the modeling of the behavior of the froth phase in flotation columns in which uniaxial transport is dominānt [1988] and has gained considerable attention due to increased interest in column flotation. Yianatos et al. [1986] identified that the column froth zone consists of three regions, i.e., (1) an expanded bubble bed (next to the froth-pulp interface), (2) a packed bubble bed above that, and (3) a conventional draining froth above the wash water inlet.

Effects of flotation operating parameters on froth stability have been investigated by a number of authors. Szatkowski [1987] concluded that the coalescence of bubbles at the pulp-froth interface and in the lowest part of the froth enhances gangue rejection. In coal flotation, the rate of ash rejection was fairly high and most of the froth upgrading action occurred within the initial $1-3 \mathrm{~cm}$ of the froth height. He also showed that higher froth residence time yields higher concentrations of ash at all levels of the froth by reducing ash drainage.

Finch et al. [1989] studied the influence of wash water on the stability of two- 
phase column froth and showed that wash water can stabilize the froth providing bias rate $J_{b}>0.1 \mathrm{~cm} / \mathrm{s}$. Moys [1989] showed that the increase in gas rate would result in more stable froth and higher water recovery based on the work with several minerals. Feteris et al. [1987] and Engelbrecht and Woodbum [1975] demonstrated that froth stability is also dependent on the height (depth) of froth zone. Froth would eventually collapse with increasing height due to liquid film thinning by drainage. Smaller bubble size is very helpful in improving flotation rate constant but Moys [1989] concluded that it could deteriorate the separation efficiency by entraining more water.

\section{Effects of Solid Particles on Froth Stability}

The presence of solid particles, incorporated within the froth structure, has a profound effect on the characteristics of the froth and its stability. This effect depends on many factors associated with particles. They include particle size, hydrophobicity, shape, concentration in solution, etc.

Szatkowski and Freyberger [1985] observed that quartz particles in three size fractions, i.e., $+20 \mu \mathrm{m},-20+10 \mu \mathrm{m}$ and $-10 \mu \mathrm{m}$, rendered fine bubbles $(10-100 \mu \mathrm{m})$ to be more resistant to coalescence and promoted the production of the stable froth. Klassen and Mokrousov [1963] reported that more hydrophobic particles had greater effects on stabilizing the froth. Only coarse particles were considered to be able to act as buffers between bubbles and prevent bubble coalescence, consequently strengthening the stability of the froth [1965]. Studies carried out by Lovell [1976] on apatite and calcite showed that the froth produced in the presence of tall oil fatty acid 
could be destabilized by both minerals of lower concentrations in the pulp and stabilized at higher solids toncentrations.

Johansson and Pugh [1992] investigated the effects of particle size and hydrophobicity on the stability of froths with methylated quartz samples. They concluded that particles of intermediate hydrophobicity (corresponding contact angle $\left.\theta \approx 65^{\circ}\right)$ would enhance froth stability but more hydrophobic particles $(\theta>909$ would destabilize the froth. More hydrophilic particles $\left(\theta<40^{\circ}\right)$ would not influence the froth properties. By recording artificial thinning process of water film with high-speed cinematography, Dippenaar [1982] performed a detailed study of the role in determining froth stability played by hydrophobicity of solid particles, the shape of the particles, particle roughness and size, the type of frother, etc. He found that highly hydrophobic particles (contact angles $\theta>90^{\circ}$ ) have froth breaking ability due to facilitated thinning of interbubble liquid bridged by the particle. This result is in agreement with the study of Johansson and Pugh [1992]. He conciuded that the liquid lamellae separating bubbles has to be thinned to half the diameter of a particle or less before it can be ruptured by the particle. This suggests that smaller particles are more powerful than larger particles in destabilizing froths, which was confirmed in his experiments. With moderately hydrophobic particles (e.g., cubic galena particles with a contact angle $\theta \approx 74^{\circ}$ ), stabilization or destabilization of froth could occur depending on the orientation of the cleavage plane. Stable films were formed when the cleavage plane formed a smooth regular arrangement along the interface and 
allowed easy movement of the three-phase contact. However, film rupture occurred as soon as the bubble bridged both surfaces of the film regardless of the value of contact angle. Dippenaar [1982] also demonstrated that although the froth stability can be drastically reduced by the presence of a relatively small number of hydrophobic particles, a large number of small particles could stabilize froth by forming a closely packed monolayer which prevents the particles from being forced out of the film and prevents the interfaces from touching.

Engel and Smitham [1988] investigated the stability of froths produced in a coal flotation process and has revealed that increased froth stability occuirs as the size distribution of the feed material is made finer. Coals of higher rank generate froths with exceptional stability and the volume and stability of the product froths decreases as coal rank decreases. In the presence of collector, froth stability is determined solely by particle size.

\section{Thermodynamics Governing Froth/Foam Stability}

The stability of a foam/froth is determined by two most important factors: surface elasticity and surface viscosity. The Gibbs surface elasticity $E$ is defined by

$$
E=\frac{2 d y}{d \ln A}
$$

where $y$ is surface tension, $A$ is the surface area of the film. The fundamental reason for the stability of foam is, as indicated by the definition of $E$, the ability of the lamella 
to respond to stress by local adjustment of the surface tension.

The surface dilational viscosity is defined by:

$$
\kappa=\frac{\Delta \gamma \times A}{d A / d t}
$$

that is, the surface viscosity is proportional to the reciprocal of the change in surface area per unit time per unit applied surface pressure.

There are many variables that can affect the stability of mineral/coal froth. These variables can be classified into three categories, namely, particle properties, chemical regime, and hydrodynamic conditions. The hydrodynamic conditions include turbulence, bubble size, aeration rate, etc. Chemical regime refers to the presence of various chemicals (such as surfactants, dispersants, and polymers) as well as chemical conditions ( $\mathrm{pH}$, electrolyte concentration, etc.). The presence of solid particles can either increase or decrease the stability of a froth, depending on their surface and bulk properties. Highly hydrophobic particles have strong defoaming effects, while hydrophilic particles can stabilize a froth. In addition, particle size and shape can also strongly influence the froth stability. These factors are interactive in a three-phase froth system. For example, it was shown that there are strong interactions between frother(s) and collector(s) at the particle/water/air interface as well as in bulk solution. The presence of surfactants will not only reduce the surface tension of water/air, but can also increase the surface hydrophobicity of 
particles.

Consequently, there are a number of approaches to destabilizing froths/foams. One approach will be to use chemicals commonly known as defoamers. The defoamer is insoluble in the foaming liquid and is more surface-active than the foaming liquid. The insoluble defoamer functions largely by spreading on the surface of the foam and forming a thin film that does not support foam. The thermodynamic condition required for spreading of a duplex film over a liquid surface is:

$$
S=Y_{L}-Y_{D}-Y_{D-L}>0
$$

where $S$ is the spreading coefficient, $\gamma_{L}$ surface tension of liquid, $\gamma_{D}$ surface tension of duplex film and $\gamma_{D L}$ is surface tension at liquid-duplex film interface. When the defoamer phase becomes saturated with foaming phase, the surface tension of the defoamer and the interfacial tension are affected, decreasing the value of the spreading coefficient. The other function of the defoamer is to penetrate into the foam surface and destabilize it. The thermodynamic requirement for this condition is given by:

$$
K_{E}=Y_{L}+Y_{D-L}-Y_{D}<0
$$




\section{EXPERIMENTAL}

1

Coal Siurry Samples and Reagents

For the flotation froth destabilization studies column flotation feed and froth product were obtained from the Pittston Coal Company's Holston Coal Preparation Plant located at Hatfield, Kentucky. This plant uses Microcel ${ }^{\mathrm{TM}}$ columns to recover fine coal from the waste stream. The flotation feed contained $32.93 \%$ ash and column froth product $8.54 \%$ ash. The solids content of clean coal froth was about 12.6\%. The frother, Allied Colloids $944 \mathrm{~B}$ used in this study was the same as used at the preparation plant for coal flotation.

\section{Experimental Apparatus}

In the present program the UKCAER developed "Foam Stabo System" shown in Figure 1 was used to characterize stability of froth. It mainly consisted of two jacketed glass cylinders with an identical volume of approximately 1 -liter each. The right cylinder was used as the working cell where froth was generated and the left cylinder used as a reference cell contained surfactant-free water of equal volume to solution or slumy in the right cylinder. The tube ends were connected to a differential pressure transducer model DP103 manufactured by Validyne Engineering Corp. that required $10 \mathrm{~V}$ of $\mathrm{DC}$ power to operate. The voltage output of the pressure transducer was continually monitored using a PC computer. 


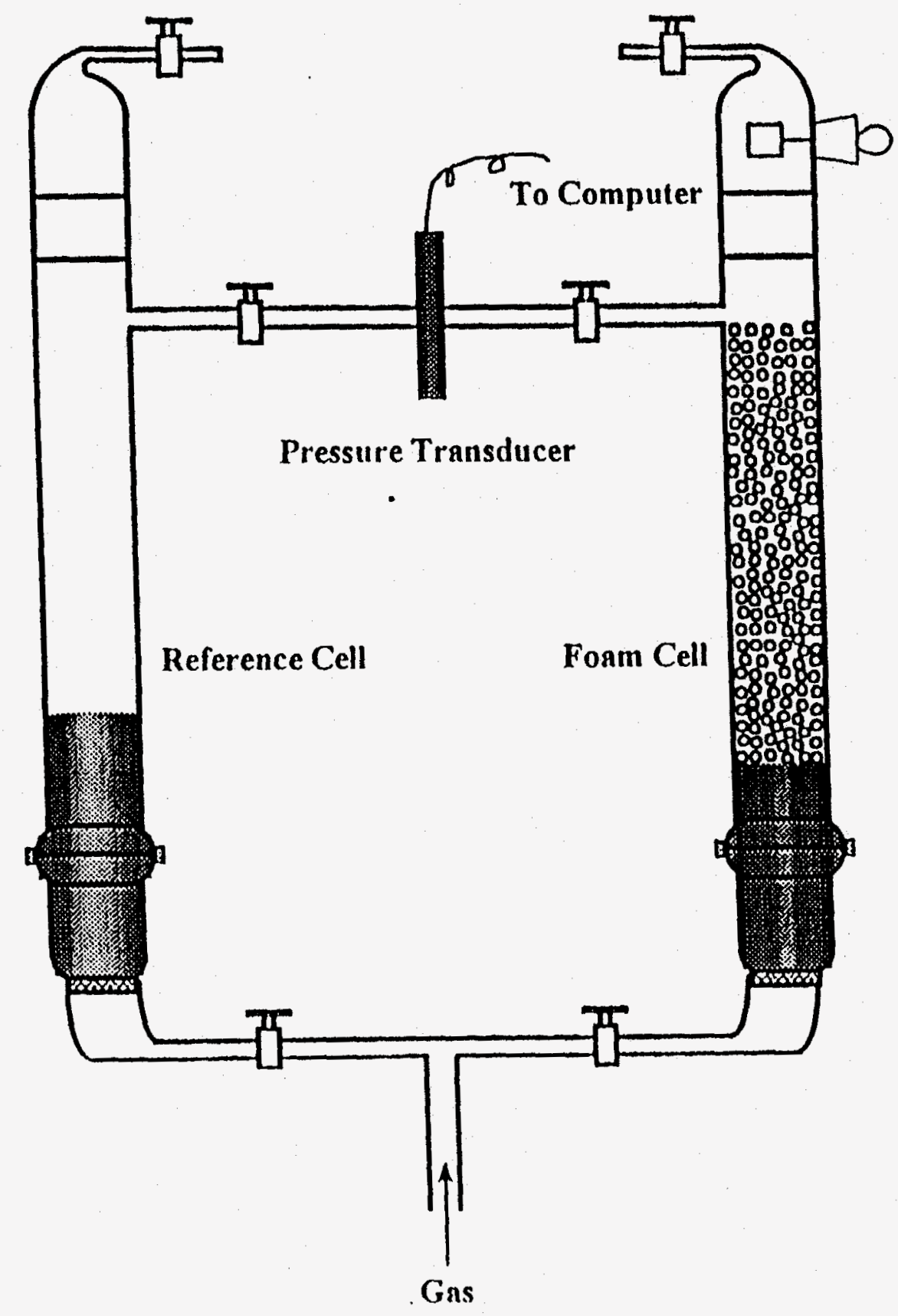

Fig. 1. Schematics of the "foam Stabo System". 
Differential pressures of the magnitude of a few torricelli were typically attained with the present apparatus. The differential approach for measuring pressure has the advantage over the absolute approach in that random pressure changes caused by environmental temperature fluctuations can be largely canceled out. To do so most effectively, a reference cylinder of identical internal volume must be made part of the system. Both cylinders have a double wall and their temperature was kept constant by means of circulating water controlled by a HAAKE $\mathrm{C}$ constant temperature bath.

For the measurement of foam stability two hundred milliliters of solution or slurry was added into the working cylinder and the same volume of surfactant-free water into the reference cylinder. Compressed nitrogen gas or air was then passed through a fine frit $(4-8 \mu \mathrm{m})$ to create the froth in the working cylinder. After a period of 20 seconds of froth generation, all valves were closed at the same time to seal the system and separate the two cylinders. The differential pressure increased as the foam in the working cylinder decayed and energy released. The equipment has been designed to add a small amount of froth destabilizer from the top of the working cylinder to destroy the froth and obtain the value of $\Delta P_{-}$defined below.

The decay of froth stability with time can be fundamentally described by the rate of decrease of the total area of gas-liquid interface. The equation of state of froth [Ross, 1969] relates the total area of liquid surface within a froth to the pressure of its contained gas, making it possible to quantify froth decay in fundamental terms by 
determining the rate of the build-up of gas pressure at a constant volume and temperature in the head space above the froth.

The equation of state for froth in the present experimental system can be described as follows:

$$
n_{f} R T=P_{e} V_{f}+2 \sigma A / 3
$$

where

$n_{q}$ number of moles of gas contained in the froth

$P_{\mathrm{e}}:$ pressure external to the froth

$V_{f}$ volume of gas in the froth

$\sigma:$ surface tension

A: area of liquid surface in the froth.

Ross [1969] and Nishioka and Rose [1981] have derived that for a closed system, such as the one shown in Figure 1, at constant volume containing a froth, the equation of state can be simplified to:

$$
A(t)=(3 V / 2 \sigma)\left(\Delta P_{\infty}-\Delta P(t)\right)
$$


Where $A(t)$ : area of liquid surface in the foam at time $t$

$\Delta P(t)$ : change in pressure extemal to a froth at time $t$

$\Delta \mathrm{P}_{\text {. }}$ : change in pressure when the foam completely collapses.

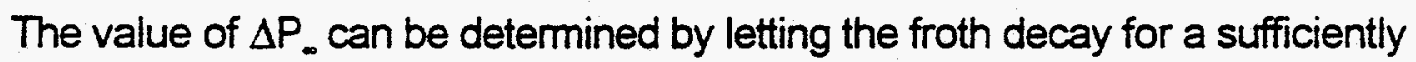
long time or by adding a small amount of antifoamer to the system. Interfacial area of a foam can be measured, therefore, by monitoring the change in pressure extemal to a froth in a vessel of constant volume and temperature, if the total volume of the system is kept constant and the surface tension of the liquid can be determined.

The pressure transducer was calibrated to establish the relationship between the output of voltameter and the pressure. The calibration curve is shown in Figure 2. The best fitting equation can be described as:

$$
\text { Pressure }\left(\mathrm{mm} \mathrm{H}_{2} \mathrm{O}\right)=35.92 \text { Voltage (volts) }
$$

\section{RESULTS AND DISCUSSION}

Particle size distribution of the flotation feed and product representative samples is shown in Figures 3 and 4 , respectively. The average size $\left(D_{50}\right)$ for the feed and product was 40 and $80 \mu \mathrm{m}$, respectively. The ash and solids contents of feed were $32.93 \%$ ash and $7.25 \%$, respectively. Similarly, ash and solids contents of 


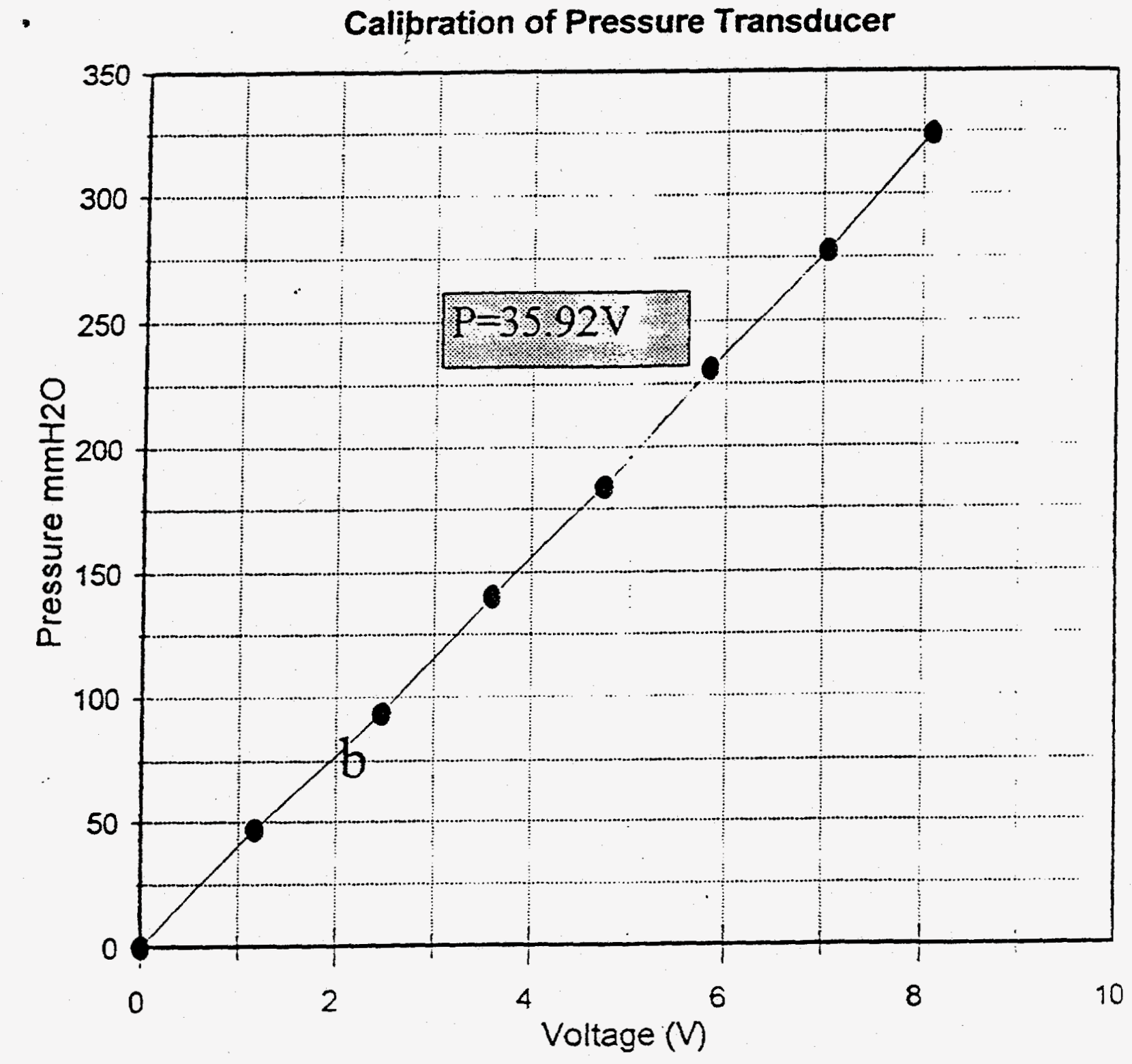

Fig. 2. Calibration curve of the pressure transducer voltage output and pressure in $\mathrm{mm} \mathrm{H} \mathrm{H}_{2} \mathrm{O}$. 


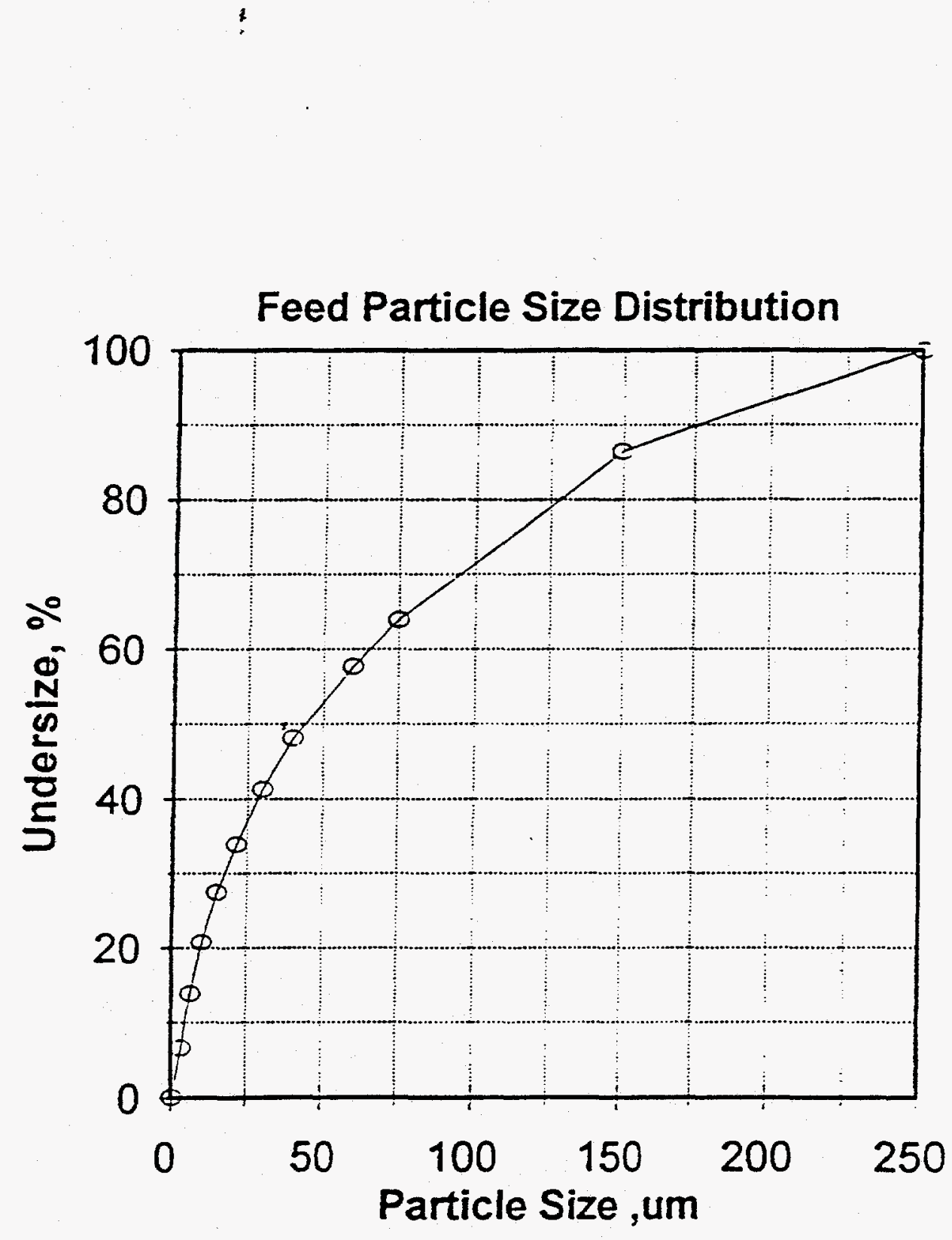

Fig. 3. Particle size distribution of flotation feed 


\section{Concentrate Particle Distribution}

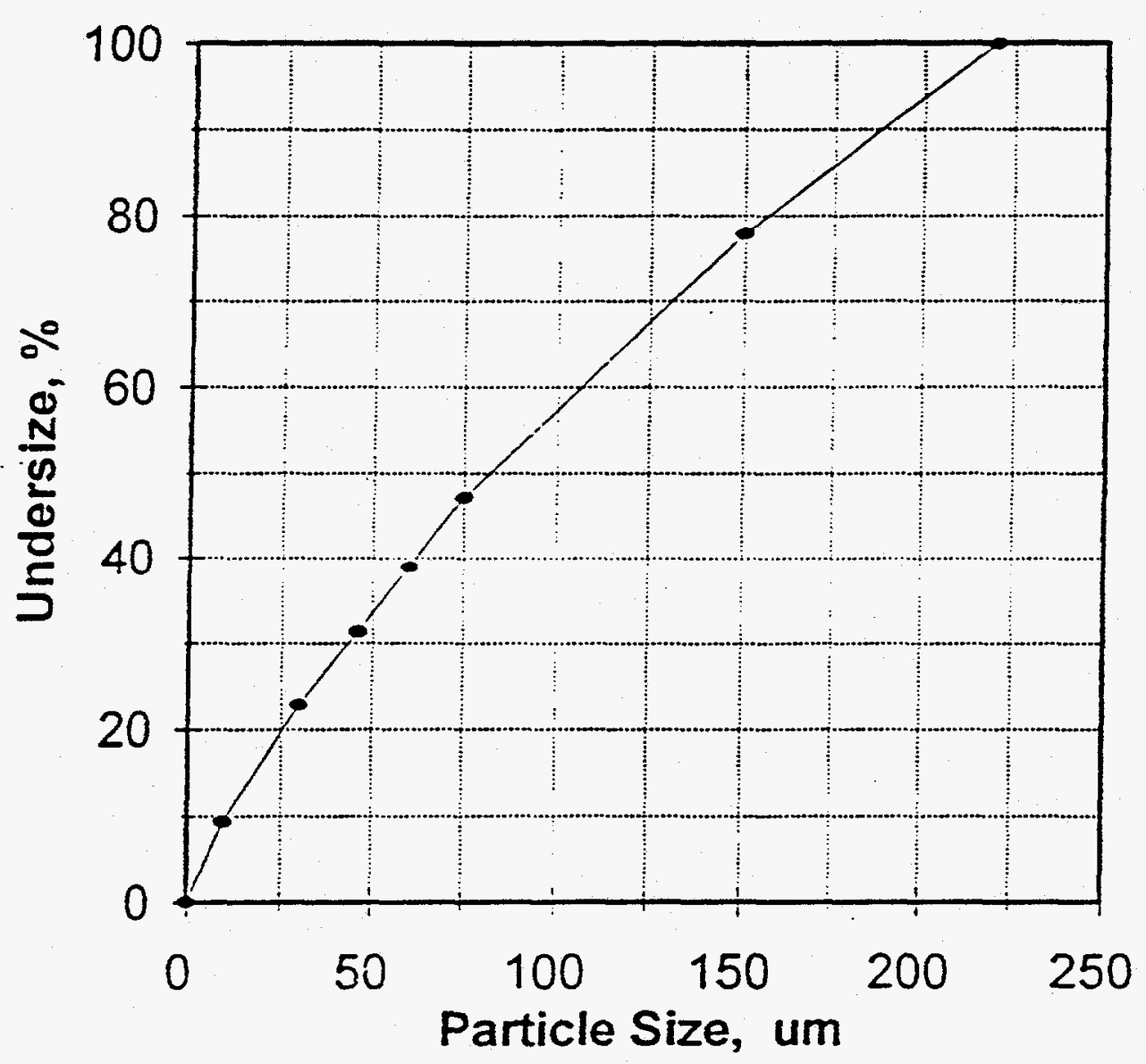

Fig. 4. Particle size distribution of flotation product 
the froth product were $8.54 \%$ and $12.62 \%$, respectively.

In order to calculate the surface area of froth in the working column from the measured differential pressure using equation (6), the surface tension of Allied Colloids $944 \mathrm{~B}$, the frother currently used at the Pittston Holston plant, was determined as a function of frother concentration from 0 to $66 \mathrm{ppm}$. Two different methods were employed for the frother solution preparation: a), mixing using a magnetic stirrer for 5 minutes and $b$ ), emulsifying in a blender. The results shown in Figure 5 shows that there is a large degree of scatter among the data obtained with the solution prepared using the magnetic stirrer. On the other hand, data obtained with emulsified solution showed an excellent reproducibility and the curve connecting these data points lies in the middle of surface tension values produced with stirrer agitated solution. These results indicated that emulsified frother solution must be used in forth destabilization studies to ensure data accuracy.

The critical micelle concentration (CMC) for this specific surfactant was also determined. This was accomplished by measuring the surface tension of solution at different frother concentrations up to $1000 \mathrm{ppm}$. The relationship between surface tension and frother concentration is shown in Figure 6. The CMC of this frother was determined to be approximately $80 \mathrm{ppm}$. 


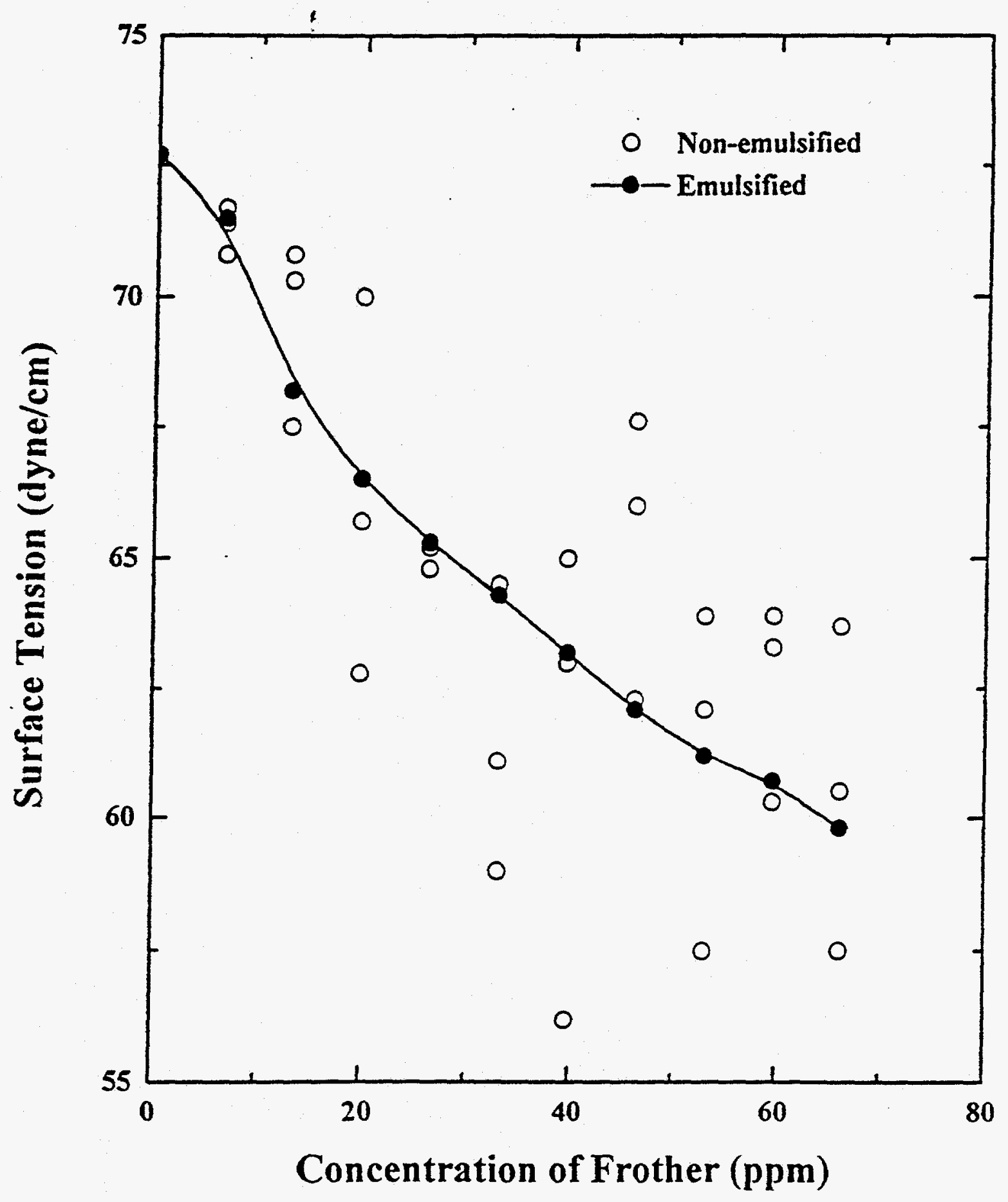

Fig. 5. Surface tension versus concentration of emulsified and nonemulsified Allied Colloid 944 B frother concentration. 


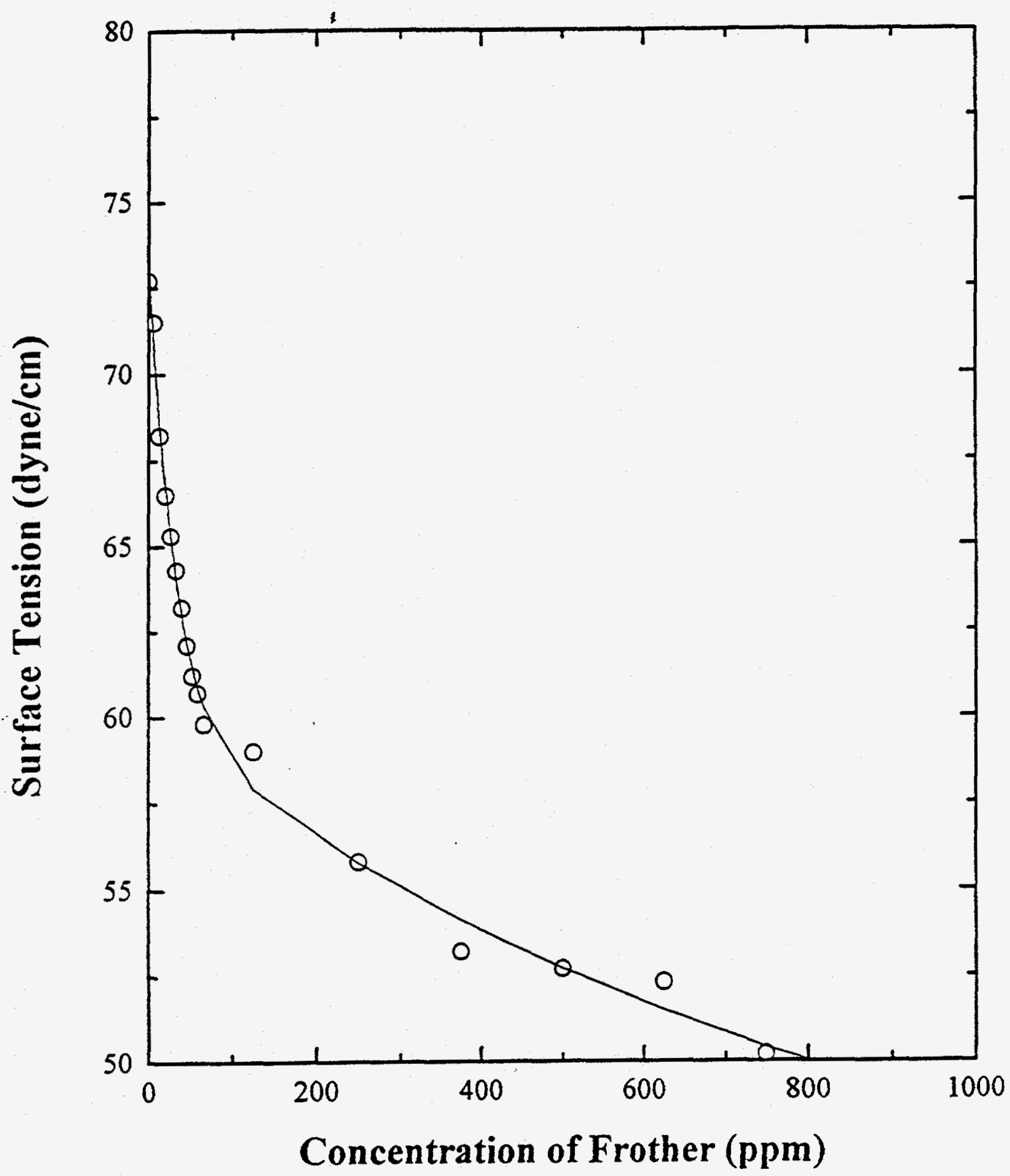

Fig. 6. Change of surface tension with the concentration of emulsified frother. 


\section{Stability of Fine Coal Froth}

Figure 7 shows the differential pressure of dynamic froth between the working column and the reference column as a function of froth drainage time. The dynamic froth was generated by passing air through fine bubble generator for 30 seconds at different air flow rates. $250 \mathrm{ppm}$ of the frother (Allied Colloids $944 \mathrm{~B}$ ) was used in all tests. The differential pressure increased with time as more bubbles broke in the working cylinder and converted surface free energy of thin liquid film to pressure. When the froth collapsed completely, the pressure reached a maximum, $\Delta \mathrm{P}_{-}$. The froth produced at higher air rates resulted in higher maximum differential pressure and required longer time to collapse. For example, at an air flow rate of $324 \mathrm{ml} / \mathrm{min}$ the maximum pressure was $12 \mathrm{~mm} \mathrm{H}_{2} \mathrm{O}$ and froth collapsed in 30 seconds. When air rate was increased to $1.0 \mathrm{l} / \mathrm{min}$, the maximum pressure increased to $42 \mathrm{~mm} \mathrm{H} \mathrm{H}_{2} \mathrm{O}$ and collapsing time to 40 seconds. This indicated a higher stability of froth generated at higher gas rates, which is in agreement with the previous conclusion derived from other techniques [Tao, 1994]. Using the surface tension value of the solution and the differential pressure, surface area of froth was calculated using Equation (6) and results are also shown in Figure 7. As can be seen from Figure 7, the surface area of bubbles in the froth decreased as bubbles coalesced. The decay rate of the froth decreased with time and there appeared to be an exponential relationship between surface area of froth and froth drainage time. 


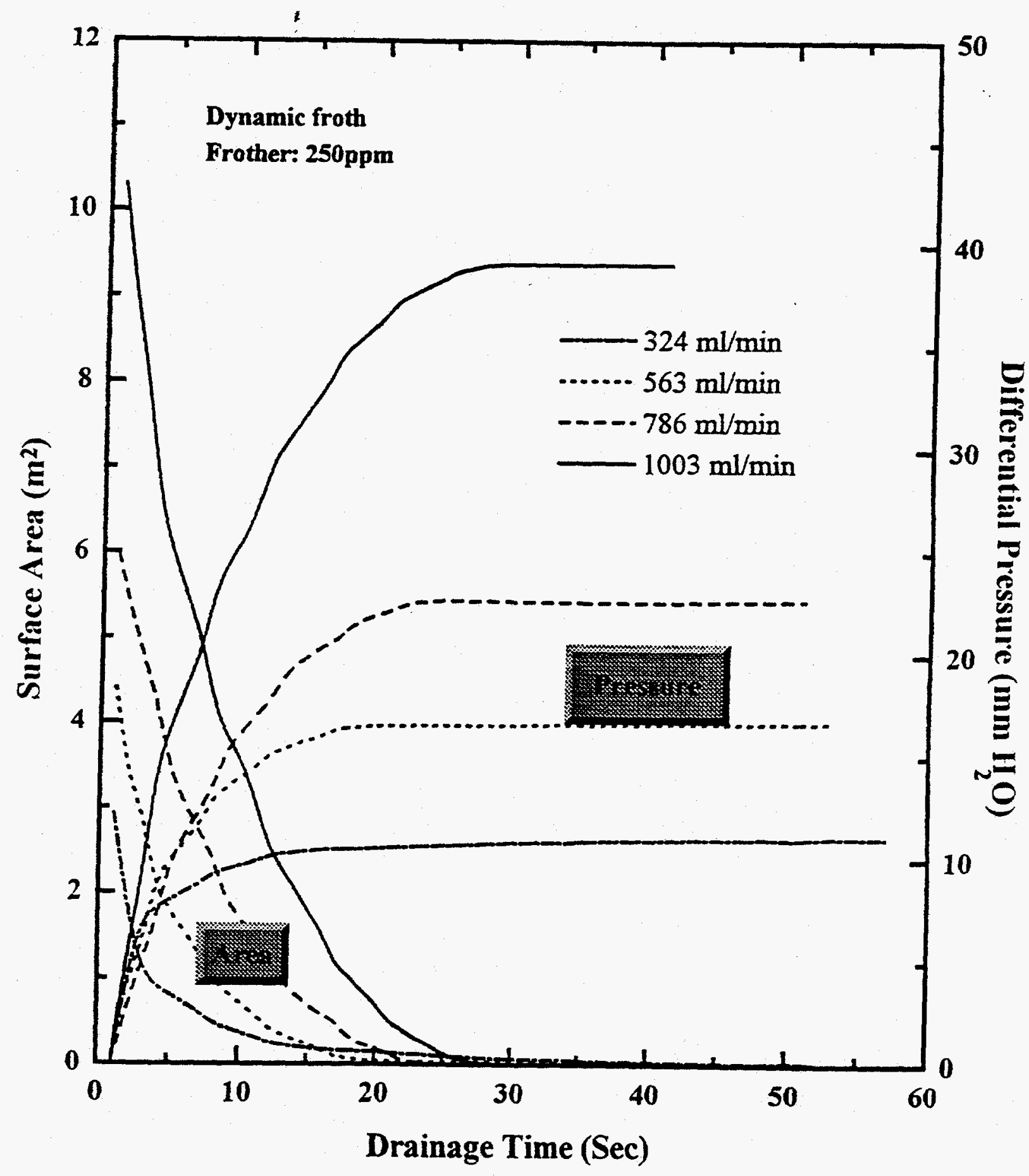

Fig. 7. Differential pressure and surface area obtained with dynamic froth as a function of drainage time using $250 \mathrm{ppm}$ frother concentration. 
Figure 8 shows changes in differential pressure and bubble surface area with drainage time for the steady state froth generated with $250 \mathrm{ppm}$ frother. The steady state froth was produced by bubbling solution for additional 3 minutes after the froth reached maximum height at a given air flow rate. The other conditions are the same as described above. Higher air flow rate produced higher maximum differential pressure, i.e., more stable froth and more surface area. In comparison with Figure 7, the maximum pressure and the initial surface area were higher in Figure 8 at a given air rate. This was because the steady state froth represented the maximum forth height that can be possibly achieved at a given gas flow rate and contained more bubbles than non-steady state froth. Increase in aeration rate generally increased froth surface area. However, less significant effect of aeration rate on surface area was observed at higher aeration rate, possibly because higher aeration rate produced larger bubble size.

Figures 9 and 10 show results obtained with dynamic and steady-state froth generated using a frother concentration of $375 \mathrm{ppm}$. The overall trend of changes in differential pressure and surface area as a function of drainage time is the same as in Figures 7 and 8 . The dynamic froth at $375 \mathrm{ppm}$ frother concentration generally showed higher equilibrium pressure and larger surface area of froth than at $250 \mathrm{ppm}$ concentration. This is consistent with the concept that more frother produces smaller bubbles and larger gas-liquid interfacial area. With steady-state froth, higher frother dosages generated higher equilibrium pressure and initial surface area at lower gas 


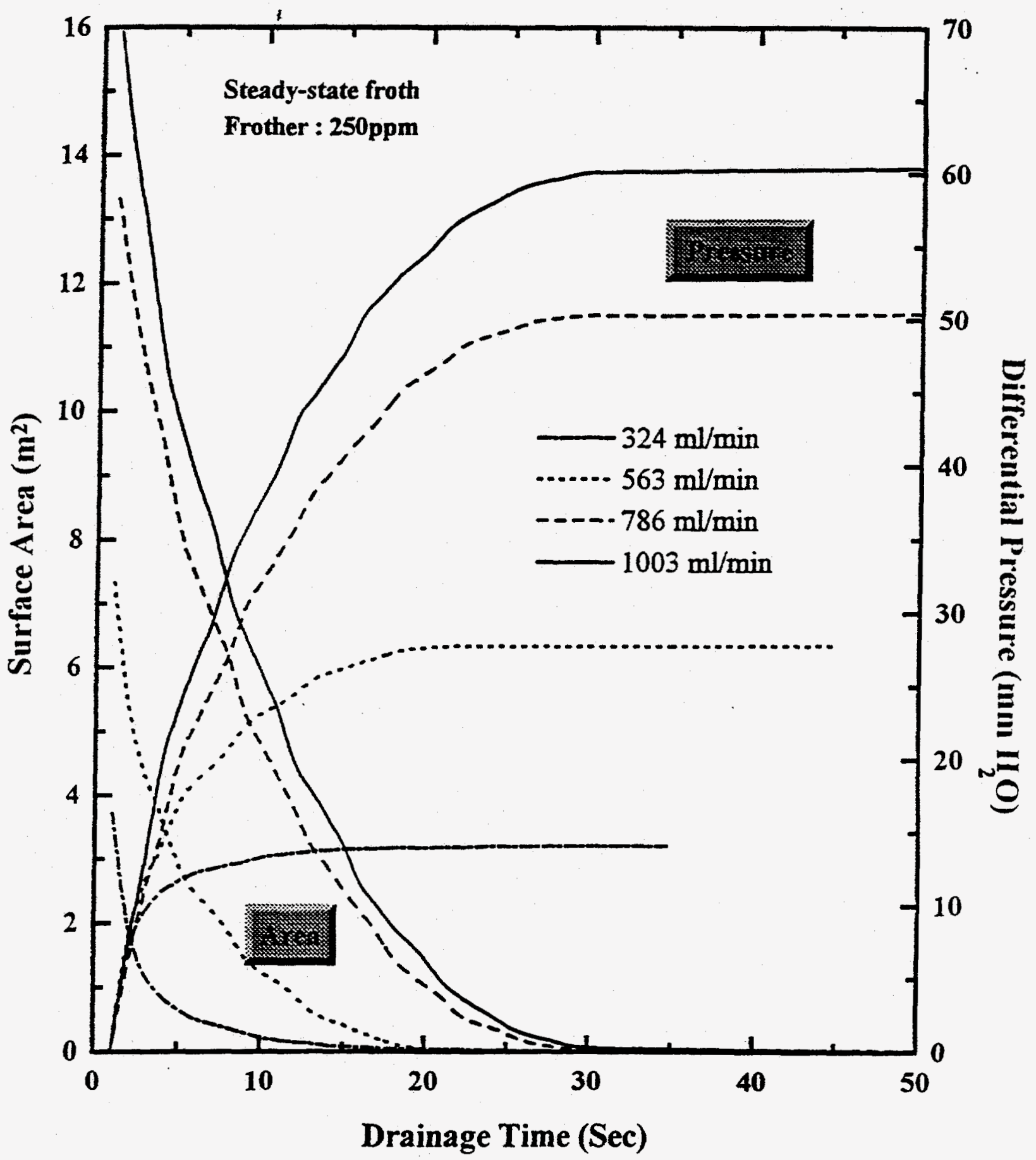

Fig. 8. Differential pressure and surface area obtained with steady state froth as a function of drainage time using $250 \mathrm{ppm}$ frother concentration. 


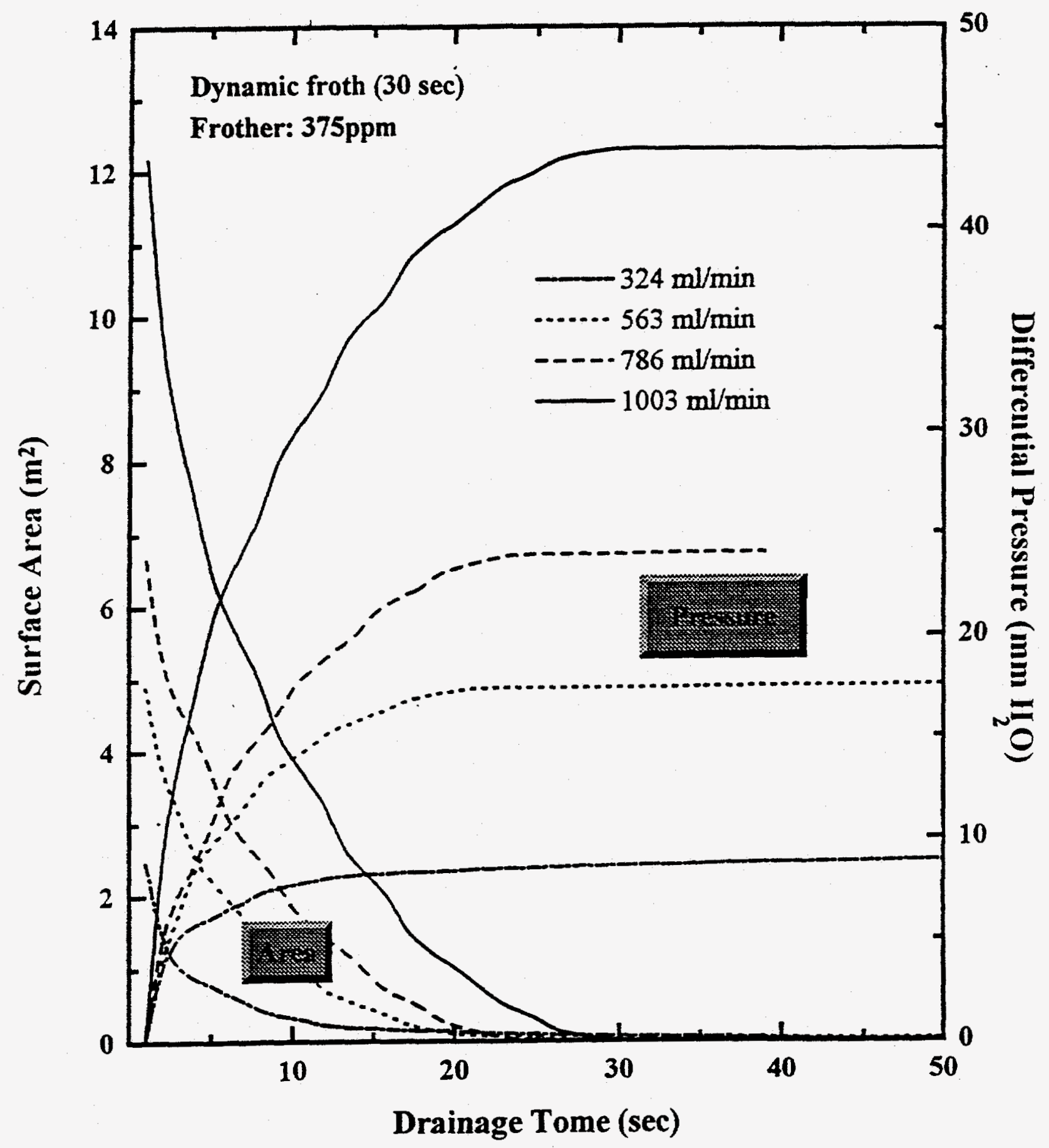

Fig. 9. Differential pressure and surface area obtained with dynamic froth as a function of drainage time using $375 \mathrm{ppm}$ frother concentration. 


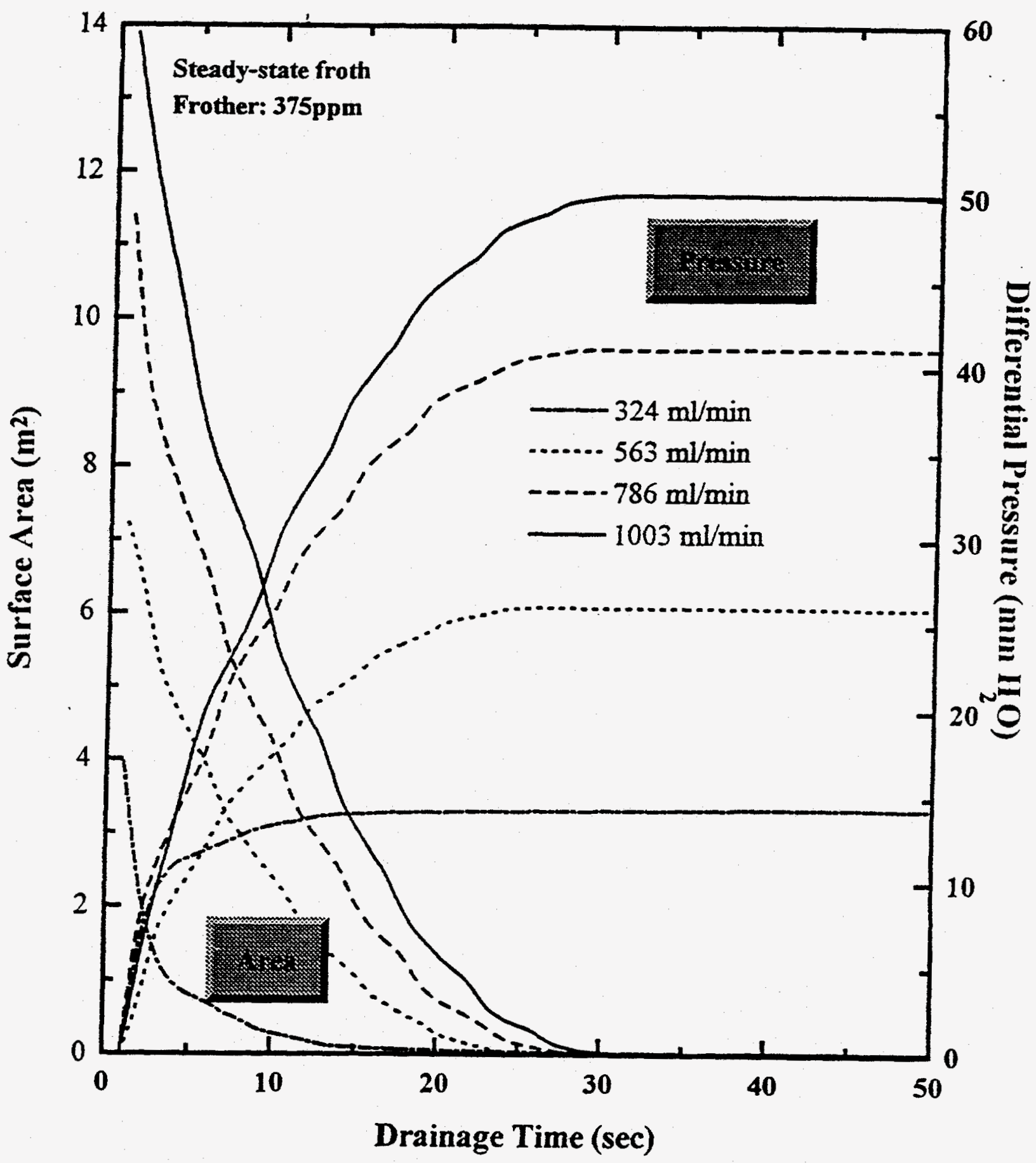

Fig. 10. Differential pressure and surface area obtained with steady state froth as a function of drainage time using $375 \mathrm{ppm}$ frother concentration. 
rates (324 and $563 \mathrm{ml} / \mathrm{min}$ ), but lower equilibrium pressure at higher gas rates (786 and $1003 \mathrm{ml} / \mathrm{min}$ ).

Tests were also performed using $500 \mathrm{ppm}$ of frother concentration. The results are shown in Figures 11 and 12 with dynamic and steady-state froth, respectively. Differential pressure increased and surface area decreased with froth drainage time, as observed in Figures 7-10. However, a significant difference in surface area of dynamic and steady-state froth at $500 \mathrm{ppm}$ frother concentration than at lower concentrations was noticed. In addition, the decay of steady-state froth was considerably slower at $500 \mathrm{ppm}$ than at lower concentrations, whereas decay of the dynamic froth at $500 \mathrm{ppm}$ was much faster.

The time required to reach the equilibrium pressure or completely destroy the froth increased with increasing the gas rate. This is due to the fact that higher gas rate generated more bubbles and more stable froth and, therefore, longer time was needed for liquid film to drain to a critical film thickness where froth collapses. Similar behavior was observed with respect to frother concentration. Higher frother concentration produced smaller bubbles which took longer time to drain, coalesce, and finally rupture.

To show the relationship between froth stability and gas rate, the half-drainage time, defined as the time required for differential pressure to increase to $50 \%$ of the equilibrium or maximum value, was plotted in Figure 13 for dynamic and steady state 


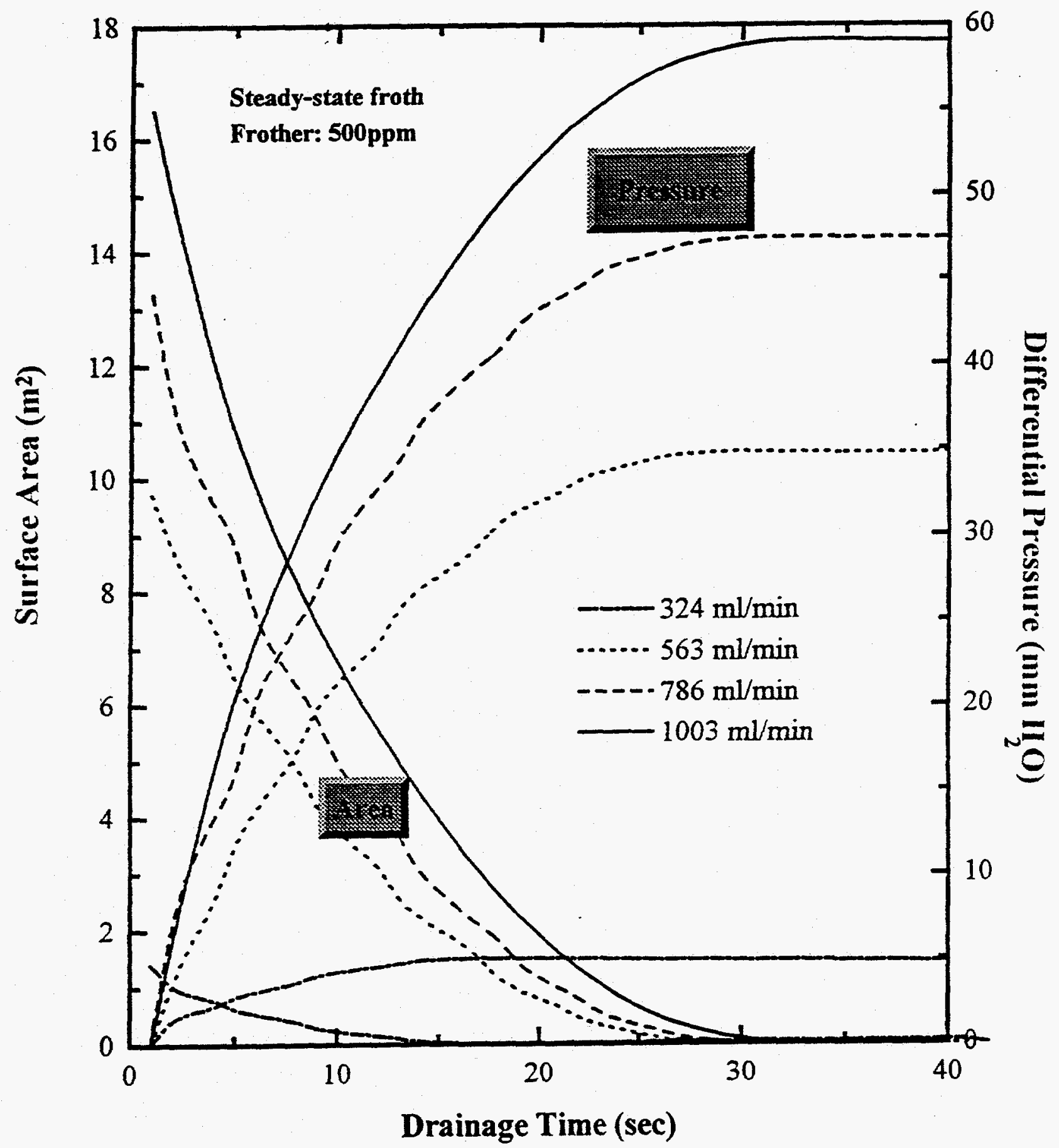

Fig. 12. Differential pressure and surface area obtained with steady state froth as a function of drainage time using $500 \mathrm{ppm}$ frother concentration. 


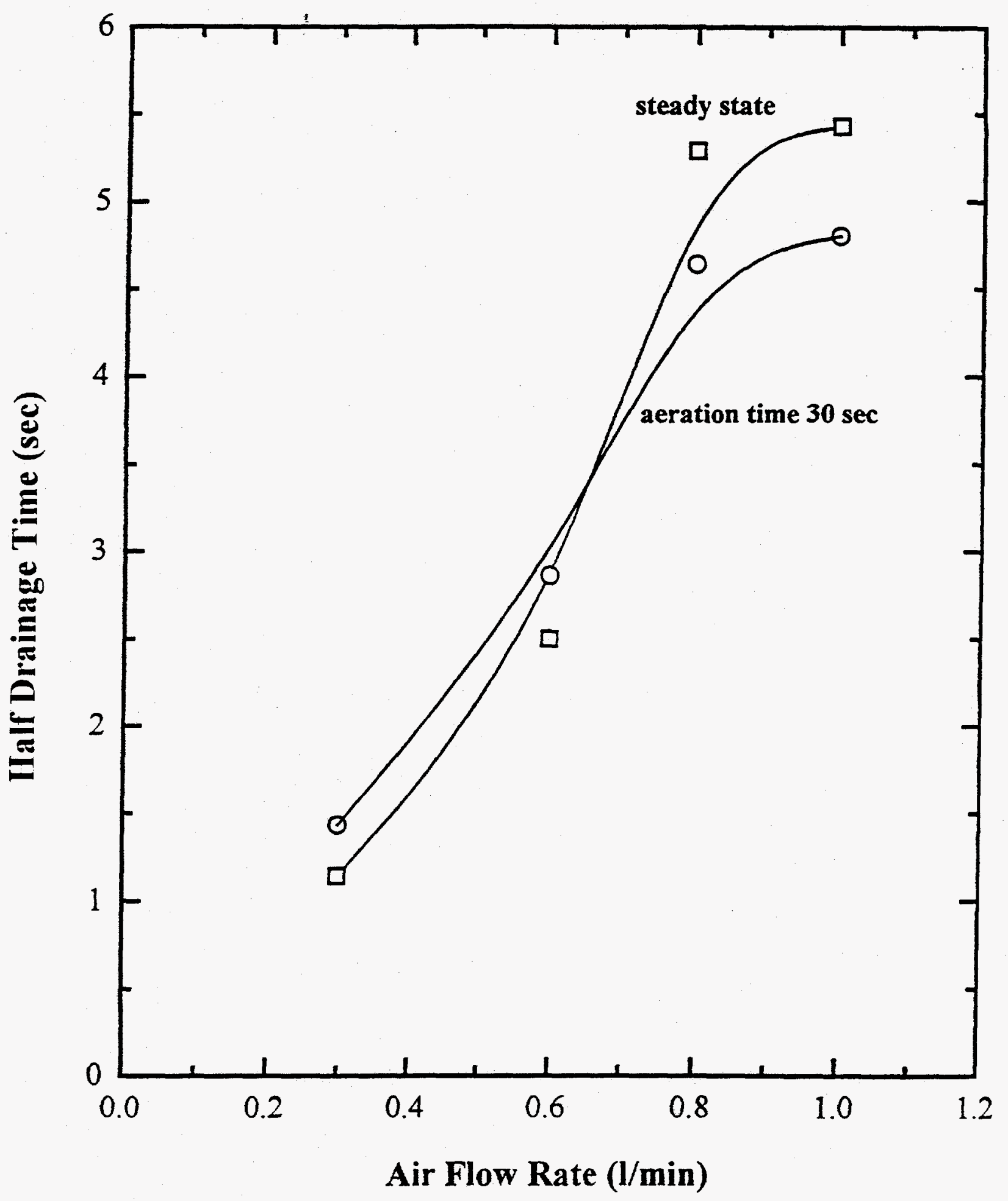

Fig. 13. Half-drainage time vs. air flow rate for dynamic and steady state froth using $250 \mathrm{ppm}$ frother concentration. 
froths produced at a frother concentration of $250 \mathrm{ppm}$. As seen from the figure, more stable froth was obtained at higher gas rate.

Figure 14 shows the change of differential pressure and surface area of froth as a function of drainage time at different frother concentrations. Increase in the frother concentration from 125 to $375 \mathrm{ppm}$ stabilized the froth. However, a frother concentration of $500 \mathrm{ppm}$ produced less stable froth than $375 \mathrm{ppm}$ concentration, indicating that an excessive dosage of frother is detrimental to froth generation. Although the differential pressure generated using $125 \mathrm{ppm}$ frother was higher than that obtained using $500 \mathrm{ppm}$, the surface area was higher using $500 \mathrm{ppm}$ than 125 ppm frother. This was attributed to lower surface tension produced by higher frother concentration.

Table I shows the drainage constant and the half-drainage time obtained at different frother concentrations. These values were obtained by fitting the curves in Figure 14 with the exponential growth equation shown below.

$$
y=a\left(1-e^{-k t}\right)
$$

The most stable froth was obtained at a frother concentration of $375 \mathrm{ppm}$, as indicated by its drainage constant $k$ and half-drainage time. The largest surface area was also produced at $375 \mathrm{ppm}$. At other frother concentrations, the froth drainage 


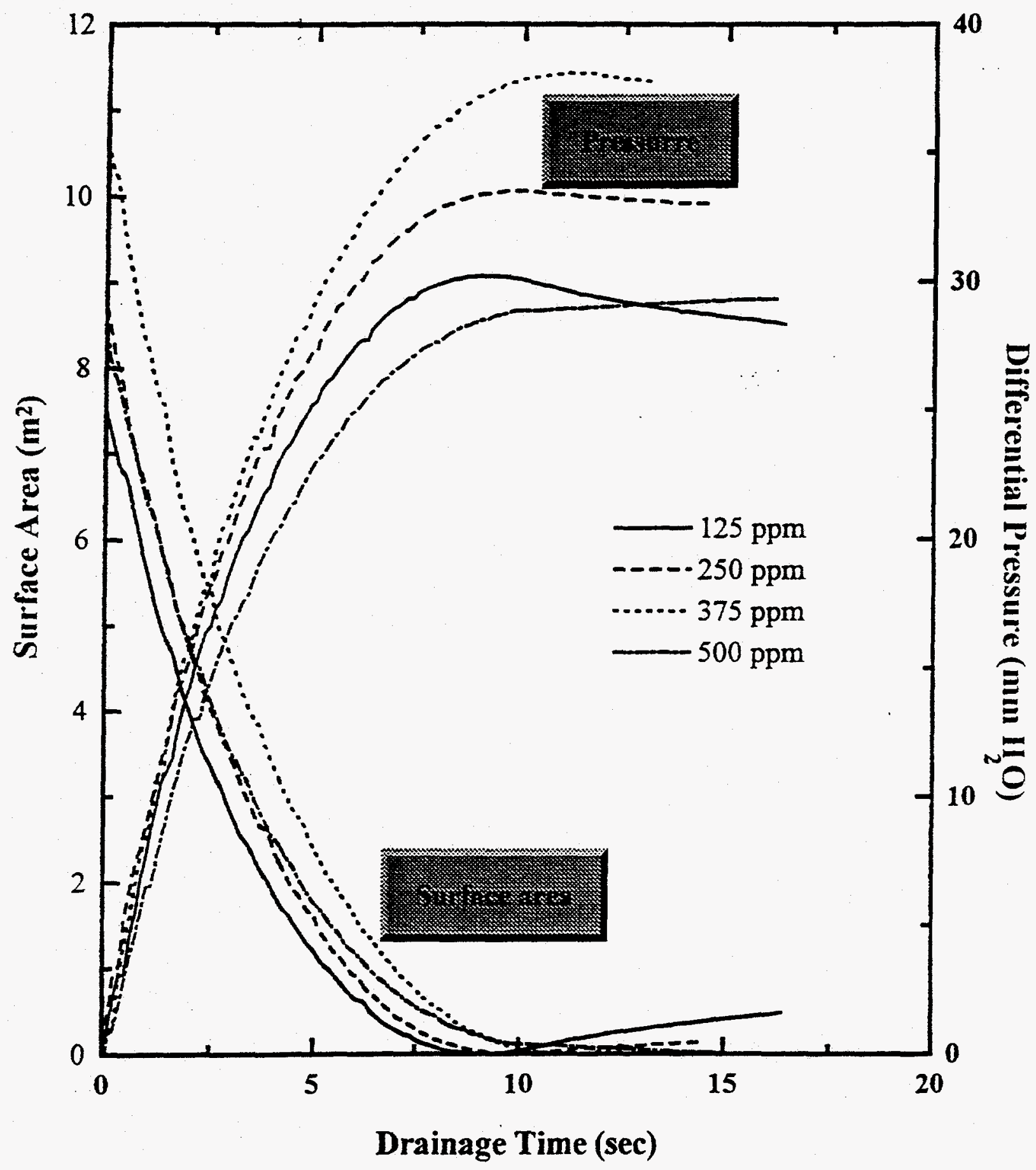

Fig. 14. Change of differential pressure and surface area of froth with drainage time at different frother concentrations 
constant and half-drainage time were nearly the same although there was significant difference in the value of differential pressure and surface area.

Table I. Drainage constant and half-drainage time at different concentrations

\begin{tabular}{|c|c|c|}
\hline $\begin{array}{c}\text { Frother Concentration } \\
(\mathrm{ppm})\end{array}$ & $\begin{array}{c}\text { Drainage Constant (k) } \\
(\mathbf{1} / \mathbf{s})\end{array}$ & $\begin{array}{c}\text { Half-Drainage Time }\left(t_{1 / 2}\right) \\
(\mathbf{s})\end{array}$ \\
\hline 125 & 0.2749 & 2.52 \\
\hline 250 & 0.2800 & 2.48 \\
\hline 375 & 0.2455 & 2.82 \\
\hline 500 & 0.2768 & 2.50 \\
\hline
\end{tabular}

For the froth destabilization experiments $200 \mathrm{ml}$ slurry containing $7.1 \%$ solids was used. In the initial tests It was found that in the presence of coal particles froth formed in the working cylinder was overly stable and pressure released from bubble breakage might not always be detected by the pressure transducer due to a dense layer of coal particles covering the top of froth. As a result, a continuous data acquisition of differential pressure became impossible. To measure froth stability and surface area under this condition, the experimental procedure was slightly changed. The system was left open for a predetermined period of froth drainage time. Immediately after all valves of the system were closed the froth was destroyed with a perforated teflon disc and a commercial defoamer 347 (Allied Colloids). 


\section{Effects of Coal Particles on Froth Stability}

Figure 15 shows changes in froth surface area as a function of the dosage of fuel oil used as collector and Allied Colloids $944 \mathrm{~B}$ frother. The surface area was that of froth remaining in the cylinder after $10 \mathrm{~min}$ froth drainage time, determined from the measured pressure differential. The ratio of collector and frother dosage was kept constant at unity in these tests. The froth surface area increased consistently with reagent dosage, due to reduced bubble size and increased froth stability. There is an essentially linear relationship between the surface area and the dosage in the dosage range of $100-500 \mathrm{~g} / \mathrm{t}$. It should be noted that in the absence of coal particles froth completely disappeared in a few minutes. Results shown in Figure 15 clearly indicated that coal particles significantly increased froth stability.

Figure 16 shows the effects of coal slurry solids concentration on surface area of froth remaining after 10 minute drainage. The surface area increased sharply as the quantity of coal particles increased. Higher solids concentration generated more froth surface area. Obviously coal particles have remarkable froth-stabilizing effects. This is possibly because coal particles coated on bubble surface act as buffers between bubbles that retard film thinning and prevent bubble coalescence.

\section{Effects of Different Frothers on Coal Froth Stability}

Figures 17 and 18 show changes of froth surface area with increasing 


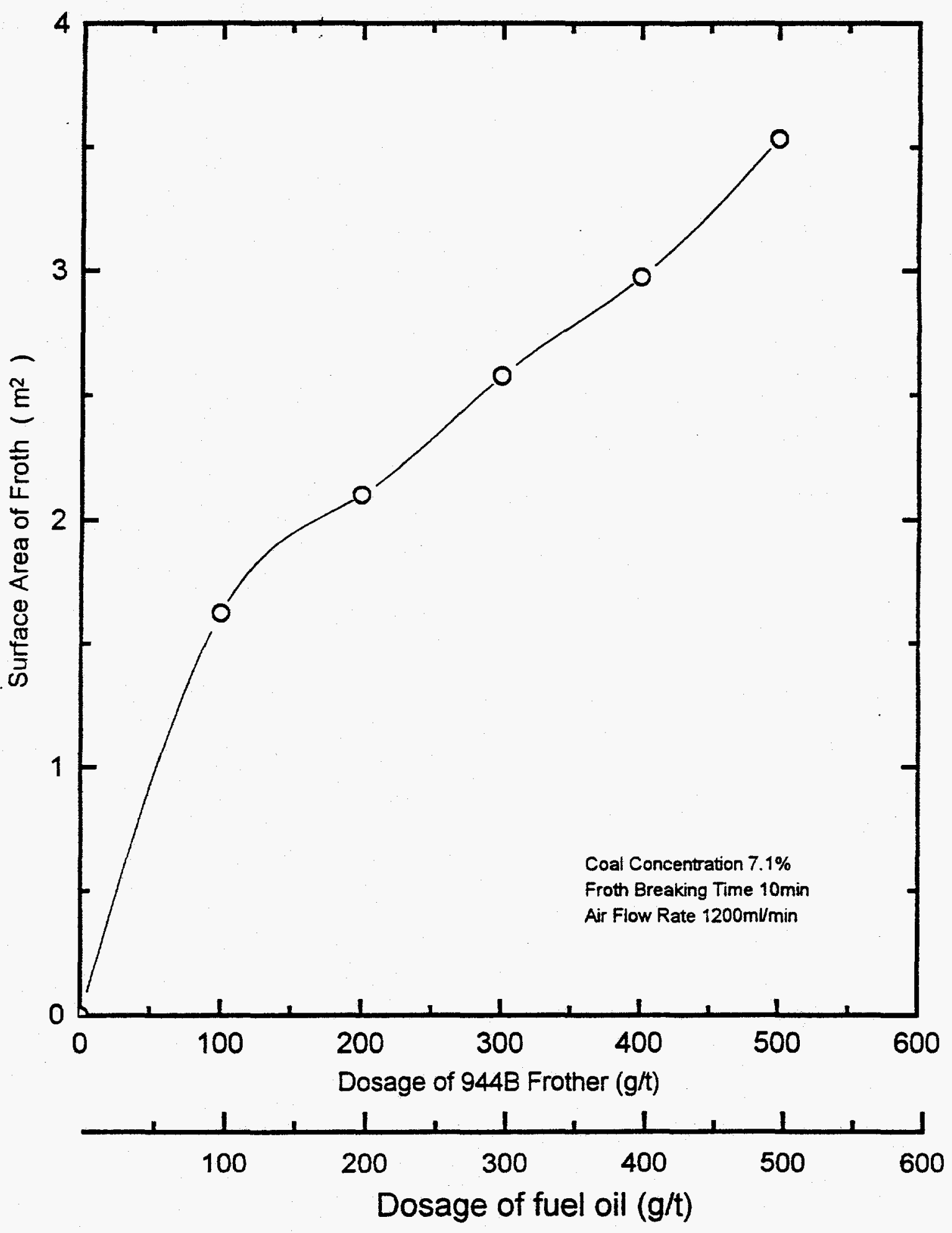

Fig. 15. Effects of reagent concentration on surface area of froth remaining after 10 minutes. 


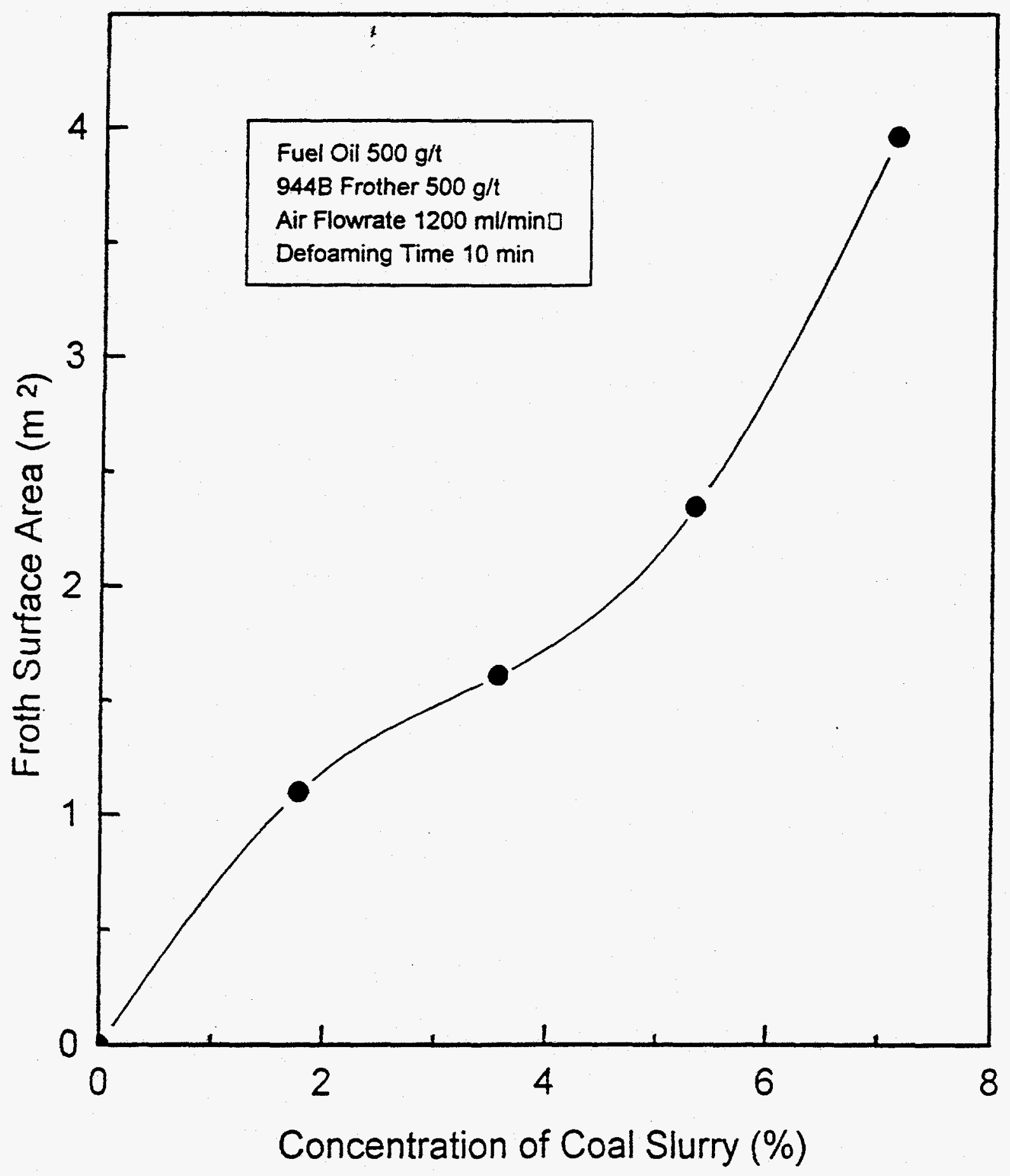

Fig. 16. Effects of solids concentration in siurry on surface area of froth remaining after 10 minutes. 


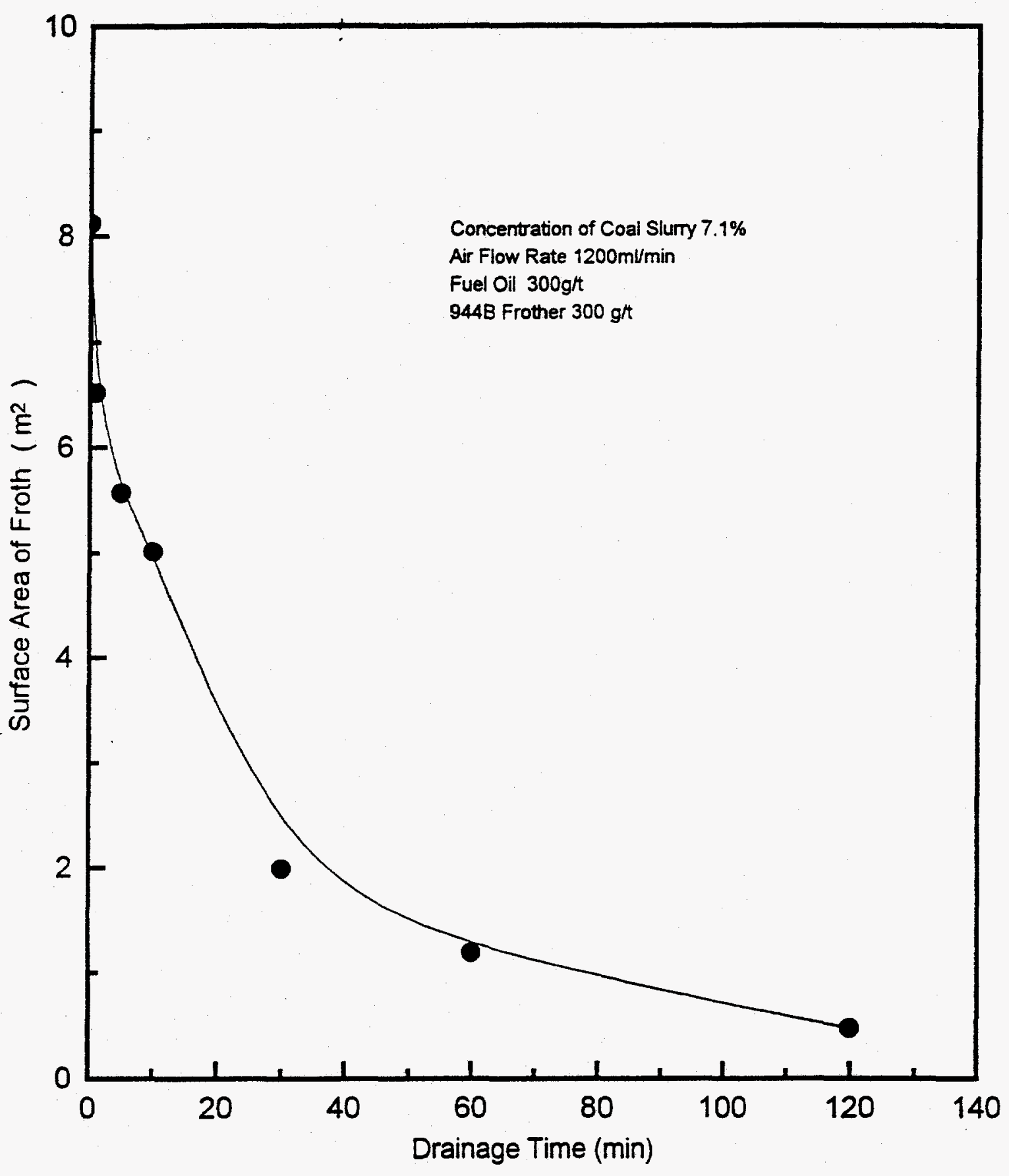

Fig. 17. Changes in surface area of coal froth with drainage time in the presence of frother 944B. 


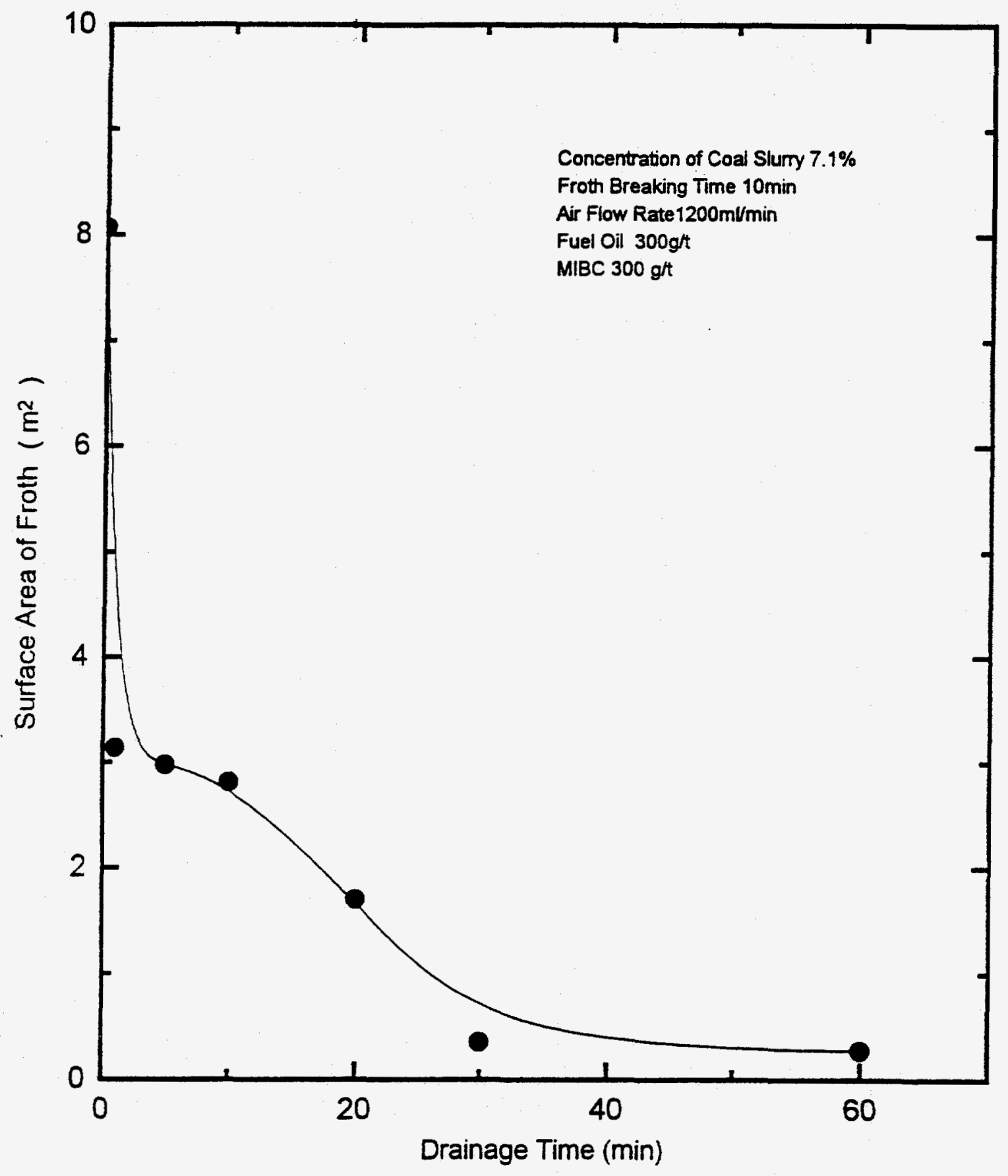

Fig. 18. Changes in surface area of coal froth with drainage time in the presence of frother MIBC. 
drainage time of froth generated with frother $944 \mathrm{~B}$ and MIBC, respectively. Note, that half drainage time is about 18 and 1 minute for $944 B$ and MIBC generated froth, respectively. Approximately two hours were needed for $944 B$ generated froth to disappear, however, only thirty minutes were needed for MIBC generated froth. Apparently $944 \mathrm{~B}$ produced much more stable froth than MIBC. Unless otherwise specified, all froth destabilization tests reported hereafter were conducted with froth generated with frother 944B.

\section{Coal Froth Destabilization with Commercial Defoamers}

Two different commercial defoamer were acquired from Allied Colloids to examine their effectiveness in destabilizing coal froth. They were silicon based defoamer 347 and oil emulsion defoamer 0149. Figure 19 shows surface area of froth as a function of dosage of defoamer 347 added on the top of froth. The surface area of bubbles decreased with increasing dosage of defoamer 347 , indicating use of this reagent destroyed froth. However, it required a dosage of more than $7 \mathrm{~kg} / \mathrm{t}$ to destroy the froth completely. Figure 20 shows defoaming effects of defoamer 0149 on coal froth. Compared to silicon based defoamer 347 a much higher dosage of this defoamer was needed to reduce surface area to a given value. In addition the lowest surface area was about $1.7 \mathrm{~m}^{2}$ obtained with defoamer 0149 at a dosage of $11 \mathrm{~kg} / \mathrm{t}$, much higher than $0.7 \mathrm{~m}^{2}$ produced with $7 \mathrm{~kg} / \mathrm{t}$ of defoamer 347.

Figure 21 shows changes of surface area of froth with increasing dosage of 


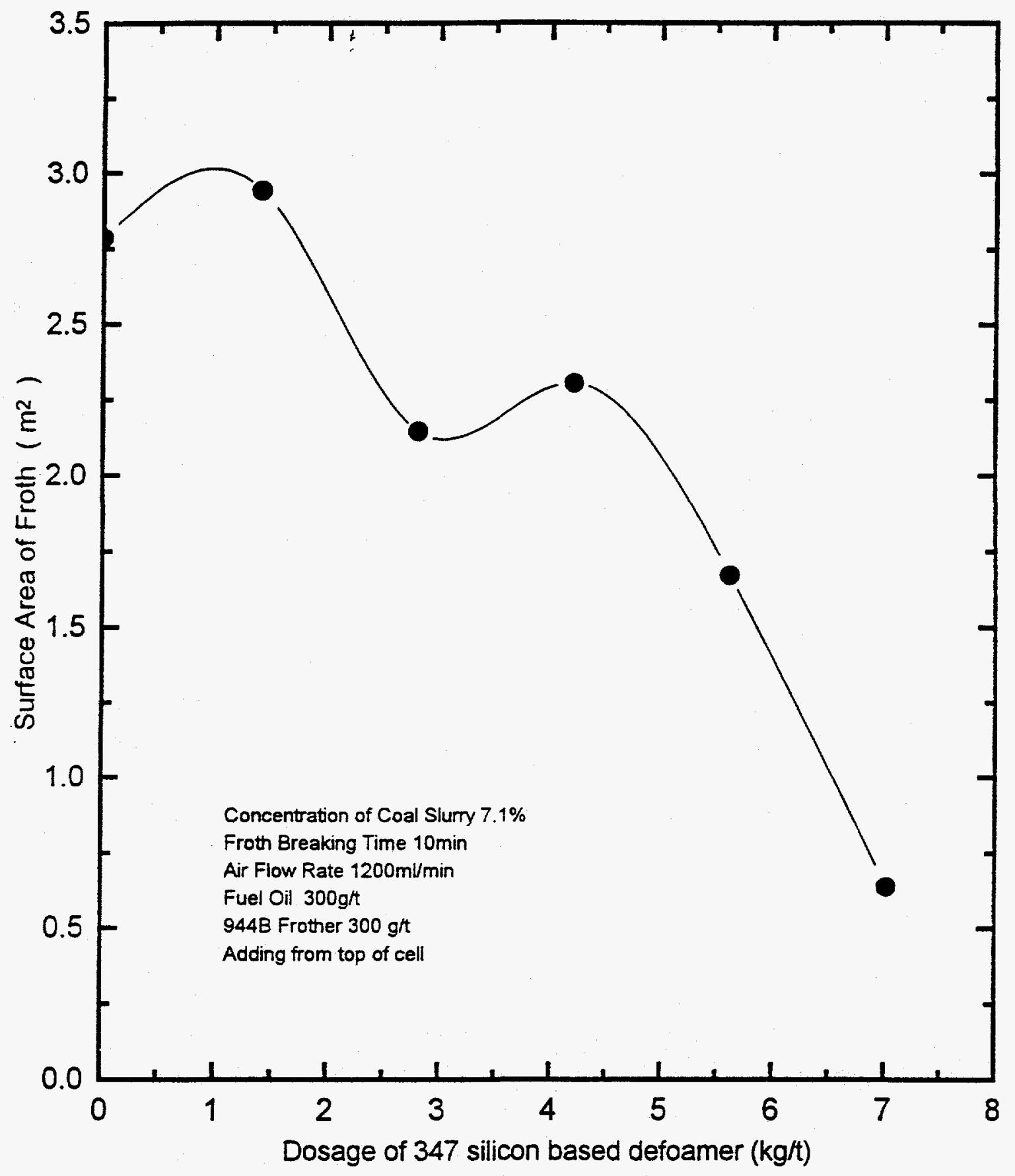

Fig. 19. Changes in surface area of coal froth with dosage of defoamer 347 added to the top of froth. 


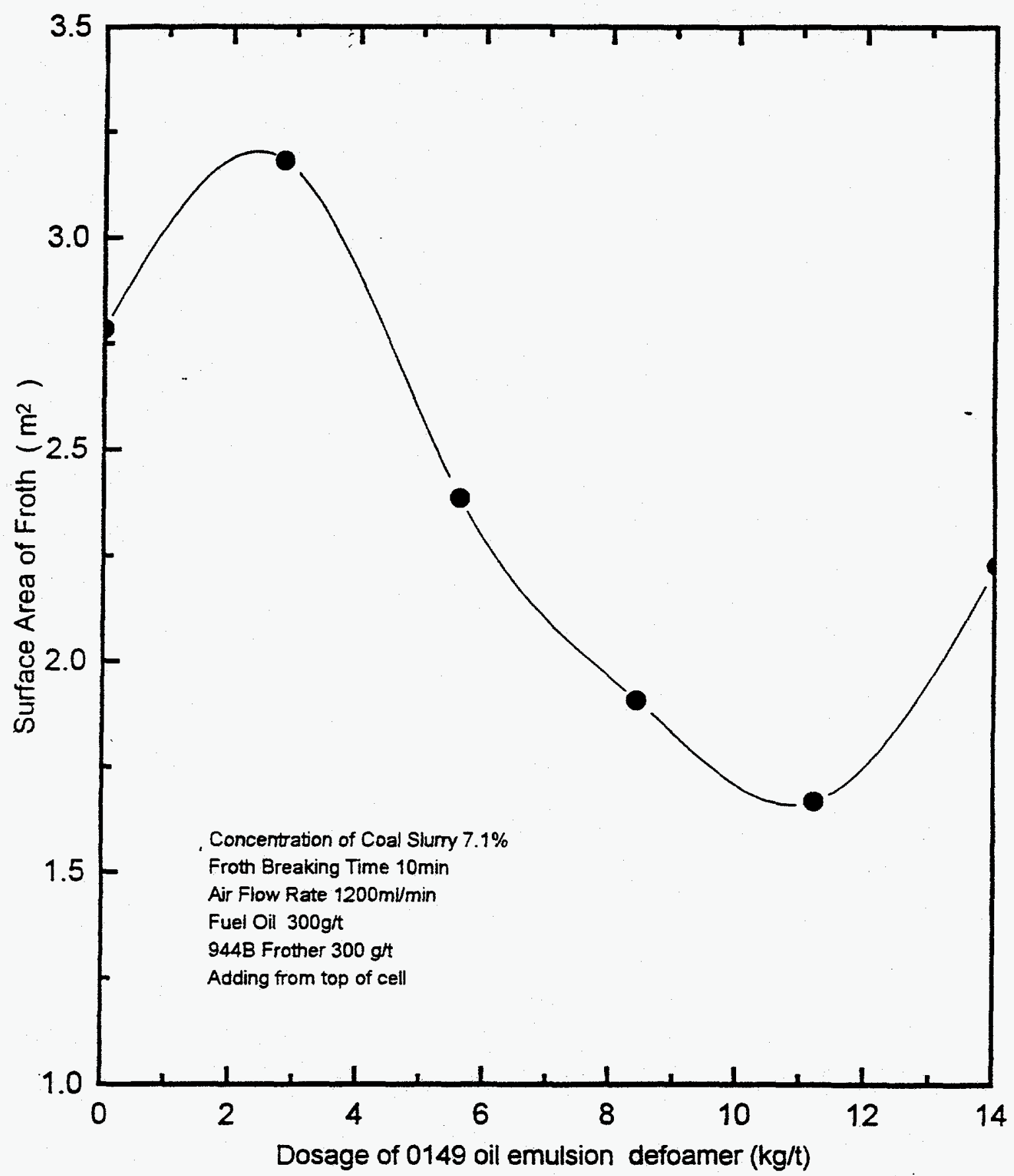

Fig. 20. Changes in surface area of coal froth with dosage of defoamer 0149 added to the top of froth. 


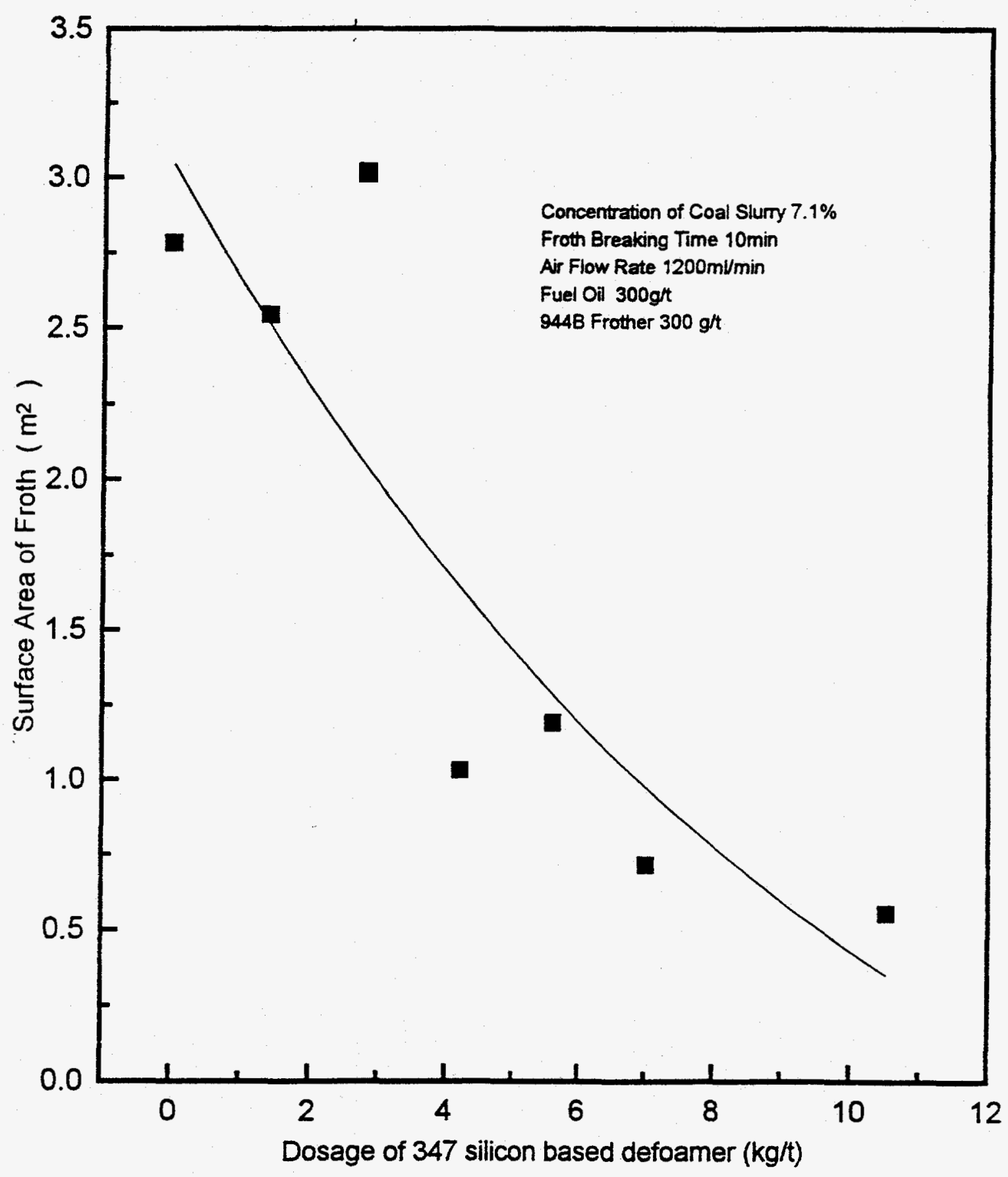

Fig. 21. Changes in surface area of coal froth with dosage of defoamer 347 addec to the slurry prior to flotation. 
defoamer 347 which was added to the slumy and conditioned for 24 seconds. Surface area of froth decreased drastically with increasing the dosage of defoamer $347 \mathrm{up} \mathrm{to}$ about $7 \mathrm{~kg} / \mathrm{t}$. Further increase in dosage did not show much additional froth destabilization effects. Comparison of Figures 19 and 21 shows that the slope of curve is greater in Figure 21 than in Figure 19, indicating that when added directly to the slurry defoamer 347 showed stronger froth destabilizing effects. For example the bubble surface area was decreased to $1 \mathrm{~m}^{2}$ by use of $4 \mathrm{~kg} / \mathrm{t}$ of the defoamer when added to the slurry directly, as opposed to use of more than $6 \mathrm{~kg} / \mathrm{t}$ of the defoamer when added on the top of froth.

\section{Coal Froth Destabilization with Hydrophobic Solid Particles}

Figure 22 shows froth destabilizing effects due to addition of limestone particles that were used as such or coated with the surfactant cetylpyridinium chloride (CPCL) in fuel oil \#2. The surface area of froth decreased dramatically with increasing the limestone dosage (expressed as weight percentage of coal slumy) up to $0.4 \%$. Further increase in limestone dosage had less pronounced but still significant froth destabilizing effects. Use of about 0.85 weight percent of $40-50$ mesh limestone particles coated with the surfactant reduced froth surface area from 2.75 to $0.4 \mathrm{~m}^{2}$, representing an $85 \%$ reduction. By comparison, uncoated limestone particles were less effective in destabilizing froth, due to its hydrophilic nature.

Figure 23 shows effects of particle size of uncoated limestone particles on 


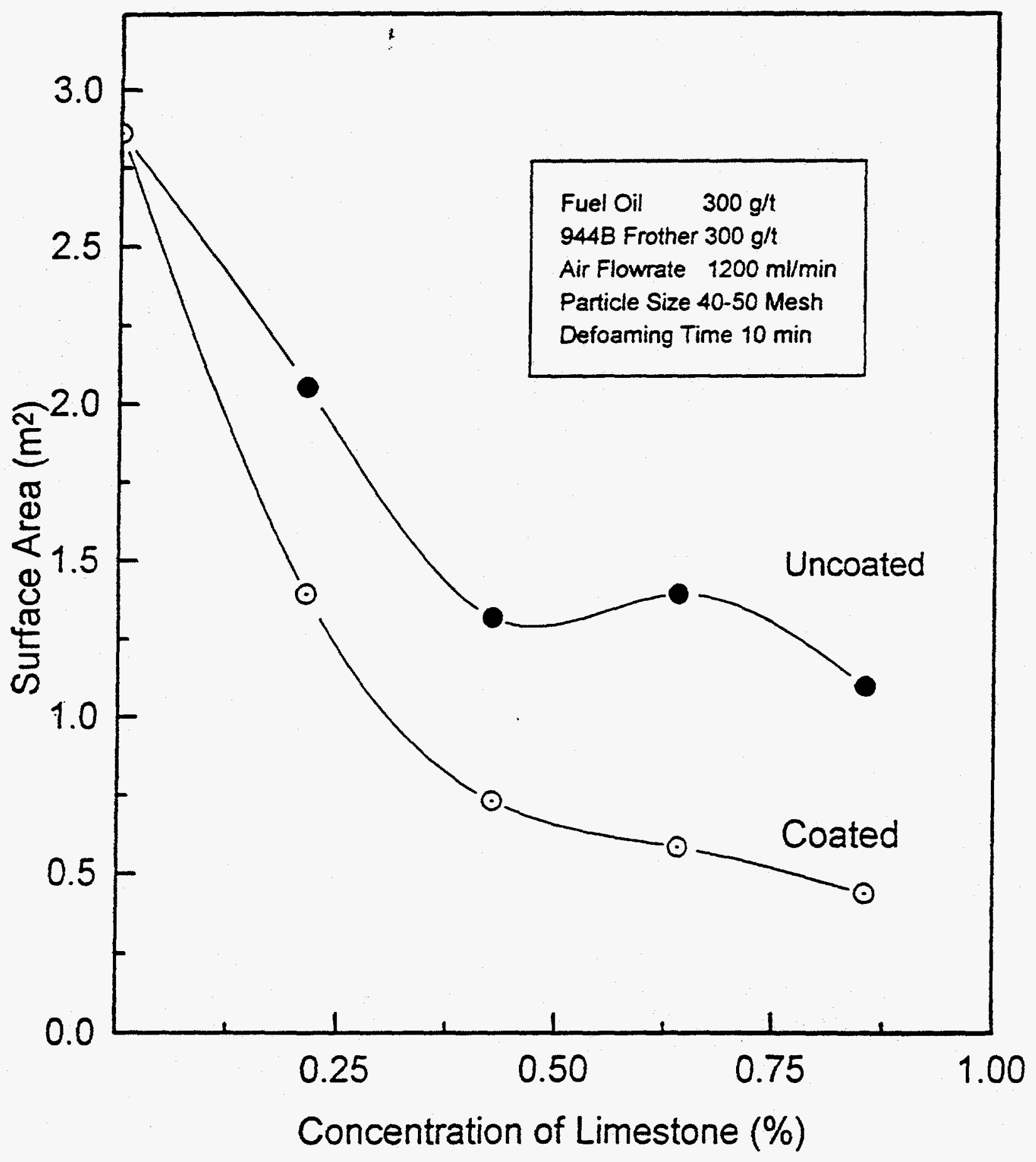

Fig. 22. Effects of limestone concentration on surface area of froth remaining after 10 minutes. ( $\odot$ coated with cetylpyridinium chloride) 


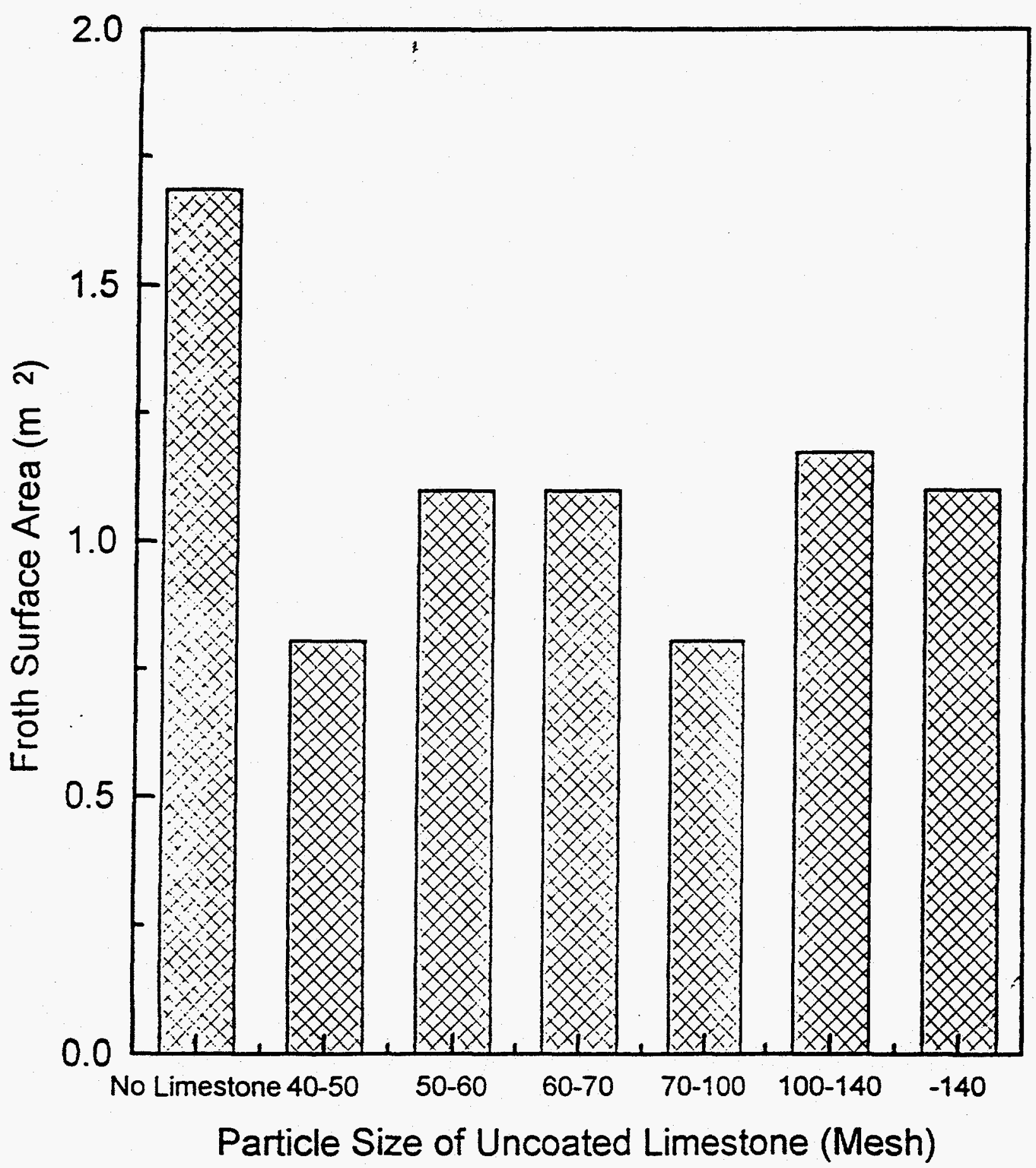

Fig. 23. Effects of uncoated limestone particle size on surface area of froth remaining after 10 minutes. 
froth destabilizing ability. Smaller froth surface area indicates a stronger froth destabilizing ability, whict' means less froth remained after limestone particles were applied to the froth. The results suggested that the particle size did not have explicit effects on froth destabilizing ability. This is possibly because particle size has two counteracting effects: smaller particles possess larger surface area but they also have weaker penetration capability in the froth due to their small inertia. Figure 24 shows froth destabilizing effects of concentration of minus 100 mesh $(150 \mu \mathrm{m})$ surfactant coated limestone particles. Froth surface area decreased substantially with increasing limestone concentration up to about 0.8-1 weight percent and then leveled off. This result suggests that the concentration of limestone particles is an important factor determining froth destabilizing ability.

Magnetite particles with an average size of $9.23 \mu \mathrm{m}$ were also used to study destabilization effect on froth. The results shown in Figure 25 indicate that uncoated particles were not effective in destabilizing froth. The maximum froth area reduction, from 2.0 to $1.75 \mathrm{~m}^{2}$, was observed at a dosage of 0.43 weight percent of magnetite. Surfactant coated magnetite particles were much more effective than uncoated ones in destabilizing froth. Even low dosages of magnetite ( $<0.2$ weight percent) showed a significant froth destabilizing effect. At a dosage of 0.21 weight percent the froth area was reduced to $0.5 \mathrm{~m}^{2}$. Higher dosages had no significant additional benefits. Comparing the results obtained with limestone and magnetite it appears that reagent coated magnetite particles were more effective in destroying froth. 


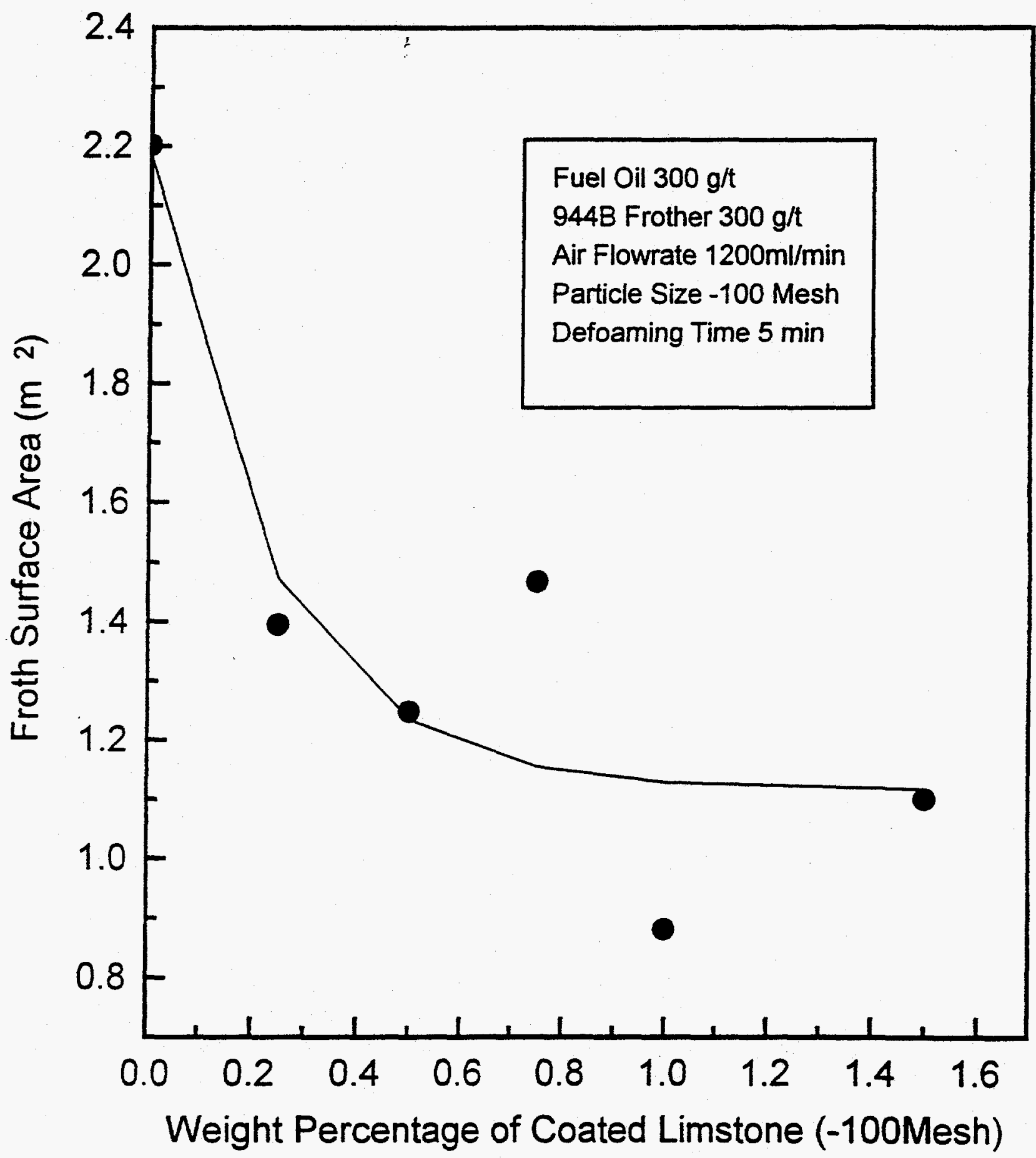

Fig. 24. Effects of surfactant coated limestone particle concentration on surface area of froth remaining after 5 minutes. 


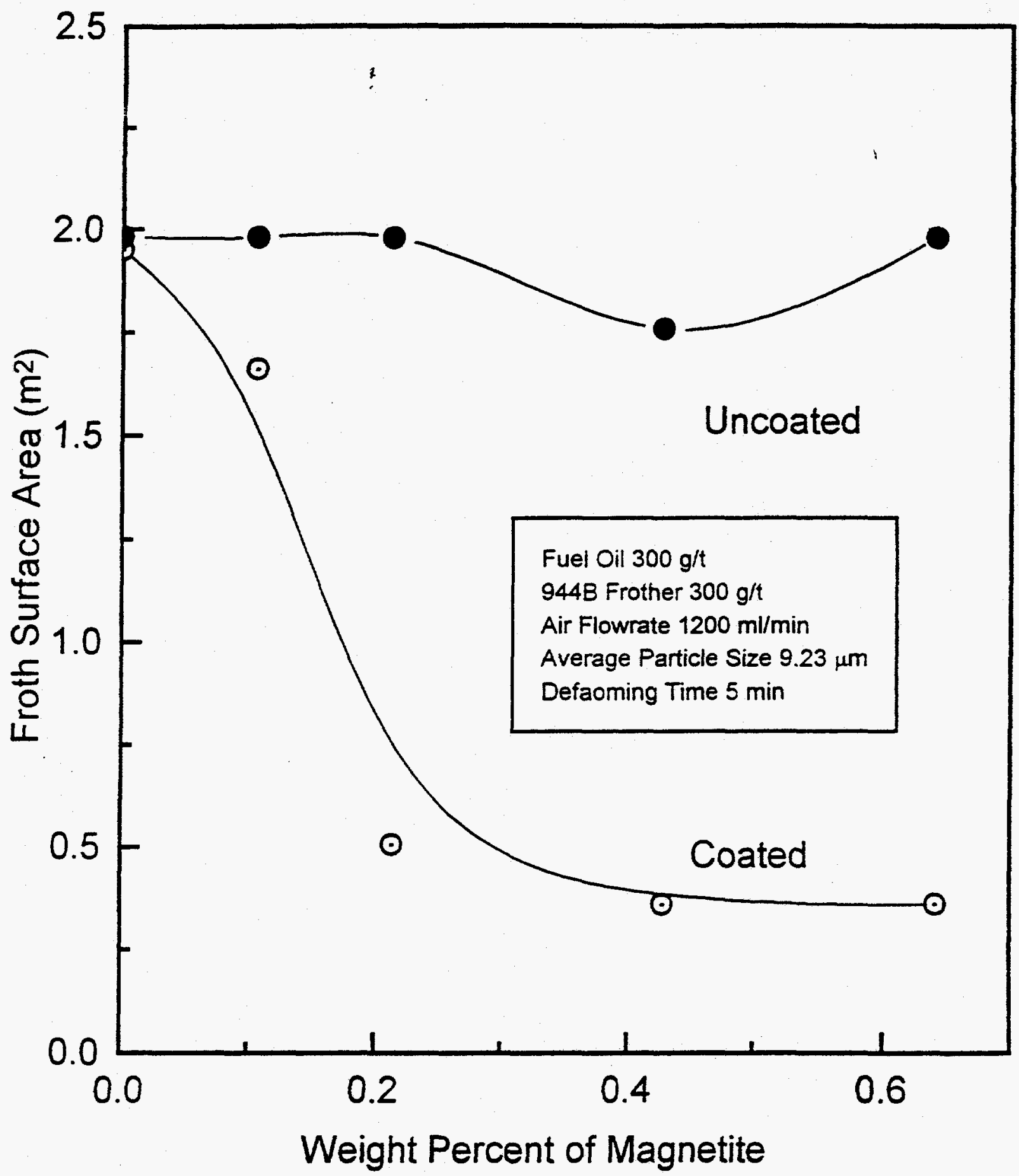

Fig. 25. Effects of concentration of magnetite particles coated/uncoated with surfactant on surface area of froth remaining after 5 minutes. 
To determine most effective froth destabilizing means, detailed studies of coating reagents and procedures were performed with different solid particles. Figures 26 and 27 shows froth surface area as a function of magnetite dosage in terms of $\mathrm{kg}$ of magnetite per ton of coal when coated with commercial Defoamer 0149 and 347 in water. As can be seen from the figures, use of magnetite particles treated under these conditions stabilized froth. It was observed during these experiments that addition of magnetite particles coated with the defoamers in water formed a layer of magnetite particles on top of the froth that hindered bubbles from advancing and breaking.

Figure 28 shows changes of froth surface area with dosage of magnetite coated with Defoamer 0149 in water. In these tests magnetite was added to the froth together with $5 \mathrm{ml}$ water that was used to enhance froth penetration of magnetite particles. Surface area increased from 2.8 to $4.2 \mathrm{~m}^{2}$ with increasing magnetite dosage to $100 \mathrm{~kg} / \mathrm{t}$ and then decreased back to $2.8 \mathrm{~m}^{2}$ at a dosage of $140 \mathrm{~kg} / \mathrm{t}$. It was noticed in the experiment that magnetite particles penetrated froth at a dosage of $140 \mathrm{~kg} / \mathrm{t}$.

Figure 29 shows effects on froth surface area of dosage of magnetite particles coated with CPCL in water and added to the top of froth. Froth surface area increased initially with the addition of magnetite and then showed slight decline with increasing dosage. However, when magnetite was added to the coal slumy in the cylinder and stirred for 24 seconds before bubble generation, froth surface area 


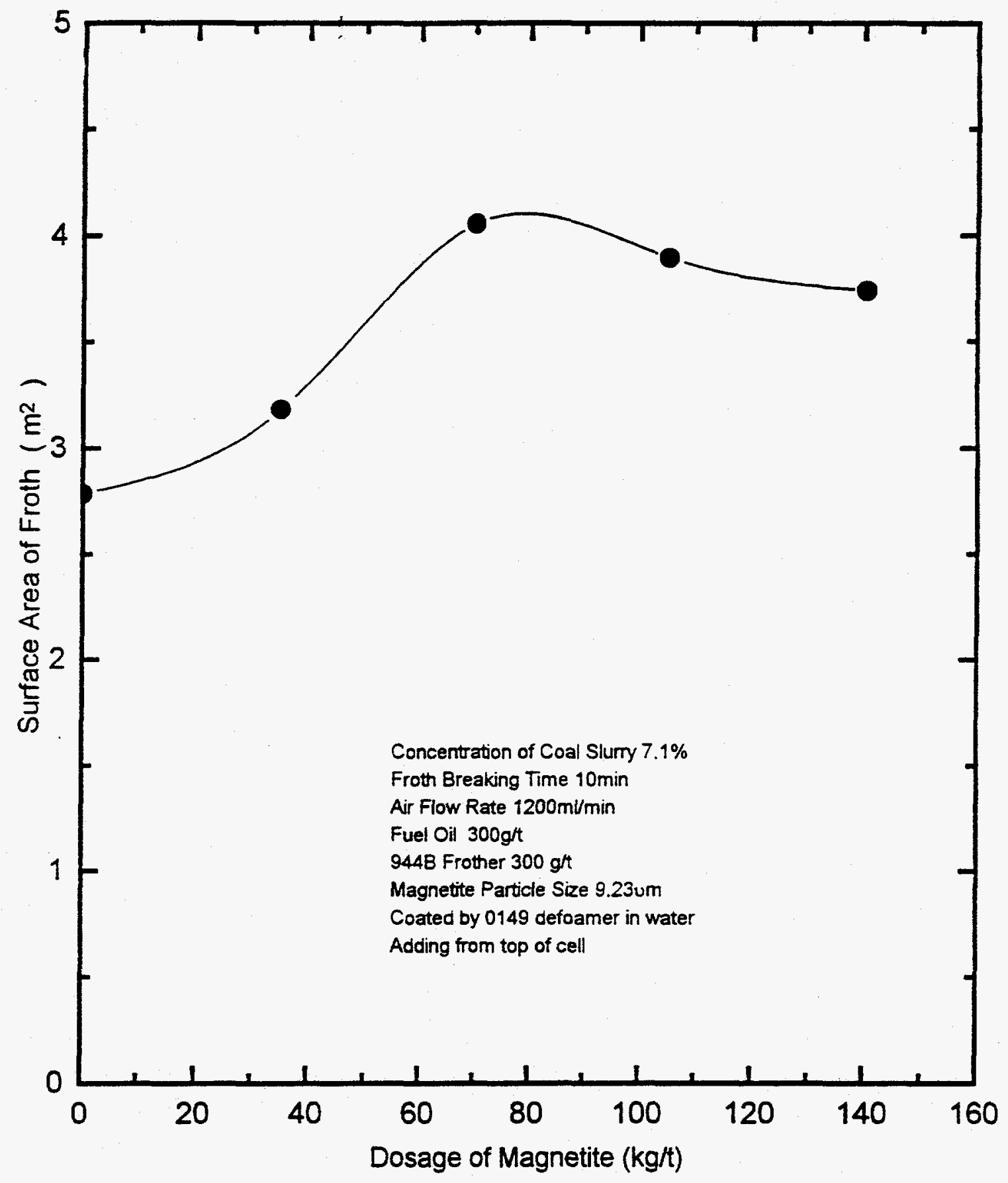

Fig. 26. Froth destabilizing effects of magnetite particles coated with defoamer 0149 in water and added to the top of froth. 


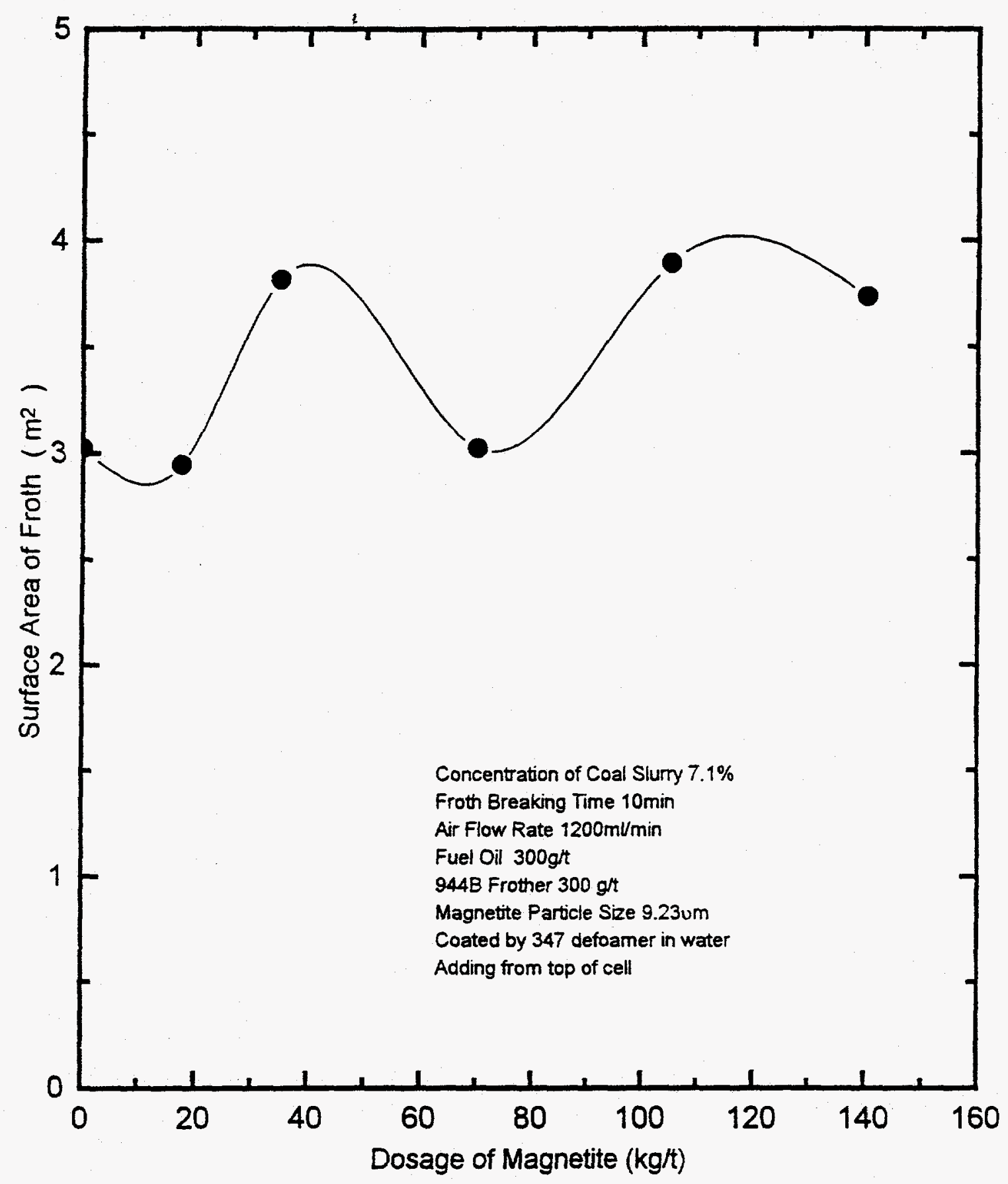

Fig. 27. Froth destabilizing effects of magnetite particles coated with defoamer 347 in water and added to the top of froth. 


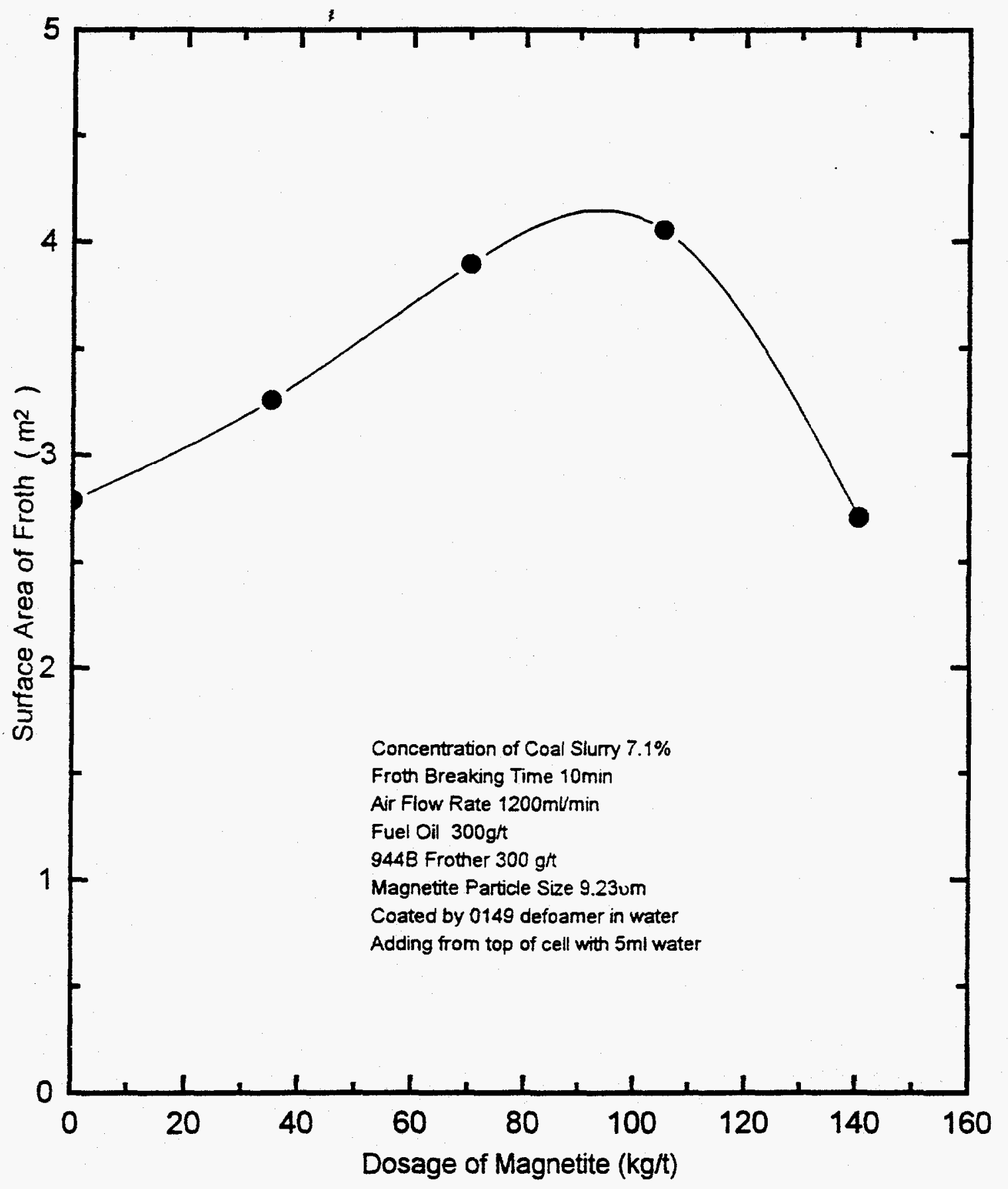

Fig. 28. Froth destabilizing effects of magnetite particles coated with defoamer 0149 in water and added to the top of froth together with $5 \mathrm{ml}$ water. 


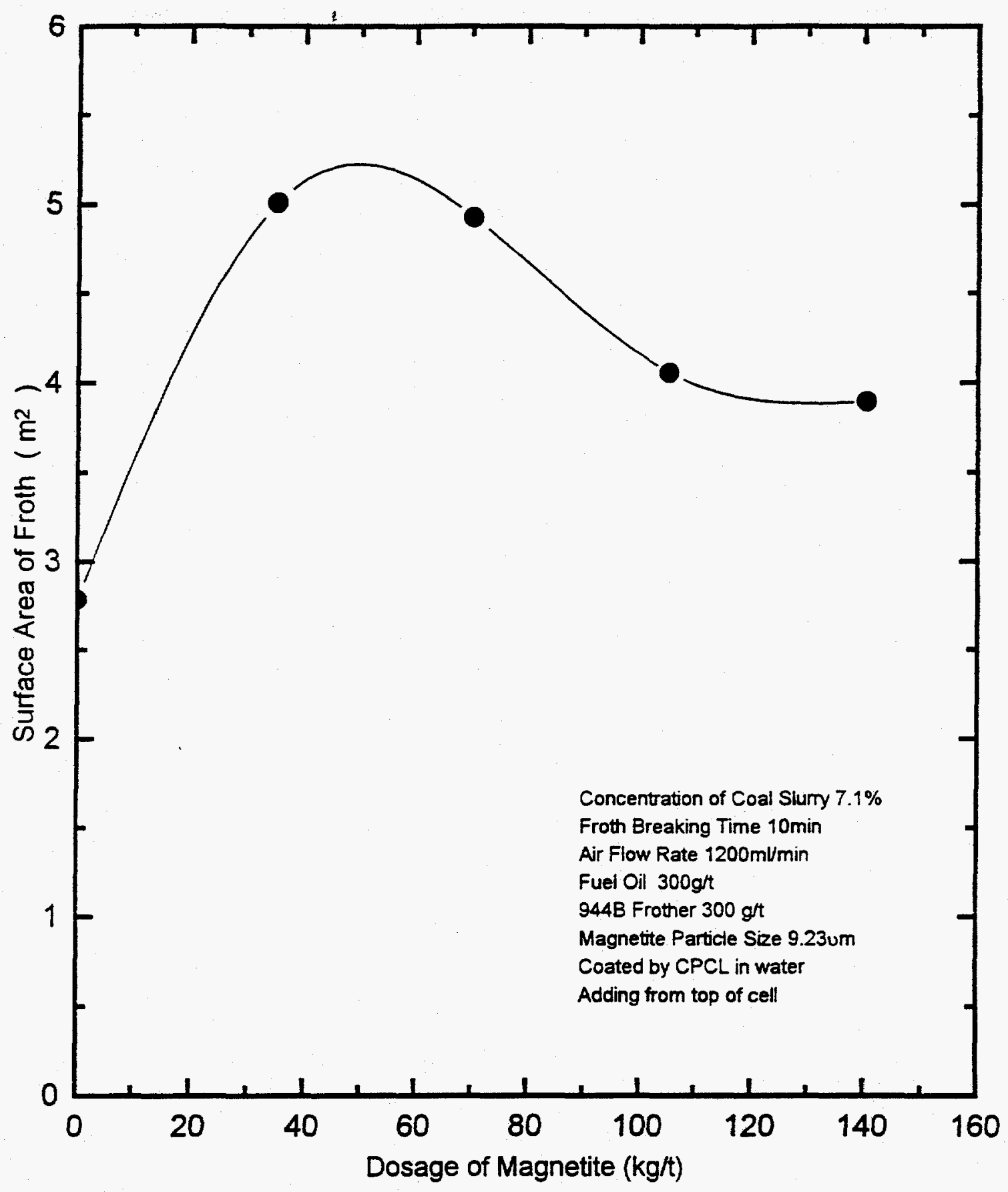

Fig. 29. Froth destabilizing effects of magnetite particles coated with CPCL in water and added to the top of froth. 
decreased consistently and dramatically with increasing magnetite dosage (Figure 30). The surface area of bubbles was about $0.3 \mathrm{~m}^{2}$ at a dosage of $140 \mathrm{~kg} / \mathrm{t}$, compared with $2.8 \mathrm{~m}^{2}$ surface area in the absence of magnetite. This represents a more than $90 \%$ reduction in surface area. It should be noted that in the present experiments a surface area of $0.3-0.5 \mathrm{~m}^{2}$ was indicative of barely visible froth.

\section{Effects of Particle Coating Media and Addition Methods}

Figure 30 indicated that substantial froth destabilization can be achieved with magnetite coated with $\mathrm{CPCL}$, the process is unrealistic for use in industry due to high magnetite dosage requirement. However, when magnetite particles were coated with CPCL and suspended in fuel oil rather than in water and added to the slurry and stirred for 24 seconds prior to flotation, the dosage of magnetite required decreased significantly, as shown in Figure 31. Use of magnetite at a dosage of only $2 \mathrm{~kg} / \mathrm{t}$ reduced froth surface area from 2.8 to $0.5 \mathrm{~m}^{2}$. Similar results were obtained with limestone coated with CPCL in fuel oil, as shown in Figure 32.

Figure 33 shows changes in surface area of froth as a function of dosages of 140 mesh coal particles coated with CPCL in fuel oil. Addition of thus-coated coal particles almost completely destroyed the froth at a dosage of about $7 \mathrm{~kg} / \mathrm{t}$. Although the dosage of coal required to destroy the froth is higher than that of magnetite or limestone, coal is readily available at coal preparation plant and therefore may be more suitable for this particular application. 


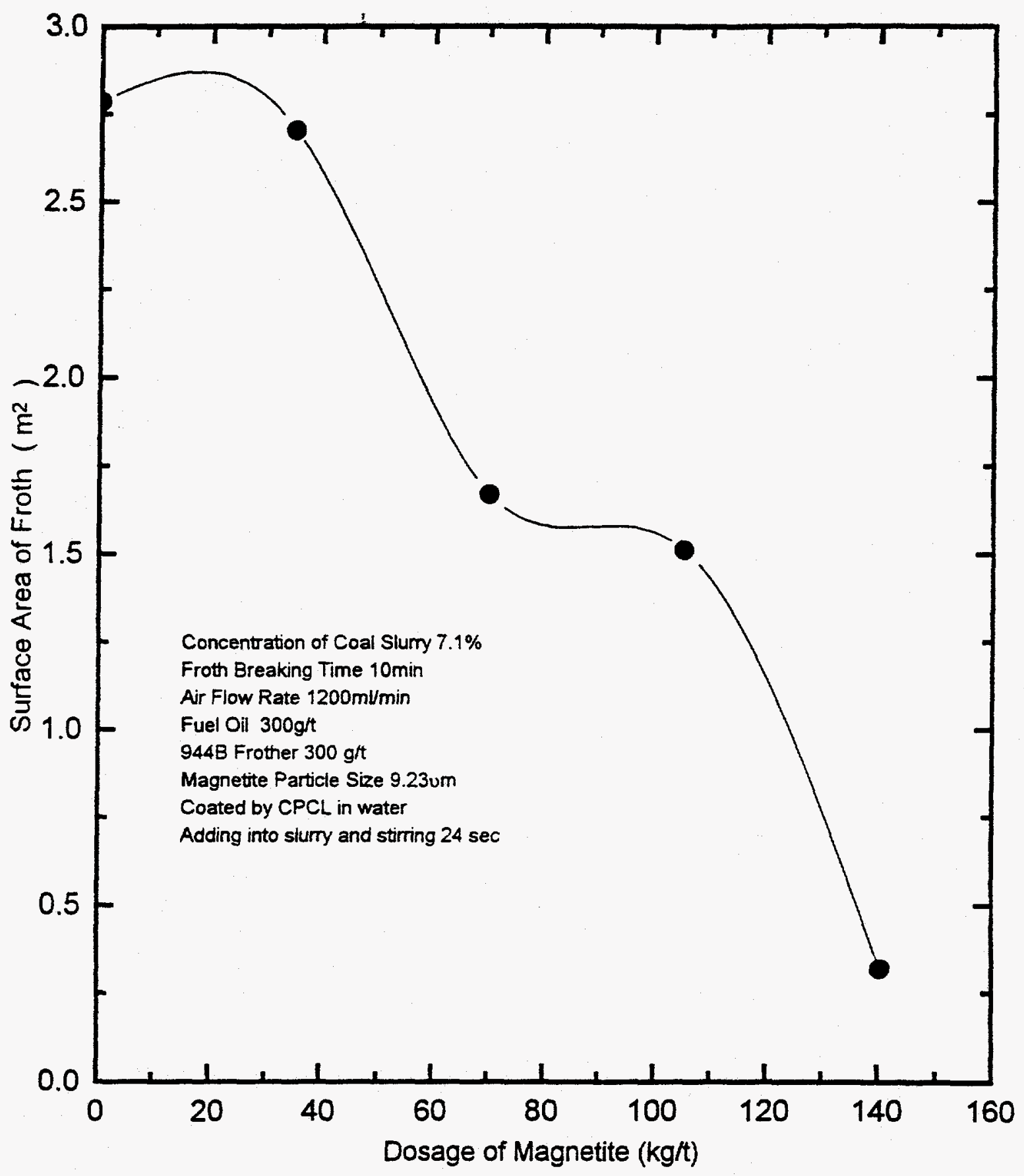

Fig. 30. Froth destabilizing effects of magnetite particles coated with CPCL in water and added to slurry prior to flotation. 


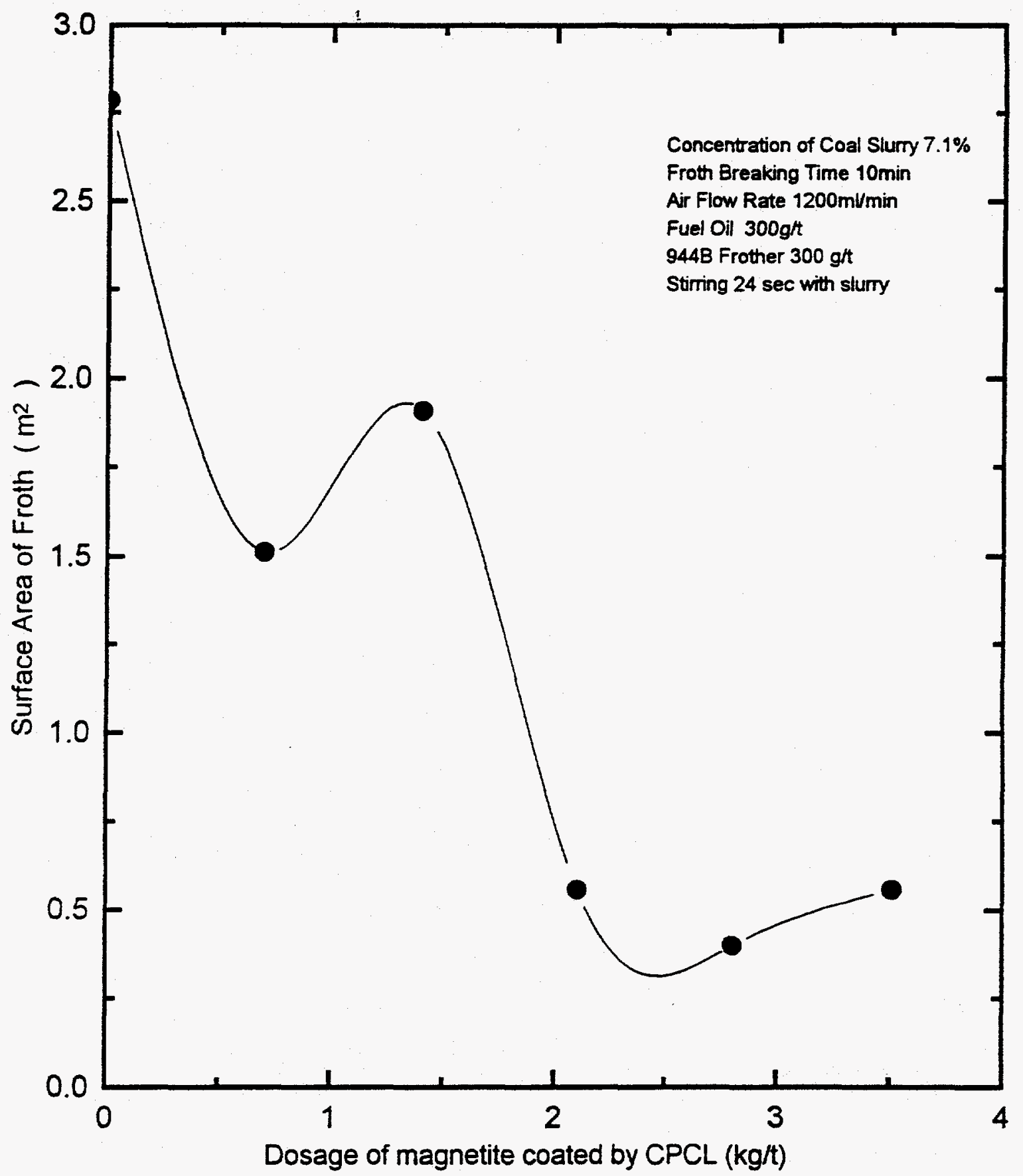

Fig. 31. Froth destabilizing effects of magnetite particles coated with $C P C L$ in fuel oil and added to slurry prior to flotation. 


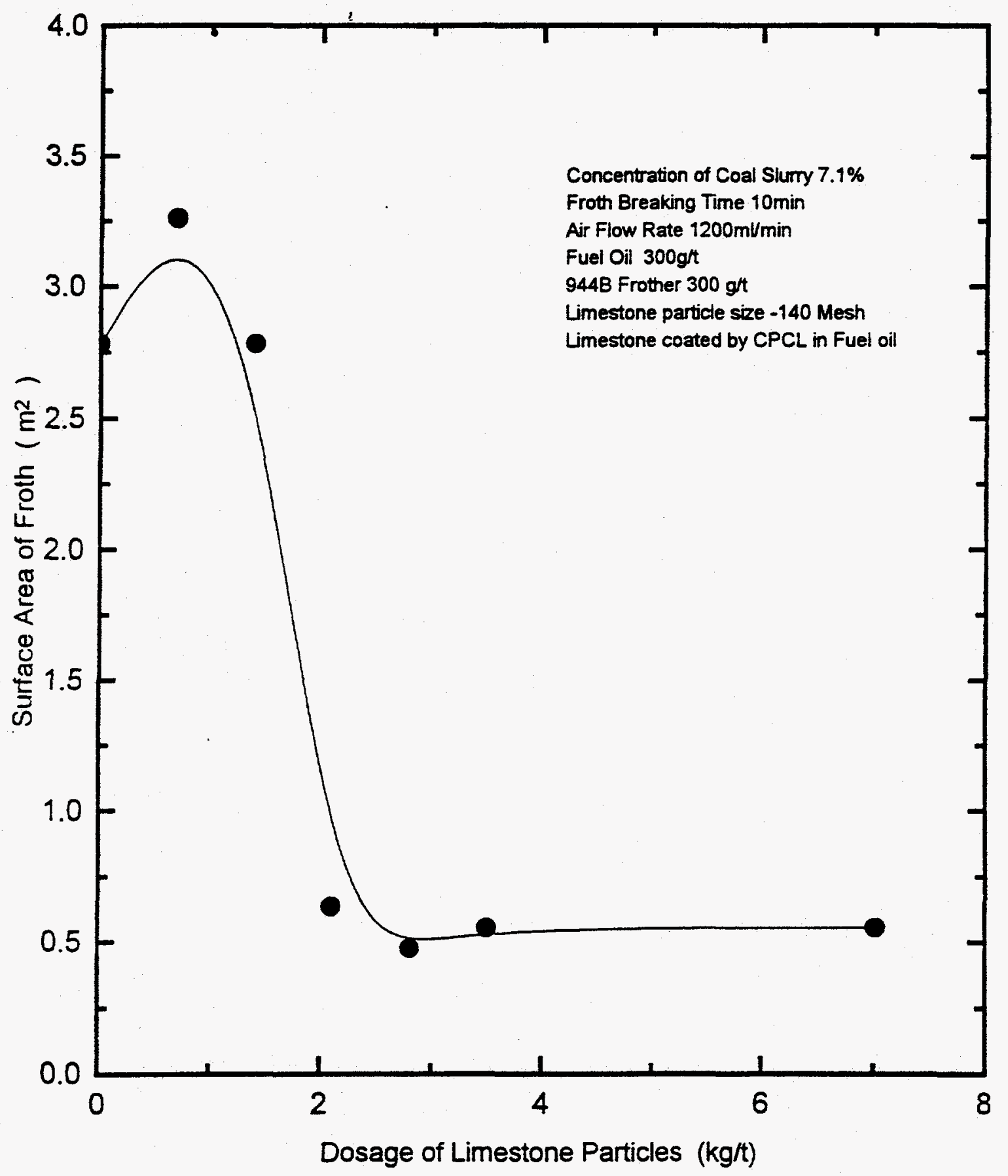

Fig. 32. Froth destabilizing effects of limestone particles coated with $C P C L$ in fuel oil and added to slumy prior to flotation. 


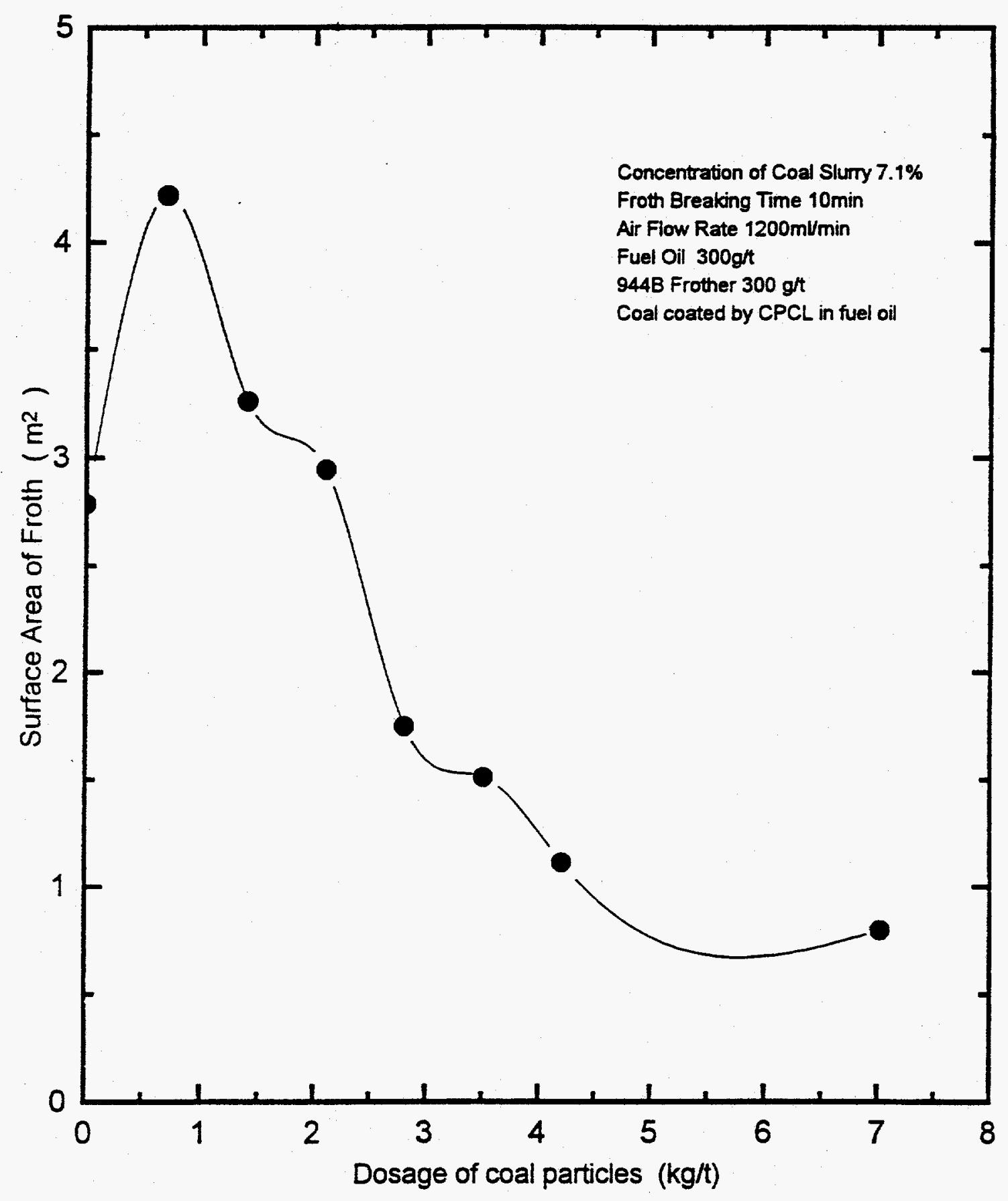

Fig. 33. Froth destabilizing effects of coal particles coated with $\mathrm{CPCL}$ in fuel oil and added to slumy prior to flotation. 


\section{Surface Tension Measurements of Coal Slumy Filtrate}

To understand the mechanisms of froth formation and stabilization in coal slumy-frother-fuel oil system, surface tension measurements were conducted with coal slumy supernatant. The supernatant was obtained by centrifuging coal slumy using a 10-in diameter centrifuge at $2500 \mathrm{rpm}$ for 5 minutes. Figure 34 shows surface tension as a function of dosage of frother $944 \mathrm{~B}$. The fuel oil dosage was maintained constant at $0.5 \mathrm{~kg} / \mathrm{t}$ in these experiments. As can be seen, the surface tension of supernatant was essentially independent of frother dosage. Similar results were obtained when fuel oil dosage was increased with increasing frother dosage in a constant 1:2 ratio, as shown in Figure 35 . This is a surprising finding with regard to the widely accepted concept that frother is used to produce froth by reducing surface tension of water as observed in Figures 5 and 6 obtained with two phase (liquid-gas) froth. It is, therefore, very likely that destabilization mechanisms of three phase (solid-liquid-gas) froth is fundamentally different from those of two phase froth.

\section{CONCLUSIONS}

- The "Foam Stabo System" developed at UKCAER has proved to be an ideal technique for studying froth stability utilizing data on froth surface area based on first principles of froth stability.

- It was found that higher gas rates and higher frother concentrations generated 


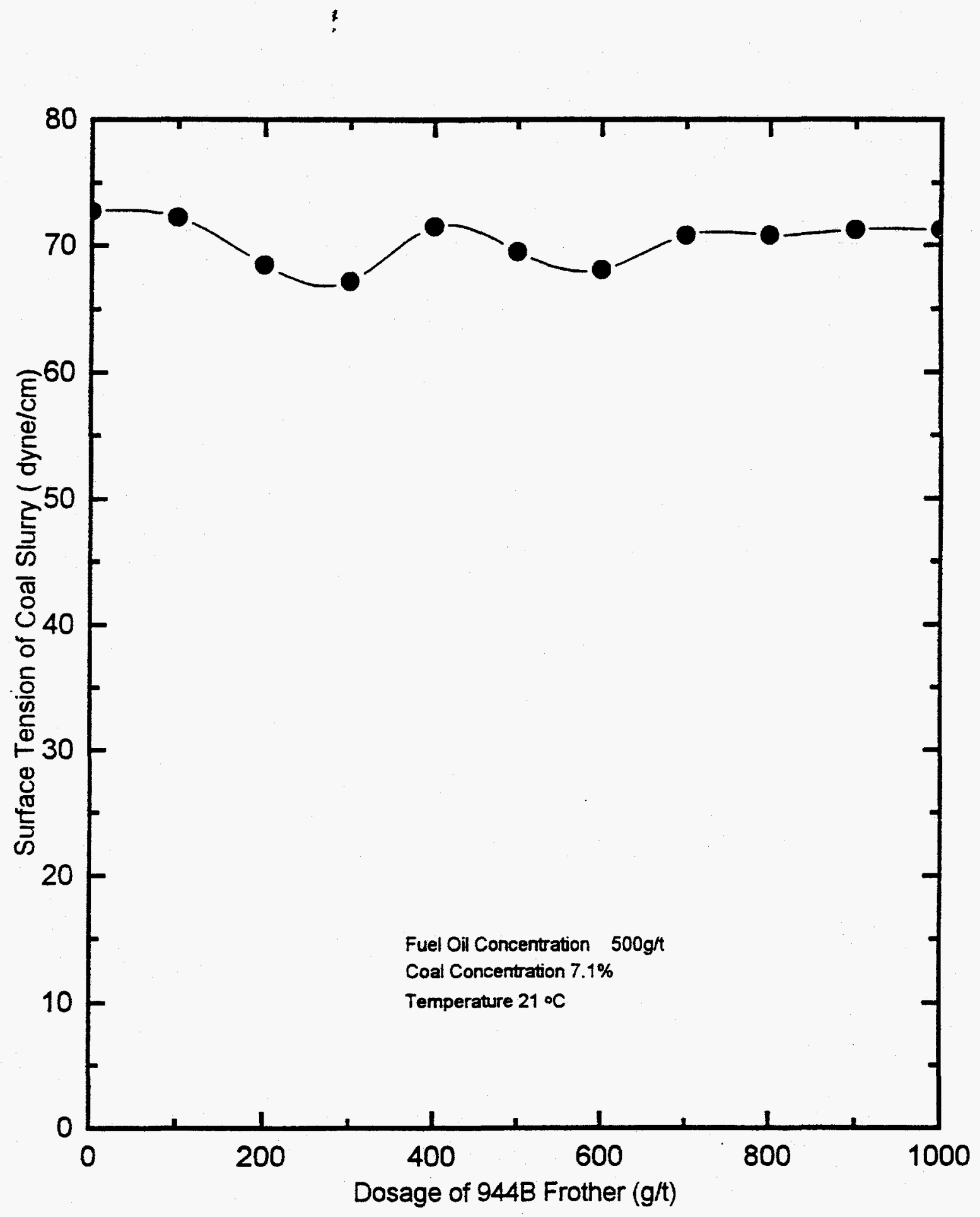

Fig. 34. Effect of dosage of frother on surface tension of coal slurry filtrate. 


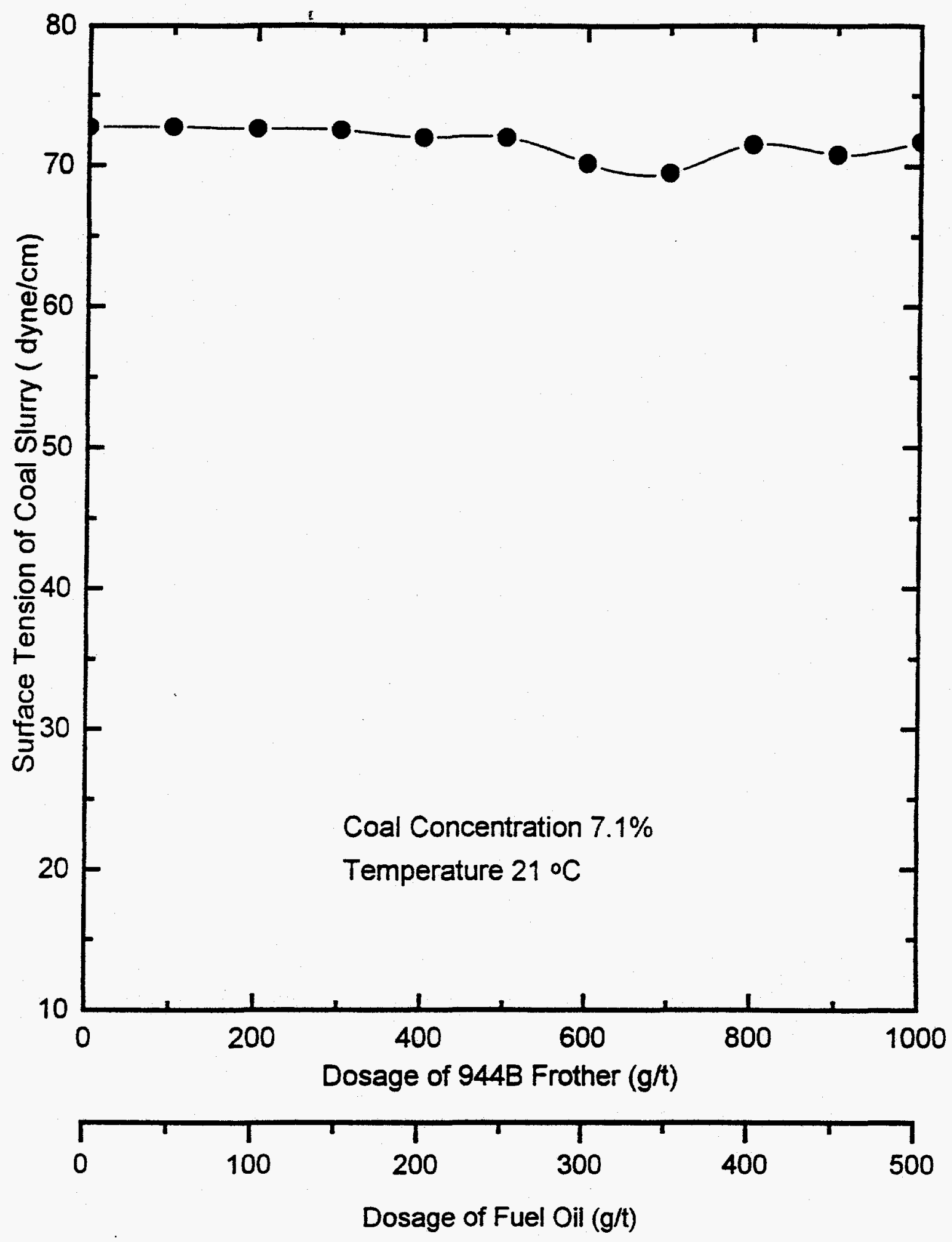

Fig. 35. Effect of dosage of frother and fuel oil at a constant ratio of 2:1 on surface tension of coal slumy filtrate. 
more stable froths. There is an almost linear relationship between froth surface area and Allied Colloid $944 \mathrm{~B}$ frother concentration up to $0.5 \mathrm{~kg} / \mathrm{t}$. However, an excessive dosage of frother destabilized frath.

- The differential pressure between the working froth column and the reference column increased almost exponentially with drainage time as froth destabilizes. At the same time, surface area of froth determined from the measured differential pressure decayed nearly exponentially during froth breakage.

- Data on surface area of froth produced at different frother concentrations showed that longer time was required for froth of smaller bubbles to drain, coalesce, and rupture.

- Three phase (coal-water-air) froth exhibited much stronger stability than two phase (water-air) froth for a given frother and fuel oil combination. Increasing coal solids concentration in slurry substantially increased froth stability. The stable coal froth could only be destroyed by using more than $7 \mathrm{Kg} / \mathrm{t}$ of commercial defoamers.

- Important factors determining defrothing effectiveness of solid particles are: type of solid, coating reagent, coating medium, dosage of particles, addition method, etc. Particle size showed relatively small effect over the range studied (50 mesh to -140 mesh). 
- Most effective coal froth destabilization was achieved by use of either magnetite or limeștone, or coal particles coated with cetylpyridinium chloride (CPCL) in fuel oil. For example, 2-3 kg/t of coal particles coated with $\mathrm{CPCL}$ in fuel oil was enough to destroy coal froth when properly added to the froth.

\section{RECOMMENDATIONS}

Based on the results obtained so far on coal froth destabilization studies the following recommendations are offered for future work:

- Measurement of surface tension of coal slurry filtrate before and after defoaming solid particles are added to the slurry. The results will help to understand froth destabilization mechanisms.

- Studies of mechanical processes for froth destabilization should be conducted utilizing cyclone, ultrasonic energy, or vacuum.

- Since the method of adding defoaming solid particles coated with reagent has significant impacts on effectiveness of defoaming, additional work is needed to find out an appropriate means of spraying defoaming particles.

- Pilot scale study of the defoaming process developed in this project should be conducted at a coal preparation plant to obtain techno-economic information for a commercial operation. Factors to be considered in evaluation include: type of solid, solid dosage, reagent type and consumption by solid coating, etc. 


\section{REFERENCES}

1. Arbiter, N. and Harris, C.C., 1962. "Flotation kinetics," In: Froth Flotation, 50th Anniversary Volume, AIME, Ed. by D.W. Fuerstenau, pp. 215-246.

2. Booth, R.B. and Freyberger, 1962, "Froth and Frothing Agents", Chapter 10, Froth Flotation 50th Anniversary Volume, D.W. Fuerstenau (Ed.), AIME.

3. Brown, A.G., Thurman, W.C. and McBain, J.W., 1953, J. Colloid Science, Vol. 8, pp. 491.

4. Cooper, H.R., 1966. "Feedback process model of mineral flotation. Part I. development of a model for froth flotation," Trans. SME AIME, 235, pp. 439446.

5. Dippenaar, A., 1982. "The destabilization of froth by solids, I. The mechanism of film rupture," International Joumal of Mineral Processing, 9, pp. 1-14.

6. Dippenaar, A., 1982. "The destabilization of froth by solids, II. The rate determining step," International Joumal of Mineral Processing, 9, pp. 15-27.

7. Engel, M.D. and Smitham J.B., 1988. "The relationship between coal particle size and hydrophobicity in the formation of particle-stabilized froths, "Australian IMM Bulletin and Processing, 293, pp. 63-66. 
8. Engelbrecht, J.A. and Woodbum, E.T., 1975. The effect of froth height, aeration rate and gas precipitation on flotation," Journal of S. African Institute of Mining and Metallurgy, 76, pp. 125-132.

9. Feteris, S.M., Frew, J.A, and Jowett, A., 1987. "Modeling the effect of Froth depth in flotation," Intemational Journal of Mineral Processing, 20, pp. 121-135.

10. Finch, J.A., Yianatos, J., and Dobby, G., 1989. "Column froths," Mineral processing and Extractive Metallurgy Review, 5, pp. 281-305.

11. Groppo, J.G. and Parekh, B.K, 1993. "Comparison of bubble generating devices for column flotation of fine coal from refuse," Minerals and Metallurgical Processing, February, pp. 9-12.

12. Johansson, G., and Pugh, R.J., 1992. "The influence of particle size and hydrophobicity on the stability of mineralized froths," International Joumal of Mineral Processing, 34, pp. 1-21.

13. Klassen, V.I. and Mokrousov, V.A., 1963. "An introduction to the theory of flotation," London, Butterworth.

14. Livshits, A.K and Dudenkov, S.V., 1965. "Some factors in flotation froth stability," in Proceedings, VIIth Int. Proc. Longr Gordon and Breach, New York, N. Y., pp. $597-621$. 
15. Lovell, V.M., 1976. "Froth characteristics in phosphate flotation," in Flotation A. M. Gaudin Memonial Volume, l, Ed. by M. C. Fuersteau, AIME, New York, N. Y., pp. 597-621.

16. Moys, M.H., 1989. "Mass transport in column froths," Mineral Processing and Extractive Metallurgy Review, 5, pp. 203-228.

17. Nishioka, G., 1981. "A new method and apparatus for measuring foam stability," J. of Colloid and Interface Sci., 81(1), pp. 1-7.

18. Ross, S., 1969. Ind. Eng. Chem. 61(10):48.

19. Szatkowski, M., 1987. "Factors influencing behavior of flotation froth," Trans. Instn. Min. Metall., Sec. C, Mineral Process. Extr. Metall., 96, C115-122.

20. Szatkowski, M. and Freyburger, W.L., 1985. "Kinetics of flotation with fine bubbles," Trans. Instn. Min. Metall., Sec. C, 94, C61-70.

21. Tao, D.P., 1994. "A comprehensive study of the electrochemistry and floatability of pyrite in coal flotation," Ph.D. dissertation, Department of Mining and Minerals Engineering, Virginia Polytechnic Institute and State University, Blacksburg, Virginia.

22. Yianatos, J.B., Finch, J.A., and Laplante, A.R., 1988. "Selectivity in column flotation froths," International Journal of Mineral Processing, 23, pp. 279-292. 
23. Yianatos, J.B., Finch, J,A., and Laplante, A.R., 1986. "Holdup profile and bubble size distribution of flotation column froths," Canadian Metallurgical Quarterly, 25(1), pp. 23-29. 
TECHNICAL PROGRESS REPORT

(

APPALACHIAN CLEAN COAL TECHNOLOGY CONSORTIUM

Cooperative Agreement No.: DE-FC22-94PC94152

Project Report for the period

October 10, 1994 - March 31, 1997

\author{
by \\ T. Meloy \\ West Virginia University Research Corporation \\ P.O. Box 6845 \\ Morgantown, WV, 26506-6845
}

Date Submitted: 28 April 1997

Contracting Officer's Representative: Richard Read

U.S./DOE patent clearance is not required prior to publication of this document. 


\section{DISCLAIMER}

$+$

This report was prepared as an account of work sponsored by an agency of the United States Government. Neither the United States Government nor any agency thereof, nor any of their employees, makes any warranty, express or implied, or assumes any legal liability or responsibility for the accuracy, completeness, or usefulness of any information, apparatus, product, or process disclosed, or represents that its use would not infringe privately owned rights. Reference herein to any specific commercial product, process, or service by trade name, trademark, manufacturer, or otherwise does not necessarily constitute or imply its endorsement. recommendation, or favoring by the United States Government or any agency thereof. The views and opinions of authors expressed herein do not necessarily state or reflect those of the United States Government or any agency thereof. 


\section{SPIRALS - FINAL REPORT}

INTRODUCTION

Spirals are an ancient, environmentally friendly method of separating sand size dense minerals from low density minerals. Widely used in the Iron Ore and Phosphate Sand industry, hitherto, spirals have been designed empirically. To improve the efficiency of said equipment, the PI was asked to physically and mathematically model said spirals. Once modeled, then optimum spirals could be designed theoretically.

In spite of the extraordinary difficult theoretical problems - multi phase open surface fluid flow, the modeling analysis was wildly successful. In the first year of what was to be a four year program, the accurate physical model was developed and then reduced to tractable mathematical statements. In turn, the mathematics were stated in software called Mathematica and then computed. For the scant experimental data available, the computed and experimental results matched closely.

For both simplicity and lack of experimental data for cross-sectional shapes other than ellipses, all calculations were programed to be done on spirals with elliptical cross sections. As the work was being done, industry moved to new complex cross-sectional shapes. Thus no comparing of modeling predictions on these new shapes was or is possible without serious reprogramming. This work was planned for the second year.

While in physical-mathematical modeling work, reality checks are both welcome and necessary, few problems are anticipated in revising the code in Mathematica to handle any type of proposed spiral cross-sectional. Calculations will take longer, but the with newer faster machines, the actual calculation time will remain the same.

Because open surface fluid flow requires numerical solutions, no closed form optimum solution is possible. It is anticipated that local optimums in terms of slope, radius, cross-section and roughness will readily be found for a given feed. Moreover, these local optimums will vary significantly with the feed size and density profiles. Finally, as a "guesstimate," in this mature technology, for initial changes, improvements of up to $30 \%$ are expected in spiral performance.

For the researchers, physical-mathematical modeling of spirals is one area where more research will have a large ROI. The work is intense, difficult and tricky, but also promising. Below is presented the two sections of the completed analysis. 


\section{A PHYSICAL MODEL OF SPIRALS, Part 1}

$t$

Abstract

Force equilibrium models of spirals are used to explore extending the spiral performance envelop employing mathematical simulation. In this first paper of this series on spirals, a detailed geometric description of the helical spiral and its trough or channel contour is provided. The secondary circulatory fluid motion in the transverse direction that develops when water flows down a tightly turning curvilinear path and its implications for gravity separation are also discussed. Different forces that act on the particle during its passage through the spiral are enumerated and quantified for a better precaution of their relative contributions and roles in the separation process. Three force equilibrium models from the hydrology literature on sediment transport are employed to simulate a typical spiral. While the results are promising in that the models mimic the broad performance characteristics of the spiral, it is deemed necessary to devise a more general model which takes explicit cognizance of the missing components that are essential to the spiral description, such as centrifugal force and the steep tangential slope of the channel deck. Results of this exercise are deferred to the next paper.

\section{INTRODUCTION}

Spirals are ancient mineral processing devices used by the Greeks. Probably, about the time of Jason's voyage, made famous by Jason's Fleece, the technology of spirals was imported from the Bosphorous region. In the silver mines of Athens, large diameter spirals were used to concentrate the silver ore.

During the Second World War, spirals were reintroduced into the arsenal of mineral processing tools used to separate minerals by their density. In the early '40s, spirals were used to separate phosphate sands from silica sands. Later spiral use was broadened to other minerals such as those containing iron.

Modern spiral design has been empirical. During WWII the first modern spirals were made from old automobile tires, cut radially and concatenated to form the helictical spiral. Later spirals were cast in iron but maintained the tire cross sectional profile. Even the latest spiral designs maintain the elliptical cross section of a spiral. The ineluctable conclusion is that now is the time to analyzise spiral design.

In todays world of increasing cost and environmentally conscience management, spirals are being reexamined. Spirals are a low cost, environmentally friendly method of gravity separation. Thus, if separation performanced can be enhanced by better profiles, then there will be a growing market for spiral technology. 
Flow in a mineral processing spiral is complex. Not only is the flow of a two phase slurry, but more important, it is open channel curved flow. Even in open channel straight flow of pure liquids, there are no analytical solutions. Thus mathematical modeling of spiral behavior is difficult.

Mathematical modeling is a complex discipline. To model a unit operation such as a spiral, four distinct steps are needed. These are 1) an accurate physical model, 2) an accurate mathematical description of the physical model, 3) the choice of numerical methods to solve the mathematics and these days 4) the choice of computer software to calculate the numerical methods. This paper deals primarily with number 1 above, an accurate physical model.

Mathematical models of spirals, like many other mineral processing unit operations, is an increasingly cost effective approach to improving unit operation performance. Through the experimental excursions over the decades, if not centuries of use, most "local optimums" have been emperically discovered. Moreover, experimental cost continue to rise while computer cost continue to drop rapidly. Mathematical modeling will continue to be an increasing cost and time effective way to improve a unit operations design. Unfortunately, experiments are becoming too expensive.

Regretably, some investigators, perhaps malisiously, are giving the name mathematical model to their emperical curve fitting work. While curve fitting is an old and honorable engineering art for improving processes, it is the antithesis of mathematical modeling. Curve fitting is empirical, while modeling is analytical. Moreover, curve fitting requires large amounts of data and thus becomes an increasingly expensive technique for improving unit operations performance.

\section{LITERATURE}

After a substantial period of quiesence, the spiral research area has become active. Recent work by (Sivamohan and Forssberg, 1985), (Holland-Bhatt, 1989), (Holland-Batt and Holtham, 1991), (Loveday and Cilliers, 1994), (Li et al., 1995) is designed to provide a analytical method for the design, scale-up and improvement of spirals supplementing the current empirical, experimental and intuitive methodologies.

MODEL

As particles move down the helix path, they are subjected to five forces. These are 1) hydrodynamic drag, 2) hydrodynamic lift, 3) friction, 4) gravity and 5) centrifugal forces. Paradoxically, for a given particle, these forces are balanced in the radial. Thus particles, based on their size, shape and density, have a radial equilibrium position in the spiral radial position. 
A spiral is an open channel or trough, wound in the form of a vertical circular helix having a number of turns or loops. Spiral behavior depends its diameter, height, number of turns, pitch and slope as well as the channel shape and dimensions. Altering these spiral design paramenters alters the spirals separation characterisitics for a specific feed.

It is assumed that a spiral's performance is altered by the feed. The volume of feed, the solids to liquid ratio, the feed density and even the feed's viscosity (temperature) control the sparation efficiency of a given spiral.

In the preliminary analysis presented in this paper, it will be assumed that the spiral is at equilibrium, is a vertical helix with a fixed inner and out diameter and that the trough cross section does not change with vertical position in the helix. Moreover, it is assumed that for a given particle, the particle has reached radial equilibrium and while influenced by slurry properties, its radial position is not influence by other particles in the slurry.

\section{MATHEMATICAL QUANTIFICATION OF THE HELIX}

The parametric equations of an helix in $x-y-z$ cartesian coordinates are (von Seggern, 1990):

$$
\begin{array}{lll}
x=r \operatorname{Sin}[t] & & \\
y=r \operatorname{Cos}[t] & ; & 0 \leq t \leq N \pi \\
z=\frac{u}{2 \pi} t & ; & 0 \leq z \leq H
\end{array}
$$

where $r$ is the radius, $u$ the is pitch and $H$ is the height of the helix. The spiral height, $H$, is given by:

$$
H=\frac{N u}{2}
$$

The number of turns, $T$, is:

$$
T=\frac{N}{2}
$$

impling that $\mathrm{N}$ is an even integer for loops complete.

The length or travel distance of the helical coil, $L$, is given by the following integral:

$$
L=\int_{0}^{N \pi} \sqrt{x^{\prime}(t)^{2}+y^{\prime}(t)^{2}+z^{\prime}(t)^{2}} d t
$$

where the prime represents derivative with respect to the parameter $t$. Substituting for the derivatives and integrating yields: 


$$
L=N \sqrt{4 r^{2} \pi^{2}+u^{2}}
$$

And the tangential slope, $S$, is:

$$
S=\tan [\alpha]=\frac{z^{\prime}(t)}{\sqrt{x^{\prime}(t)^{2}+y^{\prime}(t)^{2}}}
$$

or

$$
S=\frac{1}{2 \pi} \frac{u}{r}
$$

Hence both travel distance and slope are functions of the radial distance, $r$, along the width of the spiral channel and its pitch, $u$. As such, spiral diameter and pitch are the principal design parameters of this separator.

Most trough shapes are of the form of a modified quarter-circular arc. These may be represented by an elliptical curve. The parametric equations for this curve in $x-y$ cartesian coordinates are:

$$
x=c_{x} \sin [t]
$$

and

$$
y=-c_{y} \cos [t] \quad ; 0 \leq t \leq \pi / 2
$$

where $c_{x}$ is maximum width of the channel and $c_{y}$ is maximum depth. It is convenient to derive additional results in terms of either $x,\left(0 \leq x \leq c_{x}\right)$, the radial distance out from the inner side of the trough, or in $r=r_{i}+r,\left(r_{i} \leq r \leq r_{0}\right)$, the radial distance from the centerline of the spiral. From equation 10, parameter $t$ becomes:

$$
t=\arcsin \left[x / c_{x}\right]
$$

And the local slope of the channel deck in the radial or transverse direction at any point $(x, y)$ on its surface is given by:

$$
\tan [\theta]=\frac{c_{y}}{c_{x}} \tan \arcsin \left[x / c_{x}\right]
$$

Because the propose hydrological models to be tested are based on a horizontal water profile in the transverse direction, for the time being, we ignore the inclination phenomenon known as superelevation by centrifugal acceleration and represent the surface of the water by a horizontal line which meets the concave side of the channel at coordinates $\left(x_{w}, y_{w}\right)$. The depth, $h$, of water at any point $\{x, y$ I on the trough surface is:

$$
h=y-y_{w}
$$

which after appropriate substitutions becomes:

$$
h=\frac{c_{y}}{c_{x}}\left[x \cot \arcsin \left[x / c_{x}\right]-x_{w} \cot \arcsin \left[x_{w} / c_{x}\right]\right]
$$

A typical Humphry spiral has following approximate dimensions: height, $H=1.524 \mathrm{~m}$, inner diameter, $r_{i}=0.134 \mathrm{~m}$, outer diameter, $r_{0}=0.286 \mathrm{~m}$, number of 
turns, $T=6$, trough width, $c_{x}=0.152 \mathrm{~m}$, and the maximum depth, $c_{y}=0.125 \mathrm{~m}$. Using these data we found that the travel length, $L$, varies almost linearly with $r$ and the longitudinal slope, $S$, drops by nearly one-half from the inner convex side of the trough to the outer concave rim. Radial slope and water depth vary with radial distance. The latter plot has been calculated by taking $x_{w}=0.5 c_{x}$. While there are many mathematical functions suitable for describing the contour of the spiral trough, few are more convenient that the elliptical contour.

\section{Forces on Particles}

During their passage through the spiral, particles are subjected to five forces. They are hydrodynamic drag, hydrodynamic lift, friction, gravity and centrifugal forces. We estimate these force magnitudes in a spiral operation and thereby acertain their relative contribution to the overall force balance on a particle.

\section{Gravity Force}

Force of gravity or weight of a particle of diameter $d$ and density $\sigma$ submerged in a liquid of density $\rho$ is:

$$
F_{g}=\frac{\pi}{6} d^{3}(\sigma-\rho)
$$

The relative density of solids in spiral feeds varies from less than 1.3 for coal to greater than 4.5 for heavy minerals and the size ranges from $0.05 \mathrm{~mm}$ to $3 \mathrm{~mm}$ (up to $6 \mathrm{~mm}$ for coal). Two 3-dimensional plots show the magnitude of the gravity force acting vertically downward on particles under water whose relative density and size lie between 1 to 3 and 0 to $2 \mathrm{~mm}$, respectively. Noted that the particle weight would be less than $5 \times 10^{-5}$ Newton.

\section{Drag Force}

A flowing stream of water exerts a drag force in the direction of flow on a particle lying in its path because of the particies skin friction and to eddies induced pressure difference between its upstream and downstream sides. This drag force can be described by the following equation (Allen, 1982a):

$$
F_{d}=\frac{\pi}{4} d^{2} \tau_{0}
$$

where tau, $\tau_{0}$, is the bed shear stress or unit tractive force. For one-demensional flow in a straight sloping channel the boundary shear stress is given by:

$$
\tau_{o}=\rho g h \sin [\alpha]
$$

We recognize that the boundary shear stress in a curvilinear path would be different than what is given in equation 19 (Chang, 1988). However, in the absence of any analysis and data for the kind of trough contours found in spirals, we are constrained to utilize equantion 19. Combining equantions 18 and 19 yields an expression for drag force:

$$
F_{d}=\frac{\pi \rho g}{4} d^{2} h \sin [\alpha]
$$


Inserting slope and depth values at the mid-point of the trough into equation 20 we obtain estimates of the drag force acting on different size particles in a spiral operation. The drag force is only marginally higher than gravity force in the size range of interest for spirals.

\section{Lift Force}

Comparatively large particles moving in the vicinity of the channel deck can be subjected to hydrodynamic lift forces (Bagnold, 1954 and 1966; Allen, 1982a) by the influences of the nearby boundary, fluid shear and particle spin (Magnus effect). In spirals the role of lift force seemingly is to act as a bed dilator, and in conjunction with other forces, lift particles of different sizes to approximately the same extent in the high velocity upper layers of the flowing pulp (Sivamohan and Forssberg, 1985).

A particle traveling more slowly than the surrounding fluid at a free separation distance of no more than its diameter from the bed is acted upon by a normal force because of the restriction placed on the motion of the fluid on the underside. A lift is generated as the fluid is slowed down between the bed and the particle and the fluid pressure builds up. Another source of lift force, is because of the relative motion of a particle within a sheared fluid when it moves up the gradient of relative velocity and across the lines of flow. Again, the particle must travel more slowly than the surrounding fluid for it to experience a positive lift. The fluid shear lift increases with increase in particle size and shear rate. Lift force due to particle spin also requires a finite relative velocity between particle and flow. Again, this lift increases with particle size and relative velocity.

Though lift force can be directly related to drag force, it is, however, difficult to assign a specific value to the constant of proportionality. Experimentally determined values ranging from $1 / 7$ to unity have been reported (Simons and Senturk, 1976). Thus, it is not uncommon to lump drag and lift forces together with an appropriately modified drag coefficient. We propose in first instant to estimate lift force in following manner:

$$
F_{l}=k_{l} F_{d}
$$

with $k_{i}=0.33$.

\section{Centrifugal Force}

Because of relatively fast and tightly turning flow in the spiral, centrifugal force should play a significant role in its operation. Centrifugal force acting on a submerged particle moving with a velocity, $v$, in a circular path of radius, $r$, is given by:

$$
F_{c}=\frac{\pi}{6} \frac{d^{3}(\sigma-\rho) v^{2}}{r}
$$

In general, the velocity of the particle will differ from that of the fluid, as well as, the variables of particle size, density, position in the radial direction and depth under water. As theoretical analysis of the particle velocity in a rotating two-phase flow may not be a simple undertaking, we have adopted an indirect mean for 
incorporating the local centrifugal force by appropriate force balance on the particle - as demonstrated in Part 2 of this report. In order to obtain at least an order-ofmagnitude estimates of centrifugal force acting on particles, based on the reported fluid velocities in spirals, we have assumed $0.25 \mathrm{~m} / \mathrm{s}$ velocity to the particle. Centrifugal force obtained by this procedure as a function of size and density at the centerline of the spiral channel may be plotted. In most instances this force is likely to be less than $1 \times 10^{-5}$ Newton.

\section{Friction Force}

At the threshold of particle motion the overall sum of tractive forces is equal to the resistance to motion. This resistance is proportional to the normal components of all forces acting on the particle. The constant of proportionality is the coefficient of static friction, $\tan \left[\phi_{s}\right]$, where the angle $\phi_{s}$ is the angle of repose or the internal friction angle under water, which according to Bagnold is virtually same as the coefficient of dynamic friction $\tan [\phi]$ (Allen, 1982a). Allen also provided a graphical relationship between the size of the natural occurring grains and the coefficient of dynamic friction which shows that between approximately $0.4 \mathrm{~mm}$ to $2 \mathrm{~mm}$ the coefficient drops almost linearly from 0.963 to 0.482 ; finer than $0.4 \mathrm{~mm}$ sizes have the upper value and larger than $2 \mathrm{~mm}$ sizes the lower value. Good fit of Engelund-Bridge model to laboratory and natural point bar profiles were obtained with values of 0.4 to 0.5 (Chang, 1988). Therefore we propose that friction force is related to normal force by:

$$
F_{f}=0.5 F_{n}
$$

All gravity separation processes entail countering the force of gravity by imposing some other force(s). Inspection of data presented reveal two points. One, with the exception of gravity force, all other forces have a strong dependence on the spiral geometry. Two, the magnitude of gravity force is comparable to that of drag and centrifugal forces in the size range of particles normally processed in spirals. Thus, it is not so much the magnitude of forces, as the rate of change of forces with particle size, density and position which utlimately determines the efficiency of separation in a spiral.

\section{Force Equilibrium in Spirals by Hydrological Models}

There are essentially two particle mechanics-based approaches to modeling the spiral. Either one can attempt to map the trajectory of the particle down the spiral trough or one can try to establish the conditions for static and or dynamic equilibrium by appropriate force balance on the particle. Because of the complex nature of fluid flow alluded to above, the latter approach is more tractable. A number of equilibrium models exist in the hydrology literature on transverse profile of bed slope and grain size distribution in rivers and streams in fully developed flow. The analogy of these natural phenomena with the operation of a spiral becomes, if one considers the sedimentation processes in channel bends and in the meandering rivers which exhibit a roughly sinusoidal path. In this section we propose to 
employ, with suitable modifications, three such models to the working of our spiral to verify whether the force equilibrium approach is appropriate to this equipment.

The simplest model is by Allen (1982b). Allen considers particle stability in the transverse direction of a sloping surface in a meandering open channel. Ignoring superelevation, longitudinal slope and lift and centrifugal forces, the criterion for static equilibrium is given by simply equating the gravity force and drag force components in the transverse direction:

$$
\frac{\pi}{6}(\sigma-\rho) d^{3} g \sin [\theta]=\frac{\pi}{4} d^{2} \tau_{s} \sin [\delta]
$$

where the mean bed shear stress $\tau_{0}$, is related to $\tau_{s}$ the mean bed shear stress along a limiting bed streamline at an angle of $\delta$ with the longitudinal direction by:

$$
\tau_{o}=\tau_{s} \cos [\delta]
$$

and $\theta$ is the local transverse slope at radial distance, $r$, from the center line described previously. Successive substitutions of equations 25,16 and 19 into equation 24 yields:

$$
d=\frac{33}{2}\left(\frac{\rho}{\sigma-\rho}\right) \frac{h^{2} \sin [\alpha]}{\left(r_{i}+x\right) \sin [\theta]}
$$

In which angle $\alpha$ is given in equation 8 , angle $\theta$ in equation 13 and local water depth $h$ in equation 15 . Equation 26 provides an explicit relationship between particle size and its stable position on the sloping surface of the spiral trough in radial distance $r=r_{i}+r$ in terms of spiral design parameters and particle density. Plotting the data in the equation shows the spatial distribution for particles of relative densities of $1.5,2,2.5,3$ and 3.5 .

Both static equilibrium in the transverse direction and dynamic equilibrium in the longitudinal direction are utilized in Engelund-Bridge model (Chang, 1988), but superelevation and centrifugal forces are ignored. The resulting expression is:

$$
d=\frac{3}{2} \frac{\tau_{0}}{(\sigma-\rho) g \tan [\phi]}
$$

which on substitution of equation 19 for boundary shear stress and 0.5 for coefficient of friction yields:

$$
d=3 \frac{\rho h \sin [\alpha]}{(\sigma-\rho)}
$$

where $\alpha$ and $h$ are given in equations. 8 and 15, respectively. Plotting this data shows the variation of particle size with equilibrium radial distance along the trough width. The third and last model is by Odgaard (Chang, 1988) who showed that:

$$
d=k_{o} \frac{h^{5 / 3}}{r^{3 / 2}}
$$

where $k_{0}$ is a normalizing or reference parameter. In order to bring Odgaard model in conformity with the previous two models we arbitrarily assign the following form to this parameter: 


$$
k_{o}=C \frac{\rho}{(\sigma-\rho)}
$$

where $C$ is an unknown numerical constant taken to be equal to unity in our simulation of the spiral. Obviously, in the absence of any definitive knowledge of the reference parameter this simulation should be seen as only indicative of the trend in the equilibrium position for particles of different sizes.

Inspection of the resultant data reveals that the force balance models, even though developed in the context of hydrological phenomena taking place on vastly larger scales of channel dimensions and flows, are capable of exhibiting at least the broad performance characteristics of the spiral. The slimes and low density solids are driven to the outer rim of the trough and the heavy and coarse particles segregate on the inner side. There is a continuous classification of the middlings along the width of the trough. However, the spread of particle size in these mathematical simulations is significantly broader, that is, the rate of change of size with radial distance is greater, especially in the Allen model, than what is encountered in a spiral. This is due to the omission of centrifugal force and the steep tangential slope of the spiral in the models, apart from the fact that all three models are based on horizontal water surface in the transverse direction. In this first paper of this series on spirals we have forcast further planned research. In future papers, we plan to fill these lacunae by formulating a general force balance spiral model, more in tune with the spiral characteristics.

\section{References}

Allen, J.R.L. Sedimentary Structures: Their character and physical basis. Vol.l. Elsevier Scientific Publishing Co., 1982a. Chap 2 and Chap 7.

Allen, J.R.L. Sedimentary Structures: Their character and physical basis. Vol.ll. Elsevier Scientific Publishing Co., 1982b, Chap 2 and Chap 3.

Bagnold, R.A. 1954. Experiments on a gravity-free dispersion of large spheres in a Newtonian fluid under shear. Proc. R. Soc., London, Ser. A, 225, 49-53.

Bagnold, R.A. 1966. An approach to the sediment transport problem from general physics. U.S. Geological Survey Professional Paper $422-1$.

Burch, C.R., 1961-1962. Helicoid performance and fine cassiterite - joint discussion. Trans. IMM, 71, 406-415.

Burt, R.O. Gravity Concentration Technology. Elsevier Science Publishers, 1984, 261

Chang, H.H. Eluvial Processes in Riven Engineering. John Wiley, 1988, Ch. 8.

Holland-Batt,A.B, 1989. Spiral separation: theory and 
simulation. Trans. Instn. Min. Metall.

(Sec. C) 98, C46-C60.

Holland-Batt, A.B, and Holtham, P.N., 1991. Particle and fluid

motion on spiral separators. Minerals

Engineeing, 4, 457-482.

Holtham, P.N., 1990. Flow visualisation of secondary currents on spiral separators. Minerals

Holtham, P.N., 1992. Primary and secondary fluid velocities

Engineering, 3, 279-286.

on spiral separators. Minerals Engineering,

5, 79-91.

Li, M., Jancar, T., Holtham, P.N., Davis. J.J. and

Fletcher, C.A. Approaches to the development of coal spiral models, in High Efficiency Coal

Preparation: An International

Symposium. Kawatra, S.K.

(Editor), Soc. Mining,

Metallurgy and Exploration,

Littleton, Co., 1995, 335-345.

Loveday, G.K and Cilliers, J.J., 1994. Fluid flow modelling on spiral concentrators. Minerals Engineering, 7, 223-237.

Mankosa, M.J., Stanley, F.L. and Honaker, R.Q. Combining hydraulic classification and spiral concentration for improved efficiency in fine coal recovery circuits, in High Efficiency Coal Preparation: An International Symposium. Kawatra, S.K. (Editor), Soc. Mining, Metallurgy and Exploration, Littleton, Co., 1995, 99-107.

Palowitch, E.R., Deurbrouck, A.W. and Parsons, T.H. Wet fine particle concentration Section 2: Hydraulic concentration, in Coal Preparation. Leonard, J.W. (Editor), 5th edition. Soc. Mining, Metallurgy and Exploration, Littleton, Co., 1991, 435-449.

Rozovskii, I.L., 1961. Flow of water in bends of open channels. The Academy of Sciences of the Ukrainian SSR, 1957, translated from Russian by the Israel Program for Scientific Translations, Jerusalem. (PST Catalog No. 363, OTS 60-51133, U.S. Dept. of Commerce, Washington D.C.).

Simons, D.B. and Senturk, F., Sediment Transport Technology. 
Water Resources Publications, 1976, Ch.

7.

Sivamohan. S. and Forssberg, E., 1985. Principles of spiral concentration. International J. Mineral. Processing, 15, 173-181.

Tavares, L.M. and Sampaio, C.H. Spiral concentration for cleaning fines from major Brazilian coalfields, in High Efficiency Coal Preparation: An International Symposium. Kawatra, S.K. (Editor), Soc. Mining, Metallurgy and Exploration, Littleton, Co., 1995, 129-138.

von Seggern, D.H. CRC Handbook of Mathematical Curves and Surfaces._CRC Press, 1990, 206-209. 


\section{SPIRALS UNVEILED, Part 2:}

\section{Abstract}

In light of the encouraging results obtained in Part 1 of the report, a detailed force balance model of the spiral is derived in Part 2 which includes gravity, centrifugal, hydrodynamic drag and lift, and friction forces acting on a particle. Conditions are established for dynamic equilibrium in the forward longitudinal direction and static equilibrium in the radial transverse direction. Four power laws for Manning, Lacey, Blasius and transitional flow regimes are tested on a typical spiral geometry. Oniy the transitional or mixed flow equation gives mean fluid velocities comparable to the measured values. The flow profile associated with this regime when incorporated in the model provides equilibrium locations of particles according to their size and density along the width of the spiral trough. The simulated distributions are in reasonable agreement with the experimental data available in literature.

\section{Introduction}

Working of a spiral is commonly described in terms of various sub-processes such as hindered settling of particles, dilation and expansion of the particle bed, interstitial trickling and percolation of fines through the open matrix etc. (Burt, 1984; Palowitch et al., 1991; Sivamohan and Forssberg, 1985 ). In general, these processes and their complex interactions are not amenable to quantitative analyses. These are, however, part of and subsumed in the overall movement of particulate solids in the flowing pulp which can be resolved into the tangential direction down the spiral trough and the up and down radial direction along the channel width. Fluid driven particles can travel by one or more of the following modes: sliding, rolling, saltation (or bounding), known collectively as the bedload transport, and in suspension. In the former case, a submerged particle moving in substantially continuous contact with the bed of particles, or one lying essentially stationary on the surface is subjected to a 
variety of forces that have both transverse and longitudinal components. Their resultant determines whether a force equilibrium is attained. The equilibrium can be either static, when the particle lies stationary or in incipient motion, or dynamic, when there is zero net transport of particles across the mean flow direction (Allen, 1982a).

Li et al. (1995) mention a force balance model of spirals but no details are available to us at this time. A free-motion model based on the action of gravity, horizontal shear and centrifugal forces on suspension was reported earlier (HollandBatt, 1989; Holland-Batt and Holtham, 1991). The model employs Manning equation or a Suspension equation for the primary flow in the inner region and the free vortex equation for the outer zone. Even though the secondary circulation is decoupled from the primary flow, inordinarily large numerical computations are needed to obtain the local fluid flows and particle velocities required in the force balance equation.

Considering the few millimeter thick rotatory dense pulp flow obtaining in a spiral, it is doubtful if the process can be visualized realistically in terms of suspended transport (or free particle motion) or hindered settling, as understood in the conventional sense. It is not unreasonable to expect that with the exception of low density fines which are more or less fully entrained in the fluid, the movement of particles in a spiral is by a combination of mechanisms in which bedload transport plays an important perhaps predominant role, especially in the inner region where solid concentrations can rise to 75 per cent by weight or above. If and when a steady state is reached, the particles are in dynamic equilibrium in the longirudinal direction and in static equilibrium in the transverse direction. The latter state is of course of primary interest as it determines the degree and extent of segregation of particles according to their density and size. We therefore propose to construct a general force balance model of the spiral and then extract from it the static equilibrium position of particles, that is, particles distribution in their location on the trough in the radial direction. An unequivocal justification for the existence of the steady state regime is at present problematic. Li et al (1995) found bimodal distribution of test particles radially along the trough surface, which they attributed to non-attainment of the steady state. 
However, their data show that in some cases the secondary, and presumably transitory, peaks are as prominent or even more prominent than the primary peaks which are supposedly located at the equilibrium position. Since it is a priori not clear which peak corresponds to a steady state, there remains a question mark on the interpretation of data in terms of sorting kinetics only. On the other hand, as discussed recently by Holland-Batt (1995), more than one author have stated that the separation between heavy and light particles is essentially completed within the first two or three turns of the spiral. In which case, whether an overall steady state is reached or only some of the species in the feed solids attain an equilibrium position should depend on the nature of middings and the efficiency of the spiral including its number of turns.

\section{Force Equilibrium Model}

A particle lying or moving at any point on the sloping deck of the spiral trough is subjected to gravity, drag, centrifugal, lift and friction forces which may be resolved in the longitudinal, transverse and normal directions. The longitudinal component of forces is:

$$
F_{L}=F_{g} \sin [\theta] \sin [\alpha]-F_{c} \cos [\theta] \sin [\alpha]+F_{d} \cos [\delta]-F_{N} \tan [\phi]
$$

where $F_{g}$ is gravity force, $F_{c}$ is centrifugal force, $F_{d}$ is drag force and $F_{N}$ is the sum total of all force components on the particle in the normal direction to the channel surface. The angle $\phi$ is for dynamic friction under water and, angles $\theta$ and $\alpha$ correspond to radial and tangential directions and $\delta$ is the angle between shear direction and longitudinal direction. The normal component of forces is given by:

$$
F_{N}=F_{g} \cos [\theta]+F_{c} \sin [\theta]-F_{l}
$$

where $F_{l}$ is lift force. It can be verified that the transverse component of forces is:

$$
F_{T}=F_{c} \cos [\theta] \cos [\alpha]+F_{d} \sin [\delta]-F_{g} \sin [\theta] \cos [\alpha]
$$


At equilibrium:

$$
F_{L}=0
$$

and

$$
F_{T}=0
$$

Combining last two equations with the elimination of centrifugal force term yields the following force function:

$$
\begin{aligned}
& \sec [\alpha] \sec [\theta]\left(F_{d} \sin [\delta]-F_{g} \cos [\alpha] \sin [\theta]\right)+ \\
& \frac{F_{l} \tan [\phi]+F_{d} \cos [\delta]-F_{g}(\tan [\phi] \cos [\theta]-\sin [\alpha] \sin [\theta])}{\cos [\theta] \sin [\alpha]+\tan [\phi] \sin [\theta]}=0
\end{aligned}
$$

Substiutions of appropriate expressions for the three forces from Part 1 of this report, that is:

$$
\begin{array}{ll}
F_{g}=\frac{\pi}{6} d^{3}(\sigma-\rho) g ; & \left(\mathrm{g}=9.81 \mathrm{~m} / \mathrm{s}^{2}\right) \\
F_{d}=\frac{\pi \rho g}{4} d^{2} h \sin [\alpha] & \\
F_{l}=k_{l} F_{d} ; & \left(k_{l}=0.33\right)
\end{array}
$$

leads to the following expression:

$$
\begin{aligned}
& \frac{\rho h S}{4 \sqrt{1+S^{2}}}\left(\frac{k_{l} \tan [\phi]+\cos [\delta]+\sin [\delta] \tan [\alpha]+\tan [\phi] \sec [\alpha] \sin [\delta] \tan [\theta]}{\cos [\theta] \sin [\alpha]+\tan [\phi] \sin [\theta]}\right)- \\
& \frac{d(\sigma-\rho) g \tan [\phi]}{6}\left(\frac{\cos [\theta]+\sin [\theta] \tan [\theta]}{\cos [\theta \sin [\alpha]+\tan [\phi] \sin [\theta]}\right)=0
\end{aligned}
$$

Substitutions of appropriate relationships for angles and the slope from Part 1, that is:

$$
\alpha=\arctan \left[\frac{1}{2 \pi} \frac{u}{\left(r_{i}+x\right)}\right]
$$




$$
\begin{aligned}
& \theta=\arctan \left[\frac{c_{y} x}{c_{x}{ }^{2} \cdot \sqrt{1-\left(x / c_{x}\right)^{2}}}\right] \\
& \delta=\arctan \left[11 \frac{h}{\left(r_{i}+x\right)}\right]
\end{aligned}
$$

and

$$
S=\frac{1}{2 \pi} \frac{u}{r}
$$

results in a rather complicated force equilibrium function which we have relegated to Appendix 1. Recalling that $c_{x}=r_{0}-r_{i}$, for our purpose the force equilibrium may be represented by:

$$
F_{e q}\left(d, \sigma, \rho, r, h, k_{l}, \phi, u, r_{1}, r_{o}, c_{y}\right)=0
$$

Using this function we seek to ascertain the equilibrium location $\mathrm{r}$ of a particle of size $\mathrm{d}$ and density $\sigma$ for a spiral of design specifications given by $u, r_{i}, r_{o}$ and $c_{y}$ using "best" estimates of $k_{l}$ and $\phi$ available in the literanure. Equation 15 is readily solved provided we know the relationship between the flow depth $h$ and radial distance $r$, that is, the flow profile.

\section{Fluid Flow in Spirals}

Analysis of the fluid velocity and flow profile in a spiral is not a trivial task and that apparently is the crux of the problem in modeling this equipment especially in a context of routine plant operation. One approach meant primarily for design work is through the solution of the Navier-Stokes equations with appropriate boundary conditions ( $\mathrm{Li}$ et al., 1995). This fundamental model, apart from being highly 
computationally intensive, is yet to incorporate the two phase flow. A second, and more practical, approach, relies on velocity profiles as predicted by assuming laminar, turbulent, suspension, Manning, Bagnold type flows or combination thereof ( HollandBatt, 1989; Loveday and Cilliers, 1994; Li et al., 1995). Loveday and Cilliers attempted a critical assessment of various options but reached no definite conclusion. Experimental studies (Holland-Batt, 1989; Holtham, 1990; Loveday and Cilliers, 1994) show that about one-half to two-third of the trough from the inner side is covered with laminar flow, the outer zone is turbulent with a transitory region in between. With clear water the depth of flow and its velocity increases from the inner region to the outer region of the trough, but these differences tend to level off when heavily loaded slurries are fed to the spiral. In light of these complexities, we propose, as a preliminary trial, an "averaging" approach to the problem of flow in a spiral with no pretensions for describing its profile in any detail.

Flow of fluids in open channel is commonly described by power laws whose general form is as follows (Dingman, 1984; Chen, 1991):

$$
V=K R^{a} S^{b}
$$

where $\mathrm{V}$ is mean flow velocity, $\mathrm{R}$ is hydraulic radius, $\mathrm{K}$ is a composite resistance coefficient and the exponents $a$ and $b$ depend on the nature of the flow. The hydraulic radius is simply:

$$
R=\frac{A}{P}
$$

where for a spiral trough of parabolic contour the cross-sectional area of flow $\mathrm{A}$ is:

$$
A=\frac{\pi}{4}\left[c_{x} c_{y}-\left(c_{x}-h_{m}\right)\left(c_{y}-h_{m}\right)\right]
$$

and the wetted perimeter $\mathrm{P}$ is:

$$
P=\int_{0}^{\pi / 2} \sqrt{\left(x^{12}+y^{\prime 2}\right)} d t+h_{m}
$$


in which $h_{m}$ is mean depth normal to the channel surface and the integral term represents the wetted portion of the trough arc. Next we set $S$ in eqn. 16 equal to the channel tangential slope at the mid-point and obtain from eqn. 14:

$$
S_{m}=\frac{u}{2 \pi\left(r_{i}+c_{x} / 2\right)}
$$

Inserting eqns. 17 to 20 into eqn. 16 yields:

$$
V=K\left(\frac{\frac{\pi}{4}\left[c_{x} c_{y}-\left(c_{x}-h_{m}\right)\left(c_{y}-h_{m}\right)\right.}{\int_{0}^{\pi / 2} \sqrt{\left(x^{\prime 2}+y^{\prime 2}\right)} d t+h_{m}}\right)^{a}\left(\frac{u}{2 \pi\left(r_{t}+c_{x} / 2\right)}\right)^{b}
$$

If $Q$ is the feed rate, then another expression for the mean flow velocity is:

$$
\begin{aligned}
V & =\frac{Q}{A} \\
& =\frac{Q}{\frac{\pi}{4}\left[c_{x} c_{y}-\left(c_{x}-h_{m}\right)\left(c_{y}-h_{m}\right)\right.}
\end{aligned}
$$

Elimination of $\mathrm{V}$ from the last two equations results in:

$$
Q=K \frac{\left(\frac { \pi } { 4 } \left[c_{x} c_{y}-\left(c_{x}-h_{m}\right)\left(c_{y}-h_{m}\right)^{a+1}\right.\right.}{\left(\int_{0}^{\pi / 2} \sqrt{\left(x^{\prime 2}+y^{\prime 2}\right)} d t+h_{m}\right)^{a}}\left(\frac{u}{2 \pi\left(r_{t}+c_{x} / 2\right)}\right)^{b}
$$

Given a power law flow relationship, this equation can be solved numerically to obtain the overall mean flow depth in terms of feed rate and spiral design parameters, and the result may be substituted in eqn. 21 or 22 to compute the mean flow velocity.

Because laminar and nurbulent regimes co-exist in a spiral with a transitional state, we have tested four power laws which cover the full spectrum of flows.

\section{Manning Laminar Flow:}




$$
V=\frac{1}{n} R^{2 / 3} S^{1 / 2}
$$

where $\mathrm{n}$ is the famous Manning resistance coefficient or simply Manning's $\mathrm{n}$ which may be related to the size of the bed material by a percentile size $d_{p}$ in following manner (Dooge, 1991):

$$
. n=\frac{d_{p}^{1 / 6}}{26.4}
$$

Lacey Rough Channel Flow:

$$
V=\frac{1}{n_{l}} R^{3 / 4} S^{1 / 2}
$$

where for wide open channels the roughness coefficient is (Chen, 1991):

$$
n_{l}=\frac{d_{p}^{1 / 4}}{19.7}
$$

\section{Transitional or Mixed Flow:}

A widely accepted empirical equation for mixed or transitional regimes that prevail in the sheet or overland flows of water during rainstorm where energy dissipation occurs by viscosity and turbulence friction in relatively shallow depths is (Dingman, 1984):

$$
V=\frac{1}{n} R S^{1 / 2}
$$

\section{Blasius Turbulent Elow:}

For wide open channels the so-called $1 / 7$ th power law, originally by Blasius for turbulent flow in pipes, has been proposed (Chen, 1991): 


$$
V=196 R^{5 / 7} S^{4 / 7}
$$

Straight line plots of mean flow depth and mean flow velocity, respectively, may be shown as a function of feed rate for Manning, Lacey, transitional and Blasius power laws. The spiral dimensions were the same as described previously in Part 1 , namely, $r_{i}=0.134 \mathrm{~m}, c_{x}=0.152 \mathrm{~m}, c_{y}=0.125 \mathrm{~m}$ and $u=0.254 \mathrm{~m}$. These were obtained by solving the force equilibrium relationship in eqn.15. Even though all four models exhibit similar trends, we chose the transitional flow model for following reasons. One, it pertains to mixed laminar-turbulent flows in shallow depth which are similar to the flows in spirals. Two, the computed mean flow velocities are comparable to measured values; however the computed flow depths are greater than those reported in the literature (Holland-Batt and Holtham, 1991; Holtham, 1992; Loveday and Cilliers, 1994). Three, it leads to somewhat broader, and more realistic, range of particle size at equilibrium position than the other models.

The simulations with the transitional flow power law are more clearly illustrated in the parametric plots of size versus equilibrium position for different densities or density versus equilibrium position for different sizes. It is rather remarkable that the force equilibrium spiral model incorporating fairly involved expressions - and without any fine tuning of parameters culled from the hydrology literature - yields quite a realistic range of values for both the particle size and the density. We next proceed to compare the model results with the available experimental data.

\section{Simulated and Experimental Data}

Li et al. (1995) employed a mixture of color coded plastic particles of four densities and three size intervals as feed to a LD2 spiral. Based partly on the information made available in their paper and partly on data for various spirals provided by Holland-Batt and Holtham (1991), we have taken the spiral specifications 
of the wetted region as $r_{i}=0.075 \mathrm{~m}, r_{o}=0.33 \mathrm{~m}, c_{y}=0.135 \mathrm{~m}$ and $\mathrm{u}=0.308 \mathrm{~m}$, with $d_{p}=0.5 \mathrm{~mm}$ and a feed?rate of $3 \mathrm{~m}^{3} / \mathrm{hr}$. The simulated distributions of particles of relative densities $1.3,1.6,1.9$ and 2.2 in radial direction from the centerline may be plotted. The experimental locations and model equilibrium positions as a function of relative density may be compared for three size intervals ( $1 \times 0.71 \mathrm{~mm}, 0.51 \times 0.355 \mathrm{~mm}$ and $0.09 \times 0.063 \mathrm{~mm}$ ). For sake of consistency, data pertaining to prominent peaks only was selected for those class of particles which exhibited bimodal distributions. There was one exception, namely, fine particles of relative density 2.2 which showed two nearly equal peaks. Consequently, both data points were included for comparison in this case. The agreement for coarse and fine particles is deemed quite satisfactory considering the presence of a significant stochastic/probabilistic component inherent in the separation process itself and the fairly large error that is invariably associated with the acquisition of data, as pointed by the authors. The lack of similar agreement in case of intermediate size particles is somewhat puzzling, since it is difficult to conceive of a model description for the intermediates which is more or less separate from that of coarse and fine particles.

Loveday and Cilliers (1994) separated chromite from silica in a Multotec '21 degree' heavy mineral spiral whose specifications, as inferred from the drawing and data in their paper, were taken as $r_{i}=0.1 \mathrm{~m}, r_{o}=0.3 \mathrm{~m}$, and $c_{y}=0.125 \mathrm{~m}$, with $d_{p}=0.75 \mathrm{~mm}$ and a feed rate of $3.5 \mathrm{~m}^{3} / \mathrm{hr}$. A 21 degree slope at the mid-point of the trough corresponds to $0.48 \mathrm{~m}$ pitch, whereas in the Holland-Batt and Holtham spiral data heavy grade mineral spirals are shown to possess pitch of 0.406 to $0.432 \mathrm{~m}$. Accordingly, we selected $u=0.45$ for our simulation. Relative densities of silica and chromite were assumed to be 2.65 and 3.5 , respectively. The simulated results and experimental data for $50 \%$ of total reporting to radial positions on trough for mean sizes of $0.85 \times 0.71,0.71 \times 0.6$ and $0.6 \times 0.5 \mathrm{~mm}$ fractions may be compared. The slope of the experimental curves are reversed as the particle size of both the silica and chromite increased from the inner side to the outside. In its present stage of development, our 
model can not predict such seemingly anomalous behavior, which according to the authors is not entirely unusual.

The experimental data of Holland-Batt and Holtham (1991) are presented in form of 3-dimensional 'tent-like spike' plots from which the radial position of the spike peaks could not be read accurately. It was also obvious that most data sets could be modeled in a sense of providing only the right overall trends. An example is the separation of quartz sand by size on a LD9 spiral. The dimensions of this high ash coal cleaning spiral are taken as $r_{i}=0.09 \mathrm{~m}, r_{o}=0.34 \mathrm{~m}, c_{y}=0.14 \mathrm{~m}$ and $\mathrm{u}=0.273 \mathrm{~m}$, with $d_{p}=0.75 \mathrm{~mm}$ and a feed rate of $6 \mathrm{~m}^{3} / \mathrm{hr}$. The experimental data shows that there are multiple peaks, an inexplicable big jump in locations of particles finer than $0.2 \mathrm{~mm}$ and bunching of coarser particles at around $130 \mathrm{~mm}$ radial distance. Recognizing the problems in incorporating sieve aperture-based size into hydrodynamic data, these authors introduced an appropriate correlation for correcting the size when predicting the motion of irregular shaped particles. In order to observe the possible effect of this phenomenon, the projected area of a sphere in the expression for drag force in eqn. 8 was multiplied by factors of $1.5,1$ and 0.5 . The resulting three curves indicates that the simulation with the factor of 0.5 (bottom curve) comes closest to the measured data.

\section{Concluding_Remarks}

We stress that we have presented only a preliminary model of spirals which undoubtedly has considerable scope for improvement and refinement. The simulation results suggest that, one, the force equilibrium approach is a valid basis for the model, not withstanding the uncertainty regarding the attainment of a steady state in the process, and two, the admittedly crude averaging approximation adopted for the flow profile can provide a useful solution to this difficult and complex problem at least in an operational sense. In other words, we have taken the liberty of substituting exactitude by similitude while endeavoring to mimic the separation process as closely as possible. 
No attempt was made to fine tune the various parameters required to implement the model, that is, tailor them to a spiral operation. In any case, this exercise would require a fairly extensive and reliable data base. Finally, it is necessary to modify the model in order to account for the stochastic nature of the process which in fact is inherent in all mineral separation processes. The realistic simulations obtained, however, encourages us to believe that the model in its present form could be utilized to analyze the spiral design and its separation characteristics for different feed materials, at least in a semi-qualitative manner, as we hope to demonstrate in the ensuing Part 3 of this communication.

\section{References}

Allen, J.R.L. Sedimentary Structures: Their character and physical basis. Vol.I. Elsevier Scientific Publishing Co., 1982a, Ch.2.

Burt, R.O. Gravity Concentration Technology, Elsevier Science Publishers, 1984, 261287.

Chen, C-L. Power law of flow resistance in open channels: Manning's formula revisted, in Channel Flow Resistance: Centennial of Manning's Formula, B.C. Yen (Editor), Water Resources Publications, Littleton, Co. 1991, pp. 206-240.

Dingman, S.L. Eluvial Hydrology, W.H. Freeman and Co., 1984, Ch.6.

Dooge, J.C.I. The Manning formula in context, in Channel Flow Resistance: Centennial of Manning's Formula, B.C. Yen (Editor), Water Resources Publications, Littleton, Co. 1991, pp. 136-185.

Holland-Batt, A.B., 1989. Spiral separation: theory and simulation. Trans. Instn. Min. Metall. (Sec. C) 98, C46-C60.

Holland-Batt, A.B., 1995. The dynamics of sluice and spiral separations. Minerals Engineering, 8, 3-21. 
Holland-Batt, A.B. and Holtham, P.N., 1991. Particle and fluid motion on spiral separators. Minerals Engineeing, 4, 457-482.

Holtham, P.N., 1990. Flow visualisation of secondary currents on spiral separators.Minerals Engineering, 3, 279-286.

Holtham, P.N., 1992. Primary and secondary fluid velocities on spiral separators. Minerals Engineering, 5, 79-91.

Li, M., Jancar, T., Holtham, P.N., Davis, J.J. and Fletcher, C.A.J. Approaches to the Development of coal spiral models, in High Efficiency Coal Preparation, An international symposium. S.K. Kawatra, Editor, Soc. Mining Engineers, Littleton, Co. 1995 , 335-345.

Loveday, G.K. and Cilliers, J.J., 1994. Fluid flow modelling on spiral concentrators. Minerals Engineering, 7, 223-237.

Sivamohan, S and Forssberg, E., 1985. Principles of spiral concentration. International J. Mineral Processing, 15, 173-181.

Palowitch, E.R., Deurbrouck, A.W. and Parsons, T.H. Wet fine particle concentration Section 2: Hydraulic concentration, in Coal Preparation. Leonard, J.W. (Editor), 5th edition. Soc. Mining, Metallurgy and Exploration, Littleton, Co., 1991, 435-449. 


\section{SUMMARY}

The physical-mathematical modeling of spirals has been spectacularly successful. The work presented above shows a sound theoretical physicalmathematical method, that may be used to predict spiral performance over a wide range of design criteria. As a result of this modeling work, it is anticipated that a series of improvements will result in spiral performance.

Because only the first year of a four year program was funded, it is recommended that the program be further funded. Almost certain success in improved spiral performance may be anticipated.

A longer more detailed description of this work is planned for publication in the IJMP in the near future. With luck a continuance of the work will be published as a third paper. 